\title{
USO DE MEDIDAS DA ÁREA FOLIAR SADIA E REFLETÂNCIA NO MANEJO DA MANCHA ANGULAR DO FEIJOEIRO
}

\section{Marcelo Giovanetti Canteri}

Engenheiro Agrônomo

Orientador: Prof. Dr. ARMANDO BERGAMIN FILHO

\footnotetext{
Tese apresentada à Escola Superior de Agricultura "Luiz de Queiroz", da Universidade de São Paulo, para obtenção do título de Doutor em Agronomia. Área de Concentração: Fitopatologia.
}

P I R A C I C A B A

Estado de São Paulo - Brasil

Fevereiro de 1998 
Dados Internacionais de Catalogação na Publicação (CIP)

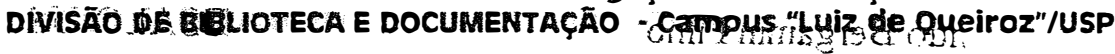

\footnotetext{
Canteri, Marcelo Giovanetti

Uso dẹ médidas da área foliar sadia e refletância no manejo da mapgha
} angular do feijoeiro / Marcelo Giovanetti Canteri. . Piracicaba, Y999.

$81 \mathrm{p}$ :

Teser (doutorado) - Escola Superior de Agricultura Luiz de Queiroz, 1999. Bibliografia.

Oin?

1. Dano 2. Feijāo 3. Folha 4. Mancha-angular-do-feijoeiro 5. Refletância I. Titulo

CDD 635.652 


\section{USO DE MEDIDAS DA ÁREA FOLIAR SADIA E REFLETÂNCIA NO MANEJO DA MANCHA ANGULAR DO FEIJOEIRO}

MARCELO GIOVANETTI CANTERI

Aprovada em: 07.04.1998

Comissão julgadora:

Prof. Dr. Armañ đo Bergaminn fitho

- TSALQRES

Prof . Dr ${ }^{\mathrm{a}}$. Lilian Amorim ESALO/USP

Prof. Dr. Richard D Bergèr

Universitv of Florida

Prof. Dr. Carlos Alberto Forcelini UPF:

Prof. Dr. Edson Luis Furtadó

UNESP / Botucatu

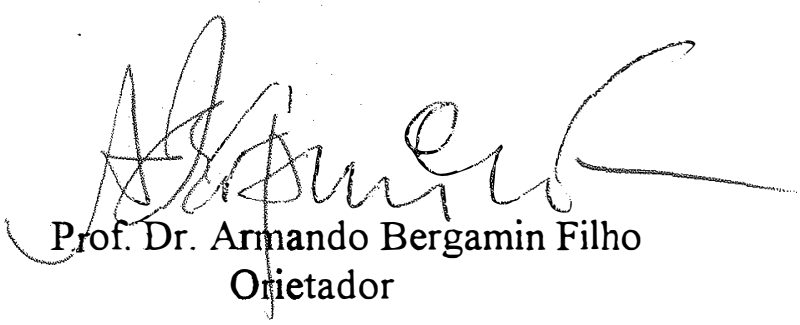




\section{AGRADECIMENTOS}

Ao Prof. Dr. Armando Bergamin Filho pela orientação e apoio.

Aos professores que co-orientaram os trabalhos, Prof ${ }^{a}$. Dr ${ }^{\mathrm{a}}$. Lilian Amorim, na ESALQ/USP, Prof. Dr. Richard D. Berger, na University of Florida e Prof. Dr. Bernhard Hau, na Universität Hannover. Ao Prof. Dr. Tasso Leo Krugner pela revisão do Summary.

À Fundação $\mathrm{ABC}$ e à Cooperativa Agropecuária Castrolanda Ltda. pelo total apoio na condução dos experimentos, especialmente aos Engenheiros Agrônomos Marcos Valentini, Rudimar Molin, Olavo Correia da Silva e ao Técnico agrícola Rontes.

Aos colegas da fitopatologia: Marilene (Jujuba), Cláudia Godoy (Kika), Éder (Brinku), Lilian Bachi, Anésio Bianchini, Gisele Torres, Juliana, Daniela, Renato, Luciana, Solange, Flávia, Cecília, Leonardo, Nilceli, Sílvia, João, Marise, Heloísa, Seu Pedro, Marina, Jeferson e todos os professores, alunos de pós-graduação e estagiários que colaboraram para a alegre e estimulante convivência no Departamento de Fitopatologia da ESALQ/USP. Aos colegas fitopatologistas do exterior Gustavo Astua Monge, Peter Schuld e Frank Meyer. A todos os brasileiros que me apoiaram em Gainesville.

À Maristella Dalla Pria pelo auxílio e correções. Aos professores da UEPG David de Souza Jaccoud e Áurea Tomoko M. Kamikoga e todos os professores do Departamento de Informática da UEPG.

À CAPES pelo auxílio financeiro durante todo o doutorado e pela bolsa "sandwich" para complemento da tese nos laboratórios do "Plant Pathology Department" da "University of Florida" em Gainesville, E.U.A.

Ao convênio CAPES/DAAD pela bolsa para estudos nos laboratórios do "Institut für Pflanzenkrankheiten und Pflanzenschutz" da "Universität Hannover", na Alemanha.

À Universidade Estadual de Ponta Grossa, em especial ao Departamento de Informática, pela liberação das atividades docentes para condução do curso de doutorado e aos laboratórios de Solos e Tecnologia de Alimentos pelas análises realizadas. 


\section{SUMÁRIO}

Página

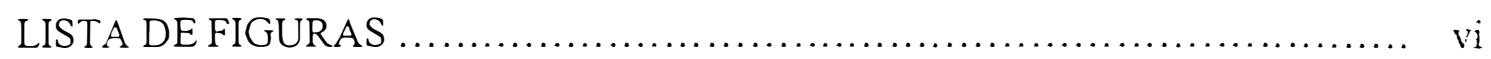

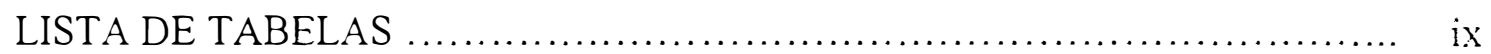

LISTA DE SIGLAS, ABREVIATURAS E SÍMBOLOS $\ldots \ldots \ldots \ldots \ldots \ldots \ldots \ldots \ldots \ldots \ldots$

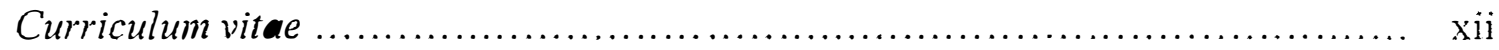

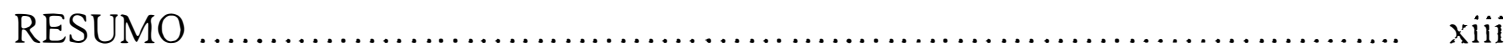

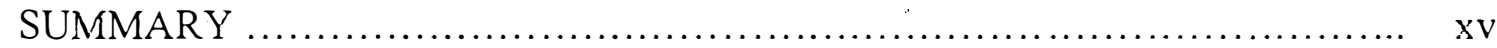

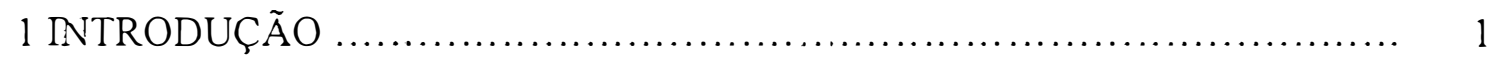

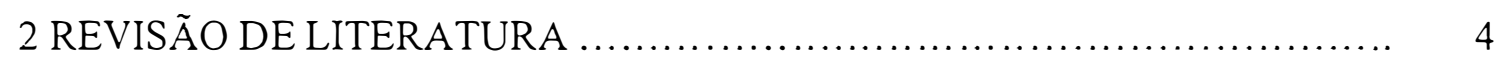

2.1 Mancha angular ............................................... 4

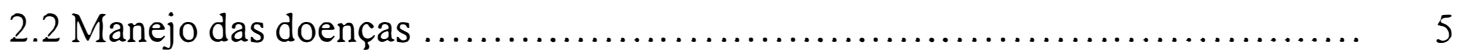

2.3 Quantificação de danos baseada em área foliar sadia ..................... 6

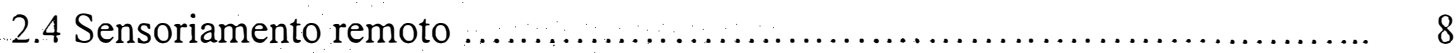

2.4.1 Radiação solar ................................................. 9

2.4.2 Refletância de folhas .......................................... 10

2.4.3 Refletância da vegetação ...................................... 11

2.4.3.1 Fatores que afetam a refletância da vegetação ................ 12

2.4.3.2 Índices de vegetação .................................. 14

2.4.4 Radiometria .................................................. 15

2.4.5 Trabalhos desenvolvidos com radiometria aplicados à fitopatologia ..... 16 3 RELAÇÕES ENTRE ÁREA FOLIAR, PRODUÇÃO, MEDIDAS DE REFLETÂNCIA E SEVERIDADE DA MANCHA ANGULAR DO FEIJOEIRO ...... 17

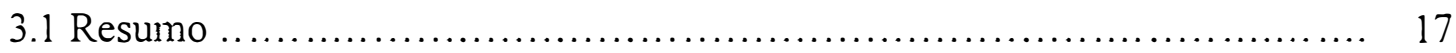

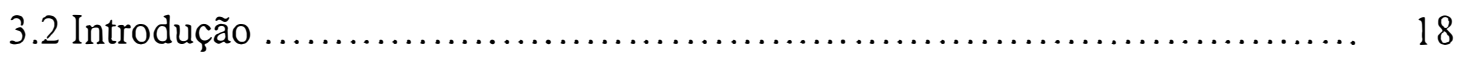

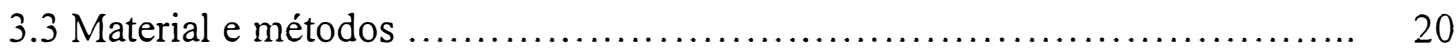

3.3.1 Experimento com folhas destacadas de feijoeiro ................... 20

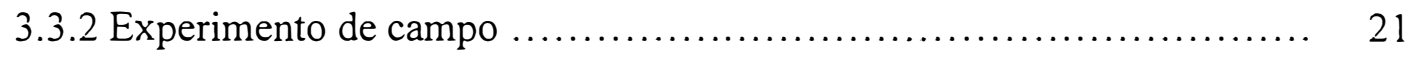

3.3.3 Crescimento de plantas, severidade da doença e produtividade .......... 21 
3.3.4 Variáveis integrais ......................................... 22

3.3.5 Medidas de refletância ....................................... 23

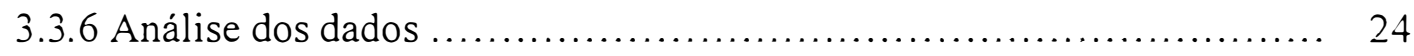

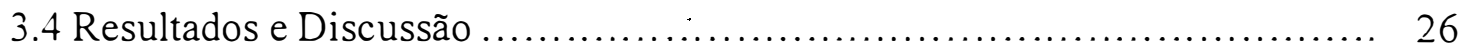

3.4.1 Comportamento do índice da área foliar, severidade da mancha angular e refletância durante o ciclo da cultura ............................. 26

3.4.2 Relações entre severidade da doença e refletância ...................... 29

3.4.3 Relações entre refletância e variáveis da área foliar .................... 32

3.4.4 Modelo para estimar HLAI .................................... 36

3.4.5 Relações da produção com variáveis da área foliar, doença e refletância. 41 4 MEDIDAS DE REFLETÂNCIA COMO PARÂMETRO DE TOMADA DE DECISÃO PARA MANEJO DA MANCHA ANGULAR DO FEIJOEIRO..... 43

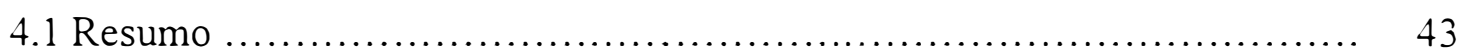

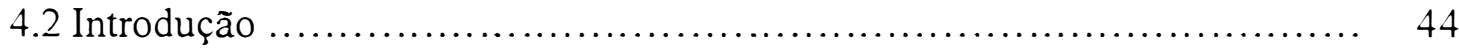

4.3 Material e Métodos ................................................. 46

4.3.1 Experimento de campo ....................................... 46

4.3.2 Crescimento de plantas, severidade da mancha angular e produtividade . 46

4.3 .3 Variáveis integrais .......................................... 47

4.3.4 Medidas de refletância .......................................... 49

4.3 .5 Análise dos dados .............................................. 49

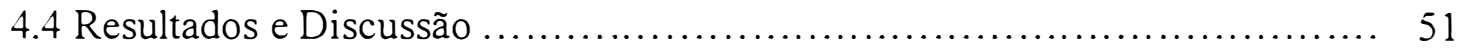

4.4.1 Comparação entre parcelas sem e com controle da doença .............. 51

4.4.2 Relações da produção com HAD, HAA, AUDPC e refletância .......... 53

4.4.3 Eficiência fotossintética ...................................... 55

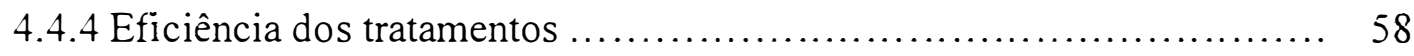

4.4.5 Medidas de refletância e relações com HLAI e HRI ..................... 60

4.4.6 Sensibilidade de medidas de refletância para detectar variações em HLAI e HRI .................................................. 63

4.4.7 Limiar de dano econômico (LDE) ................................. 65 


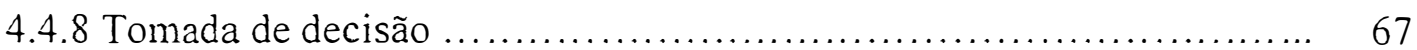

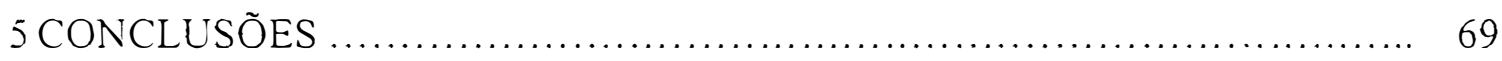

REFERÊNCIAS BIBLIOGRÁFICAS ................................ 70 


\section{LISTA DE FIGURAS}

Página

1 Principais caracteristicas da resposta espectral de folhas verdes de plantas (Hoffer, 1978; Formaggio, 1989).................................. 10

2 Severidade da mancha angular, indice da área foliar ( $L A I)$ e refletância em $810 \mathrm{~nm}\left(R_{810}\right)$ observados em feijoeiro cultivar Carioca e Iapar 44 , em duas épocas de plantio, em parcelas com (círculos cheios) e sem (círculos vazios) controle da doença. Para severidade e LAI cada ponto representa a média de 24 plantas. Para refletância, cada ponto representa a média de 12 amostragens

3 Refletância observada em folhas de feijoeiro destacadas, sem sintomas da mancha angular (0) e com severidades entre $1,5 \%$ e $2,5 \%$ (2), $8 \%$ e $12 \%$ (10) e $25 \%$ e $35 \%$ (30), nos comprimentos de onda das cores azul, em $460 \mathrm{~nm}$ (A), verde, em $510 \mathrm{~nm}$ (B), amarelo, em $560 \mathrm{~nm}$ (C), laranja, em $610 \mathrm{~nm}$ (D), vermelho, em $660 \mathrm{~nm}(\mathrm{E})$ e $710 \mathrm{~nm}$ (F) e infravermelho, em $760 \mathrm{~nm}$ $(\mathrm{G})$ e $810 \mathrm{~nm}(\mathrm{H})$ e nos indices vegetativos $(810-610) /(810+610)(\mathrm{I})$ e $(810$ $660) /(810+660)(\mathrm{J})$

4 A) Comportamento espectral de camada de folhas de feijoeiro sadias (círculos vazios), camada de folhas com 30\% da mancha angular (quadrado cheio) e camada de tecido preto opaco (círculos cheios). B) Severidade da mancha angular versus a refletância, representada pela diferença normalizada $\left(N D_{(810,610)}\right)$ utilizando os comprimentos de onda 810 e $610 \mathrm{~nm}$, observadas para dossel de feijoeiro com índice da área foliar superior a $3,6 \ldots \ldots \ldots \ldots \ldots$.

5 Relações entre as variáveis derivadas da área foliar (indice da área foliar (LAI), indice da área foliar sadio (HLAI) e absorção da área foliar sadia (HRI)) com a refletância em $810 \mathrm{~nm}\left(\mathrm{R}_{810}\right)$, a diferença normalizada usando 810 e $610 \mathrm{~nm}\left(\mathrm{ND}_{810,610}\right)$ e a diferença normalizada usando 810 e $660 \mathrm{~nm}$, observada para dossel de feijoeiro cultivares Carioca e Iapar 44, com e sem tratamento fungicida em duas épocas de plantio 
6 Modelo para estimativa do índice da área foliar sadia (HLAI) em função da refletância representada pelo índice vegetativo ND, calculado pela fórmula $\left(\mathrm{R}_{810}+\mathrm{R}_{660}\right) /\left(\mathrm{R}_{810}-\mathrm{R}_{660}\right)$

7 Relações da produção $\left(\mathrm{g} \mathrm{m}^{-2}\right)$ com duração da área foliar sadia (HAD), absorção da área foliar sadia (HAA), área sob a curva de progresso da doença (AUDPC), integral da refletância em $810 \mathrm{~nm}\left(\mathrm{AUR}_{810}\right)$ e integral da diferença normalizada ( $\left(\mathrm{UUR}_{\mathrm{ND}}\right.$ ), utilizando os comprimentos de onda de 810 e $610 \mathrm{~nm} . \mathrm{R}^{2}$ refere-se ao coeficiente de determinação da regressão representada pela reta cheia. Dados apresentados em relação a época de plantio $(\mathrm{A}, \mathrm{B}, \mathrm{C}, \mathrm{D}, \mathrm{E})$ e em relação ao tratamento 42 $(\mathrm{F}, \mathrm{G}, \mathrm{H}, \mathrm{I}, \mathrm{J})$

8 Severidade (porcentagem) da mancha angular em feijoeiro, indice da área foliar sadia (HLAI), radiação interceptada pela área foliar sadia (HRI), em $\mathrm{MJ} \mathrm{m}^{-2}$ e medidas de refletância em $810 \mathrm{~nm}$ versus o tempo, observados em parcelas com controle e sem controle químico da mancha angular. Para severidade, HLAI e HRI cada ponto representa a média de 6 plantas, para refletância cada ponto representa a média de 3 leituras. Círculos cheios representam parcelas com maior área foliar e círculos vazios parcelas com menor área foliar. Barras verticais r epresentam o erro padrão

9 Relações da produção $\left(\mathrm{g} \mathrm{m}^{-2}\right)$ com duração da área foliar sadia (HAD), absorção da área foliar sadia (HAA), área sob a curva de progresso da doença (AUDPC), integral da refletância em $810 \mathrm{~nm}\left(\mathrm{AUR}_{810}\right)$ e integral da diferença normalizada $\left(\mathrm{AUR}_{\mathrm{ND}}\right)$, utilizando os comprimentos de onda de 810 e $660 \mathrm{~nm}$, observadas em parcelas com diferentes tratamentos fungicidas para controle da mancha angular.

10 Relações entre duração da área foliar sadia (HAD) e absorção da área foliar sadia (HAA) com a área sob a curva de progresso da doença (AUDPC) e a produção $\left(\mathrm{g} \mathrm{m}^{-2}\right)$, observadas em parcelas com diferentes tratamentos fungicidas para controle da mancha angular em feijoeiro 
11 Índice da área foliar sadia (HLAI) e radiação interceptada pela área foliar sadia (HRI) em $\mathrm{MJ} \mathrm{m}^{-2}$ versus a refletância, representada pela diferença normalizada de índice de vegetação (ND), utilizando os comprimentos de onda 660 e $810 \mathrm{~nm}$ para vermelho e infravermelho, respectivamente, observados para dossel de feijoeiro entre os estádios R5 (pré-floração) e R9 (maturação fisiológica). Cada ponto representa a média de 3 leituras de refletância...........................................................

12 Diferença percentual de absorção da área foliar sadia (Delta HRI) em relação ao tratamento controle (Tratamento 01) para os tratamentos 02 (A), 03 (B), 04 (C), 06 (D) e 08 (E). Círculos cheios representam dados observados (média de 24 plantas), círculos vazios representam dados estimados (média de 12 amostragens) e linha tracejada representa suposto limiar de dano econômico. A HRI estimada foi calculada pela fórmula HRI = 0,395exp(3,599ND), com $\mathrm{R}^{2}=81,9 \%$, onde $\mathrm{ND}=(\mathrm{R} 810-\mathrm{R} 660)$, (R810+R660), sendo R810 e R660 as refletâncias observadas em $810 \mathrm{~nm}$ e

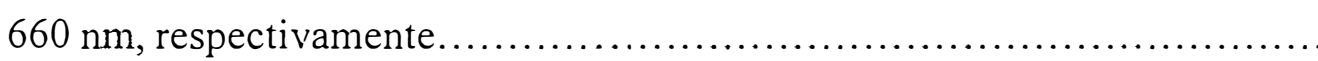




\section{LISTA DE TABELAS}

Página

1 Parâmetros estimados ( \pm erro padrão) e coeficiente de determinação $\left(R^{2}\right)$ do modelo monomolecular ajustado aos valores de refletância plotados contra 0 índice da área foliar (LAI), para dois cultivares (Carioca e Iapar 44), duas épocas de plantio ( 1 e 2), dois tratamentos fungicidas (com e sem) e dois periodos do ciclo da cultura (até a metade e após a metade do ciclo). Diferenças significativas $(\mathrm{P}<0,05)$ estão marcadas com *

2 Parâmetros estimados ( \pm erro padrão) e coeficiente de determinação $\left(R^{2}\right)$ do modelo monomolecular ajustado aos valores de refletância plotados contra o indice da área foliar sadia (HLAI), para dois cultivares (Carioca e Iapar 44), duas épocas de plantio ( 1 e 2), dois tratamentos fungicidas (com e sem) e dois períodos do ciclo da cultura (até a metade e após a metade do ciclo). Diferenças significativas $(\mathrm{P}<0,05)$ estão marcadas com * ................ 38

3 Parâmetros estimados ( \pm erro padrão) e coeficiente de determinação $\left(\mathrm{R}^{2}\right)$ do modelo monomolecular ajustado aos valores de refletância plotados contra a abosorção da área foliar sadia (HRI), para dois cultivares (Carioca e Iapar 44), duas épocas de plantio (1 e 2), dois tratamentos fungicidas (com e sem) e dois períodos do ciclo da cultura (até a metade e após a metade do ciclo). Diferenças significativas $(\mathrm{P}<0,05)$ estão marcadas com *

4 Absorção da área foliar sadia (HAA), área sob a curva de progresso da mancha angular (AUDPC), eficiência fotossintética (RUE) para produção de grãos, área sob a curva de refletância na faixa de $810 \mathrm{~nm}\left(\mathrm{AUR}_{810}\right)$ e produtividade de feijoeiro, observadas para tratamentos com diferentes épocas de aplicação de fungicidas em dias após a emergência (DAE)........ 
5 Variação de duração da área foliar sadia (HLAI) observada (obs.) e estimada (est.) e coeficiente de variação para várias épocas de avaliação, em dias após a emergência (DAE), de parcelas com diferentes tratamentos fungicidas para controle da mancha angular em feijoeiro. A HLAI estimada foi calculada pela fórmula HLAI $=0,00435 \exp (6,999 \mathrm{ND}), \mathrm{com}^{2}=71,8 \%$, onde $\mathrm{ND}=(\mathrm{R} 810$ R660) / (R810+R660), sendo R810 e R660 as refletâncias observadas em 810 $\mathrm{nm}$ e $660 \mathrm{~nm}$, respectivamente. 


\section{LISTA DE SIGLAS, ABREVIATURAS E SÍMBOLOS}

AUDPC: $\quad$ área sob a curva de progresso da doença (Are Under Disease Progress Curve).

AUR: integral da curva de medidas de refletância em determinado comprimento de onda. Ex: AUR 810 .

DAE: dias após a emergência.

HAA: absorção da radiação solar pela área foliar sadia (Healthy Area Absorption).

HAD: $\quad$ duração da área foliar sadia (Healthy le Are Duration).

HLAI: $\quad$ índice da área foliar sadia (Healthy Le Area Index).

HRI: $\quad$ absorção diária da área foliar sadia.

IR/R: índice vegetativo que relaciona refletância na faixa do IR e R.

IR: $\quad$ refletância na região do infravermelho (Infra Red).

LAI: $\quad$ indice da área foliar (Leaf Area Index).

LDE: limiar de dano econômico.

ND: indice vegetativo que usa a fórmula $\mathrm{ND}=(\mathrm{IR}-\mathrm{R}) /(\mathrm{IR}+\mathrm{R})$ (Normalized Difference).

$\mathrm{ND}_{810,610}$ : diferença normalizada que usa os comprimentos de onda de $810 \mathrm{~nm}$ e 610 nm.

$\mathrm{ND}_{810.660}$ : diferença normalizada que usa os comprimentos de onda de $810 \mathrm{~nm}$ e 660 nm.

NIR: $\quad$ faixa do espectro do infravermelho próximo (Near Infra-Red).

PAR: $\quad$ radiação fotossinteticamente ativa (Photosynthetically Active Radiation).

$\mathrm{R}$ : $\quad$ refletância na região do vermelho $(R e d)$.

RI: $\quad$ radiação interceptada.

RUE: . eficiência de uso da radiação, em $\mathrm{g} \mathrm{MJ}^{-1}$ (Radiation Use Efficiency). 


\section{Curriculum vitae}

Marcelo Giovanetti Canteri nasceu em 18 de janeiro de 1968 na cidade de Ponta Grossa, PR. Recebeu o título de Engenheiro Agrônomo e Bacharel em Informática em 16 de dezembro de 1989, na Universidade Estadual de Ponta Grossa, em Ponta Grossa, PR. Obteve o título de Mestre em Agronomia, área de concentração Fitopatologia em 25 de fevereiro de 1994, na Escola Superior de Agricultura "Luiz de Queiroz" (ESALQ/USP) em Piracicaba, SP.

Esteve na "Universität Hannover", Alemanha, por três meses em 1995 e na "University of Florida", E.U.A., por quatro meses em 1997, onde executou parte de sua tese de doutorado. Participou em mais de 15 encontros, seminários e congressos nacionais e internacionais. Foi autor de mais de 27 trabalhos apresentados. Possui artigos publicados relacionando a informática à fitopatologia. Recebeu o prêmio bolsa Atlantic em 1994, no Departamento de Fitopatologia da ESALQ/USP. Foi presidente de sessão de apresentação de trabalhos em congressos do Grupo Paulista de Fitopatologia e assessor ad hoc da revista Fitopatologia Brasileira. Foi membro em cinco bancas para contratação de professores em concurso público. Desde 1991 é professor no Departamento de Informática da Universidade Estadual de Ponta Grossa, em Ponta Grossa, PR, em regime de dedicação exclusiva, onde conduz projetos de pesquisa ligando a informática à fitopatologia. 


\title{
USO DE MEDIDAS DA ÁREA FOLIAR SADIA E REFLETÂNCIA NO MANEJO DA MANCHA ANGULAR DO FEIJOEIRO
}

\author{
Autor: Marcelo Giovanetti Canteri \\ Orientador: Prof. Dr. Armando Bergamin Filho
}

\section{RESUMO}

Foram conduzidos experimentos em feijoeiro, em dois anos de plantio, em folhas destacadas e em folhagem sob condições de campo, com o objetivo de verificar se medidas de refletância eram úteis para estimar a área foliar sadia de feijoeiro e assim serem utilizadas em programas de manejo da mancha angular (Phaeoisariopsis griseola (Sacc.) Ferraris). Foram estudadas as relações da refletância com as variáveis derivadas da área foliar, a severidade da mancha angular e a produção em feijoeiro. Testou-se a variação da refletância de acordo com a influência do cultivar, época de plantio, severidade da doença e estádio fenológico da cultura. Estimou-se a interferência da doença na eficiência fotossintética das plantas. Também se testou a sensibilidade das medidas de refletância para deteç̧ão de variações no índice da área foliar sadia e na absorção da área foliar sadia. As leituras de refletância foram feitas com um radiômetro de múltiplo espectro portátil, em 8 comprimentos de onda, entre $460 \mathrm{~nm}$ a $810 \mathrm{~nm}$, em intervalos de $50 \mathrm{~nm}$. As refletâncias do dossel em infravermelho (IR), $810 \mathrm{~nm}$ e vermelho (R), $660 \mathrm{~nm}$ e $610 \mathrm{~nm}$, foram usadas para calcular os índices vegetativos $\mathrm{ND}_{\$ 10.660}$ e $\mathrm{ND}_{\$ 10.610}$, onde $\mathrm{ND}=(\mathrm{IR}-\mathrm{R}) /(\mathrm{IR}+\mathrm{R})$. Em folhas destacadas, quanto maior $\mathrm{o}$ nível de severidade, maior foi a refletância nos comprimentos de onda de 460, 510, 560, 660 e $710 \mathrm{~nm}$ e menor em 760 e $810 \mathrm{~nm}$. Não houve um comprimento de onda ou um índice vegetativo que pudesse ser usado para estimar apenas a severidade de doença no campo. No primeiro ano de plantio, as melhores relações com índice da área foliar sadia (HLAI) foram obtidas com a refletância em $810 \mathrm{~nm}\left(\mathrm{R}_{810}\right)\left(\mathrm{R}^{2}=84,7 \%\right)$ e com a diferença 
normalizada $\left(\mathrm{ND}_{810,660}\right)$, usando 810 e $660 \mathrm{~nm}\left(\mathrm{R}^{2}=86,6 \%\right)$. A absorção da área foliar sadia (HRI) apresentou melhor relação com a $\mathrm{ND}_{810,610}\left(\mathrm{R}^{2}=82,6 \%\right)$. Houve influência do tratamento fungicida nas relações $\mathrm{R}_{810} \times$ HLAI e $\mathrm{ND}_{\$ 10,660} \times \mathrm{HLAI}$, e houve influência da época de plantio na relação $\mathrm{ND}_{810,610} \times$ HRI. No segundo ano de plantio, a produção relacionou-se significativamente $(\mathrm{P}<0,01)$ e de forma linear com as variáveis duração da área foliar sadia (HAD) $\left(\mathrm{R}^{2}=40,2 \%\right)$, absorção da área foliar sadia (HAA) $\left(\mathrm{R}^{2}=44,8 \%\right)$ e integral da diferença normalizada, usando-se os comprimentos de onda $810 \mathrm{~nm}$ e $660 \mathrm{~nm}$ (AUR $\mathrm{ND})\left(\mathrm{R}^{2}=50,1 \%\right)$. A relação produção-área sob a curva de progresso da doença (AUDPC) foi menos consistente $\left(R^{2}=31,4 \%\right)$. Parcelas com mesmo nivel de HAD apresentaram redução na produção para altos valores de AUDPC. Isto indicou uma redução da eficiência fotossintética das plantas em função da doença. Pulverizações para controle da mancha angular iniciadas aos 30 DAE apresentaram eficiência de 67,8\%, decrescendo linearmente $(\mathrm{P}<0,01)$ até $0 \%$ aos $62 \mathrm{DAE}$. $\mathrm{A} \mathrm{ND}_{810,660}$ demonstrou relação com o HLAI $\left(\mathrm{R}^{2}=89,7 \%\right)$ e com a HRI $\left(\mathrm{R}^{2}=87,7 \%\right)$. A ND apresentou potencial para ser usada para estimar o HLAI e ser usada, juntamente com uma parcela controle e avaliações de severidade de doenças, para tomada de decisão baseada em LDE, em programas de manejo da mancha angular do feijoeiro. 


\title{
USE OF HEALTHY LEAF AREA AND REFLECTANCE MEASUREMENTS IN THE MANAGEMENT OF ANGULAR LEAF SPOT OF BEAN
}

\author{
Author: Marcelo Giovanetti Canteri \\ Adviser: Prof. Dr. Armando Bergamin Filho
}

\section{SUMMARY}

Experiments were carried out with bean during two seasons, using detached leaves and field canopy, aiming to verify if reflectance readings were useful to estimate healthy leaf area to be used in angular leaf spot management programs (Phaeoisariopsis griseola (Sacc.) Ferraris). Relationships among reflectance, leaf area variables, angular leaf spot severity and yield were studied. The variation in reflectance influenced by cultivar, crop season, disease severity and growth stage were tested. The disease effect on photosynthetic efficiency was estimated. The sensibility of reflectance readings was tested to verify the possibility of detecting variations on leaf area index and on healthy leaf area absorption. Reflectance readings were made with a hand held multispectral radiometer at eight wavelengths, between $460 \mathrm{~nm}$ and $810 \mathrm{~nm}$, at $50 \mathrm{~nm}$ intervals. The canopy reflectance at infrared band (IR), $810 \mathrm{~nm}$ and red bands (R) $660 \mathrm{~nm}$ and $610 \mathrm{~nm}$ were used to calculate the vegetation index $\mathrm{ND}_{810,660}$ and $\mathrm{ND}_{810,610}$, where $\mathrm{ND}=(\mathrm{IR}$ $\mathrm{R})^{\prime}(\mathrm{IR}+\mathrm{R})$. When disease severity was high, detached leaves showed high reflectance at $460,510,560,660$, and $710 \mathrm{~nm}$, but low reflectance at 760 and $810 \mathrm{~nm}$. No wavelength or vegetation index could be used to estimate only disease severity in the field. The first crop season showed good relationships between healthy leaf area index (HLAI) with reflectance at $810 \mathrm{~nm}\left(\mathrm{R}^{2}=84,7 \%\right)$ and with normalized difference, using 810 and 660 $\mathrm{nm}\left(\mathrm{ND}_{810,660}\right)\left(\mathrm{R}^{2}=86,6 \%\right)$. The leaf area absorption (HRI) showed better relationship with $\mathrm{ND}_{810,610}\left(\mathrm{R}^{2}=82,6 \%\right)$. The fungicide treatment influenced the relationships $\mathrm{R}_{810} \mathrm{x}$ 
HLAI and ND $\$ 10,660 \times$ HLAI, and the crop season influenced the relationship $N_{810,610} \times$ HRI. During the second crop season yield presented linear relationship $(\mathrm{P}<0.01)$ when regressed against healthy leaf area duration (HAD) $\left(R^{2}=40,2 \%\right)$, healthy leaf area absorption (HAA) $\left(\mathrm{R}^{2}=44,8 \%\right)$ and $\mathrm{ND}$ integrated over the growing season, using wavelengths $810 \mathrm{~nm}$ and $660 \mathrm{~nm}\left(A U R_{N D}\right)\left(R^{2}=50,1 \%\right)$. The relationship of yield to area under disease progress curve (AUDPC) proved to be less consistent $\left(R^{2}=31,4 \%\right)$. Plots with the same HAD showed yield reduction for higher AUDPC values. This indicated a reduction in photosynthetic efficiency. Sprays beginning 30 days after emergency (DAE) provided $67,8 \%$ control of angular leaf spot, with decreased in a linear way $(\mathrm{P}<0.01)$ to $0 \%$ at 62 DAE. The $\mathrm{ND}_{810,660}$ was related to healthy leaf area index (HLAI, $\mathrm{R}^{2}=89,7 \%$ ) and to healthy leaf area absorption (HRI, $\mathrm{R}^{2}=87,7 \%$ ). The ND showed potential to be used to estimate HLAI. This relationship can thus be used together with control plot and disease severity assessment for the angular leaf spot management program in bean. 


\section{INTRODUÇÃO}

A mancha angular (Phaeoisariopsis griseola (Sacc.) Ferraris) é um dos principais problemas da cultura do feijão no Brasil, chegando a provocar reduções de até $45 \%$ na produção (Sartorato \& Rava, 1992). Entretanto, ainda não se conhece na literatura uma recomendação de controle da doença baseada nos princípios do manejo integrado, ou seja, não há um limiar de dano econômico estabelecido para a mancha angular do feijoeiro. O principal método de controle utilizado atualmente, aplicações preventivas de fungicidas, duas a três, em datas fixas podem apresentar inconveniente econômico e ambiental.

O limiar de dano econômico (LDE) pode ser definido como a intensidade de doença na qual o benefício do controle se iguala ao custo do mesmo (Zadoks, 1985). O LDE não é estático e imutável e a dificuldade para calculá-lo é um dos motivos da falta de trabalhos com aplicações práticas, apesar desse ser a pedra fundamental do manejo integrado de doenças (Zadoks, 1985). A obtenção do LDE exige estudos sobre os danos provocados pelos patógenos, que podem ser realizados em parcelas experimentais ou em plantas individuais (Bergamin Filho et al., 1995).

Vários são os modelos sugeridos para se estimar danos (Teng \& Johnson, 1988): modelos de ponto crítico, de múltiplos pontos, integrais, de superfície-resposta e sinecológicos. Todos são baseados na lógica incerta da relação injúria-dano (Waggoner $\&$ Berger, 1987). Outras desvantagens apresentadas pela maioria dos modelos baseados na relação injúria-dano são a falta de transportabilidade (Rouse, 1988) e o fato de serem destinados a apenas uma doença, situação rara de se observar no campo, onde podem ser encontradas simultaneamente várias doenças em uma mesma planta. 
Waggoner \& Berger (1987) propuseram o uso da duração da área foliar sadia (HAD - Healthy Leaf Area Duration) e da absorção da radiação solar pela área foliar sadia (HAA - Healthy Area Absorption) para estimar a redução de produção induzida pelas doenças. Os autores relembraram o conceito de que a produção de uma planta é função da energia interceptada pelas folhas durante o ciclo da cultura, dando maior consistência fisiológica às estimativas de danos.

Medições de HAD e HAA mostraram maior eficiência na determinação de danos provocados por doenças em feijoeiro (Amorim et al., 1995; Bergamin Filho, 1995; Bergamin Filho et al., 1995; Carneiro, 1995; Godoy, 1995; Iamauti, 1995; Bergamin Filho et al., 1997; Carneiro et al., 1997; Silva, 1997), mas são métodos muito mais trabalhosos que avaliações de severidade, o que inviabiliza sua aplicação prática. Para viabilizar o uso de HAD e HAA no cálculo de danos, técnicas de sensoriamento remoto têm demonstrado potencial para execução de estimativas rápidas e precisas do índice da área foliar, principalmente sob condições de campo (Asrar et al., 1984; Nilsson, 1995; Nutter Jr. \& Littrell, 1996). O método mais conhecido é aquele em que se utiliza um radiômetro portátil de múltiplo espectro para quantificar a radiação refletida pela copa do hospedeiro (Nilsson, 1995; Canteri et al., 1996).

Vários fatores podem influenciar os dados espectrais, tais como quantidade de pigmentos (clorofila), ângulo das folhas, textura da superfície das folhas, doenças e outros estresses, estádio de crescimento das plantas, condição de cultivo, ângulo do sol e outras condições mensuráveis (Nilsson, 1995). O nitrogênio e a água do solo têm uma grande influência na característica espectral do dossel. Diferenças no crescimento e desenvolvimento entre cultivares podem também mascarar efeitos de doenças em baixa intensidade (Nilsson, 1995).

O objetivo do presente estudo foi verificar se medidas de refletância são úteis para estimar a área foliar sadia de feijoeiro e assim serem utilizadas em programas de manejo da mancha angular. No item 3 foram estudadas as relações de medidas de refletância com as variáveis derivadas da área foliar, a severidade da mancha angular e a produção em feijoeiro. Também se testou a variação da refletância de acordo com a 
influência do cultivar, época de plantio, severidade da mancha angular e estádio da cultura. No item 4 testaram-se novamente as relações entre medidas de refletância com as variáveis derivadas da área foliar, produção e severidade da doença e estimou-se a interferência da doença na eficiência fotossintética das plantas. Também se testou a sensibilidade das medidas de refletância para detecção de variações no índice da área foliar sadio e na absorção da área foliar sadia para uso futuro em programas de manejo da doença. 


\section{REVISÃO DE LITERATURA}

\subsection{Mancha Angular}

A mancha angular do feijoeiro, causada pelo fungo Phaeoisariopsis griseola (Sacc.) Ferraris, apresenta como sintoma típico lesões necróticas delimitadas pelas nervuras de folhas trifolioladas. A coloração é inicialmente cinza, passando posteriormente a marrom escuro (Zaumeyer \& Thomas, 1957). As lesões podem coalescer e formar halos cloróticos ao seu redor, causando amarelecimento parcial e resultando em desfolha prematura. A doença também pode afetar as vagens, ramos e pecíolos (Bianchini et al., 1989).

Até alguns anos atrás, a mancha angular era considerada uma doença secundária para a cultura (Costa, 1971; Vieira, 1983), mas em trabalhos recentes está sendo considerada de grande importância para a produção de feijão (Sartorato, 1989; Beebe \& Pastor-Corrales, 1991). O plantio de materiais mais suscetíveis e o surgimento mais precoce da mancha angular durante o ciclo da cultura, muitas vezes provocado por um manejo inadequado aliado a um ambiente favorável (Sartorato, 1989), são provavelmente responsáveis pelo aumento nos danos causados por esta doença (Godoy, 1995).

As medidas recomendadas para o controle da mancha angular são a rotação de culturas por dois anos, eliminação de restos culturais, uso de sementes sadias, uso de cultivares resistentes e controle químico (Bianchini et al., 1989). A obtenção de materiais com alto nivel de resistência é dificultada pelo grande número de raças fisiológicas do fungo (Sartorato, 1989). Existem vários trabalhos com testes de fungicidas para controle da mancha angular (Issa et al., 1982; Tanaka \& Junqueira Neto, 
1982; Castro et al., 1989; Goulart, 1990; Oliveira et al., 1992), mas ainda não se conhece na literatura uma recomendação de aplicação baseada nos danos que possam ser ocasionados pela doença. Atualmente tem se recomendado o controle preventivo, com duas a três aplicações, de acordo com o histórico de ocorrência da doença (Menezes, 1994).

\subsection{Manejo de doenças}

Aplicações preventivas de fungicidas, duas a três em datas fixas, conforme recomendação atual para controle da mancha angular, são inconvenientes econômica e ambientalmente. Em termos econômicos, as aplicações executadas poderiam não ser necessárias e assim se estaria desperdiçando produto e dinheiro. Em termos ambientais, o excesso de aplicações provoca agressões ao homem e ao meio ambiente, principalmente no caso de fungicidas à base de estanho, muito utilizados para o controle preventivo da mancha angular (Issa et al., 1982; Tanaka \& Junqueira Neto, 1982; Castro et al., 1989; Goulart, 1990; Oliveira et al., 1992). O ideal seria a adoção de um sistema de manejo integrado para a doença.

Sistemas de manejo integrado procuram fazer com que a produção atual de uma área se aproxime ao máximo da produção econômica, com a menor agressão possível ao homem e ao meio ambiente (Bergamin Filho \& Amorim, 1996). A produção econômica pode ser definida como o nível de produção em que há maior lucro para o agricultor (Zadoks \& Schein, 1979). Sua definição não é fácil, pois os preços dos produtos variam conforme as leis de mercado e os subsídios governamentais, entre outros fatores. A aplicação prática dos sistemas de manejo integrado depende de estudos sobre o limiar de dano econômico e de considerações sobre custo/benefício, para cada patossistema.

A obtenção do limiar de dano econômico exige estudos sobre os danos provocados pelos patógenos, que podem ser realizados em parcelas experimentais ou em plantas individuais (Bergamin Filho et al., 1995). Em parcelas experimentais pode-se 
utilizar tratamentos pareados, que consistem em duas parcelas, uma doente e outra sadia, ou tratamentos múltiplos, em que dois ou mais níveis de intensidade de doença compõem o mesmo experimento. Em plantas individuais, indivíduos doentes e sadios substituem as parcelas (Lopes et al.. 1994). Vários são os modelos sugeridos para se estimar danos (Teng \& Johnson, 1988): modelos de ponto crítico, de múltiplos pontos. integrais, de superfície resposta e sinecológicos. Uma descrição mais minuciosa de como obtê-los é dada por Bergamin Filho \& Amorim (1996). A maioria dos modelos é destinada a apenas uma doença, situação rara de se observar no campo, onde pode se encontrar simultaneamente várias doenças em uma mesma planta.

\subsection{Quantificação de danos baseada em área foliar sadia}

Waggoner \& Berger (1987) criticaram a abordagem tradicional da relação doença-dano citando que uma mesma intensidade de doença pode apresentar efeito diferenciado sobre o hospedeiro, caso a epidemia tenha início precoce ou tardio. Há ainda que se considerar a necessidade de modelos que incluam outras variáveis, como crescimento do hospedeiro, área foliar remanescente, produção potencial das plantas e eficiência fotossintética das folhas sadias ou doentes. Opinião compartilhada em maior ou menor grau por Hau et al. (1980), Johnson (1987), Rouse (1988), Gaunt (1990), Campbell \& Madden (1990), Lopes et al. (1994), Bergamin Filho et al. (1995), Bergamin Filho \& Amorim (1996) e Bergamin Filho et al. (1997).

O modelo proposto por Waggoner \& Berger (1987) usa a duração da área foliar sadia (HAD - Healthy Leaf Area Duration) e a absorção da radiação solar pela área foliar sadia (HAA - Healthy Area Absorption) para estimar a redução de produção induzida pelas doenças. Ao contrário da abordagem tradicional, que se concentrava em medir apenas o aumento e desenvolvimento das doenças no tempo, esta abordagem verifica o efeito da doença na produção pela análise da folhagem do hospedeiro. Assim, a área foliar doente é subtraída do índice da área foliar (LAI) da cultura e integralizada para 
todo o ciclo de crescimento do hospedeiro para se obter a duração da área foliar sadia (HAD):

$\mathrm{HAD}=\sum_{i=1}^{n-1}\left\{\left[L A I_{i}\left(1-X_{i}\right)+L A I_{i+1}\left(1-X_{i+1}\right)\right] / 2\right\}\left(t_{i+1}-t_{i}\right)$

Prosseguindo no raciocínio obteve-se a absorção da área foliar sadia (HAA) em $\mathrm{MJM}^{-2}$ :

$\mathrm{HAA}=\sum_{i=1}^{n-1} I_{i}\left(\left\{\left(1-X_{i}\right)\left[1-\exp \left(-k L A I_{l}\right)\right]+\left(1-X_{i+1}\right)\left[1-\exp \left(-k L A I_{i+1}\right)\right]\right\} / 2\right)\left(t_{i+1}-t_{i}\right)$

onde $L A I_{i}$ é o índice da área foliar no tempo $i ; t$ é o tempo; $X_{i}$ é a severidade da doença em proporção; $I$ é a radiação solar média incidente em cada intervalo $\left(t_{i+1}-t_{i}\right)$; e $k$ é o coeficiente de extinção, que varia de 0,3 a 1,0, dependendo do ângulo de inclinação das folhas da cultura.

Apesar de eficientes e lógicos, os conceitos de Waggoner \& Berger (1987) necessitam algumas complementações. O uso da HAD considera apenas a perda ou redução da área foliar como o principal efeito da doença na produção, o que é válido para aqueles patossistemas que apresentam este efeito como característica principal, tais como Phytophthora infestans/batata (Haverkort \& Bicamumpaka, 1986), Ascochyta fabae/Vicia faba (Madeira et al., 1988) e amendoim-Cercosporidium personatum (Aquino et al., 1992). Em outros patossistemas, os efeitos das doenças também podem ser sentidos na eficiência de uso da radiação (RUE) da área foliar aparentemente sadia (Johnson, 1987; Bastiaans et al., 1994), tais como em Pyricularia grisea/arroz (Bastiaans et al., 1994).

O uso da HAA não discrimina entre os diferentes tipos de tecido, responsáveis pela produção durante o ciclo da cultura e a HAD não permite distinguir variações entre o efeito de um elevado LAI com pequena duração ou um baixo LAI por um longo periodo (Johnson, 1987). Além disto, em muitas culturas, as plantas são capazes de suportar a remoção de parte de seu LAI, sem prejuízos para a produção, havendo portanto a necessidade de serem estabelecidos limites de danos nos modelos que envolvem HAD e HAA (Boote et al., 1980; Lim \& Gaunt, 1986; Johnson, 1987). 
Outro ponto fundamental para viabilização prática dos conceitos de Waggoner \& Berger é o estabelecimento de uma forma rápida de se determinar o índice da área foliar (Campbell \& Madden, 1990). Para tanto, a utilização de técnicas de sensoriamento remoto vem sendo citada como uma possibilidade (Lopes et al., 1994, Bergamin Filho et al., 1995; Iamauti, 1995; Bergamin Filho et al., 1997).

\subsection{Sensoriamento remoto}

Sensoriamento remoto envolve métodos de mensuração de propriedades de um objeto sem contato físico entre o instrumento de medida e o objeto (Jackson, 1986). Estas medidas são não-destrutivas e não-invasivas, e um objeto específico pode ser analisado muitas vezes sem danificar a amostra (Nilsson, 1995). No caso do sensoriamento remoto aplicado à agricultura, o maior interesse recai sobre a reflexão, que é examinada sob duas variáveis: albedo, que é a relação entre toda a luz refletida pela superfïcie e toda luz incidente; e refletância, que é a razão entre a radiação refletida em uma direção específica e a radiação incidente a um determinado comprimento de onda (Koffler, 1995). A refletância de uma folhagem é função de características da própria espécie vegetal e das condições em que se encontram as plantas (Bergamin Filho \& Amorim, 1996).

\subsubsection{Radiação solar}

O fluxo radiante vindo do sol, ao atingir a superfície do dossel vegetativo, interage com o mesmo, resultando no seguinte fracionamento: a) fluxo refletido; b) fluxo absorvido pelos elementos do dossel vegetativo e c) fluxo transmitido. A quantidade relativa de cada uma destas partes depende da superficie em que o fluxo incide e varia com o comprimento de onda do espectro (Huete \& Jackson, 1988). No caso da 
vegetação, a parte refletida, que pode ser medida por sensores, resulta da interação da radiação solar com as diversas camadas ou extratos da vegetação e do solo sobre o qual ela se desenvolveu (Bauer, 1975).

A faixa espectral que se estende de $300 \mathrm{~nm}$ a $15000 \mathrm{~nm}$ é a mais usada em sensoriamento remoto (Silva, 1995). É conhecida como espectro ótico, pois se conseguem informações com aparelhos dotados de lentes, tais como máquinas fotográficas e radiômetros. A região do espectro de maior interesse à fitopatologia é a região do espectro refletivo (380 nm a $3000 \mathrm{~nm}$ ), chamada desta forma em razão da energia detectada nesta região ser basicamente originada da reflexão da energia solar por objetos na superficie terrestre. Pode ser dividido em três sub-regiões (Vettorazzi, 1992):

a) visível (380 $\mathrm{nm}$ a $720 \mathrm{~nm}$ ): corresponde à região em que o olho humano é capaz de responder à radiação eletromagnética. Também é conhecida como região das cores primárias.

b) infravermelho próximo (NIR) (720 nm a $1300 \mathrm{~nm})$.

c) infravermelho médio (1300 $\mathrm{nm}$ a $3000 \mathrm{~nm})$.

\subsubsection{Refletância de folhas}

As folhas são consideradas os principais elementos das plantas quando se trata da influência sobre as propriedades espectrais da vegetação (Formaggio, 1989). O entendimento das interações da radiação solar com a vegetação depende do conhecimento das propriedades óticas da folha (Vane \& Goetz, 1988). A refletância de folhas pode ser estudada de acordo com duas regiões do espectro: região do visivel e região do infravermelho (Figura 1). 


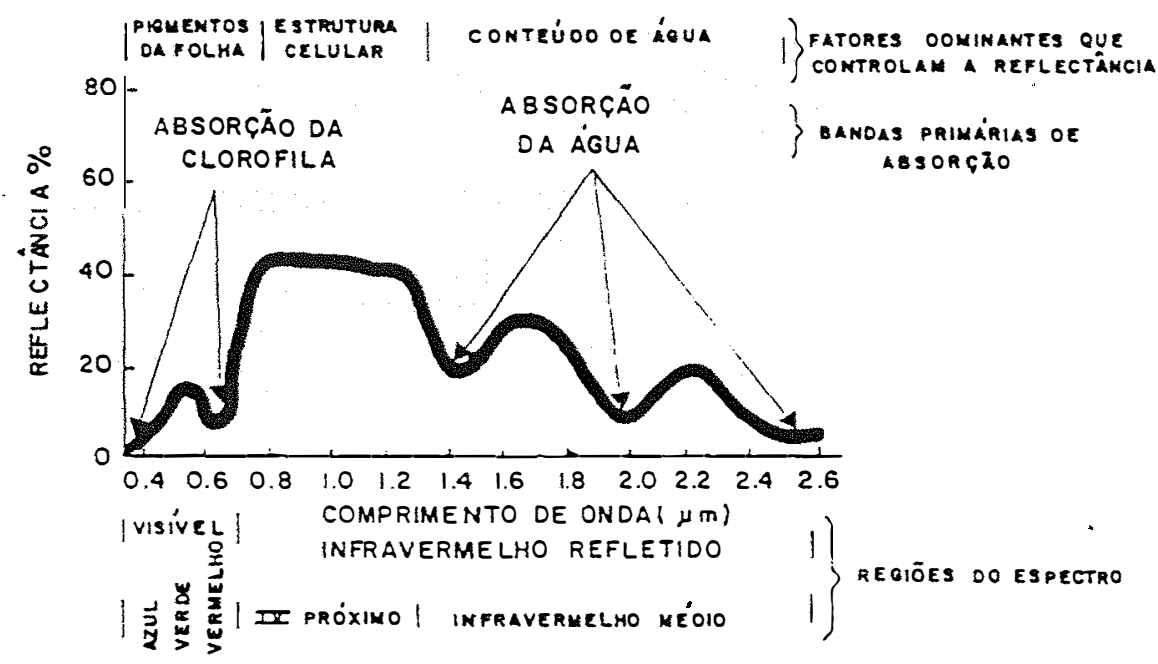

Figura 1 - Principais características da resposta espectral de folhas verdes de plantas (Hoffer, 1978; Formaggio, 1989).

Em estudos relacionados à fotossíntese recomenda-se o uso da faixa de radiação solar na região do visível, chamada de radiação fotossinteticamente ativa (Photosynthetically Active Radiation - PAR). Nesta faixa espectral a refletância das folhas é menor que $15 \%$, apresentando um pico em $530 \mathrm{~nm}$, o que explica a percepção da cor verde da vegetação (Bauer, 1975). A maior parte da PAR que incide sobre a vegetação é absorvida pelos pigmentos fotossintetizantes no mesófilo das folhas (Figura 1).

Na região do infravermelho próximo (NIR), a absorção da radiação é muito baixa (menos de $15 \%$ ) e a refletância pode chegar até 50\%, dependendo da estrutura anatômica das folhas (Tucker \& Garratt, 1977). Nesta região do espectro pode haver influência da quantidade de camada de folhas na refletância. Em estudos conduzidos por Myers (1970) houve incremento na refletância, na região do NIR, com o aumento do número de camadas de folhas de algodão.

De modo geral, medições radiométricas em folhas sadias detectam uma sutil refletância na faixa do azul $(450-480 \mathrm{~nm})$ e vermelho $(600-700 \mathrm{~nm})$, um pouco mais no 
verde $(500-550 \mathrm{~nm})$ e substancialmente mais no infravermelho próximo entre $750 \mathrm{e}$ $1100 \mathrm{~nm}$. Se há um estresse fisiológico ou doença, há um incremento na refletância na faixa do vermelho e azul e em muitos casos no amarelo também. Além disso, há freqüentemente um substancial decréscimo na refletância em infravermelho próximo (Nilsson, 1995).

\subsubsection{Refletância da vegetação}

Tudo aquilo que compõe a parte aérea de uma comunidade de plantas é definido por Assunção (1989), como dossel vegetativo ou simplesmente dossel. Em inglês existe o termo canopy usado para expressar não toda a parte aérea, mas apenas a parte do dossel das plantas exposta à radiação e envolvida diretamente nas interações com a energia solar. No presente trabalho serão utilizados os termos dossel ou copa em referência a parte do dossel das plantas exposta à radiação.

Informações obtidas em folhas individuais fornecem dados sobre o mecanismo das transformações ocorridas dentro da planta, entretanto, para se obter alguma aplicação prática necessita-se extendê-la para o nível do dossel em condições de campo (Hatfield, 1990). A refletância das culturas, durante a fase de desenvolvimento da vegetação no campo, apresenta ainda uma mistura de resposta espectral da parte aérea da planta e do solo onde a cultura foi implantada. À medida em que a vegetação atinge o seu desenvolvimento máximo, o dossel é definido como completo, ou seja, com uma cobertura vegetal de $100 \%$ da área. Após esta fase há naturalmente uma redução na cobertura vegetal com o início da senescência.

Medições radiométricas de vegetação possuem como característica uma mudança drástica na refletância entre 680 e $750 \mathrm{~nm}$ (Nilsson, 1995). Esta característica é única para vegetação verde e permite avaliações de comportamento da clorofila e índice da área foliar. São particularmente úteis para deteç̧ão precoce de estresse na vegetação. 


\subsubsection{Fatores que afetam a refletância da vegetação}

Conjuntos de folhas ou o dossel exibem as mesmas propriedades refletivas de folhas individuais, entretanto, há uma série de variáveis que devem ser consideradas. Kollenkark et al. (1982) comentam que os dosséis de culturas agrícolas exibem quatro componentes com diferentes propriedades de refletância ótica: a) vegetação iluminada, b) solo iluminado, c) vegetação sombreada e d) solo sombreado. A influência de cada um destes componentes varia com a cobertura vegetal, orientação e espaçamento das fileiras, morfologia do dossel, estrutura interna dos elementos que compõem o dossel, diâmetro da copa da planta, altura da planta, teor de água na planta e no solo, condições fitossanitárias, ângulo zenital e azimutal do sol, latitude e resolução do equipamento utilizado para medidas radiométricas (Moreira, 1997).

Como exemplo da variação nas medidas de refletância tem-se os dados de Kollenkark et al. (1982) que encontraram até 140\% de variação na refletância na região do vermelho, para a cultura da soja plantada em nove diferentes orientações de fileiras, com cobertura do solo de $64 \%$. Na região do infravermelho próximo, o sombreamento não é tão pronunciado como na região do visivel (Daughtry et al., 1982), minimizando a variação nesta faixa do espectro.

O arranjo das folhas em relação ao caule e sua orientação em relação ao sol, provocam variações entre leituras realizadas em folhas individuais e no dossel (Pinter Jr. et al., 1985). A turgidez celular pode afetar a refletância da copa de culturas, com mudanças iniciais mais pronunciadas na região do visivel do que no infravermelho próximo (Myers, 1970).

O tipo de solo é uma outra fonte de variação em medidas de refletância. A refletância do solo varia de acordo com a sua composição e umidade. Mudanças no teor de água nos $2 \mathrm{~mm}$ superficiais causam as maiores variações na refletância. Solos úmidos têm uma baixa refletância (Hatfield, 1990). A umidade pode influenciar as leituras radiométricas em diferentes formas, como orvalho, molhamento foliar, molhamento do solo e estresse hídrico das plantas (Nilsson, 1995). 
Há muitos tipos de estresses, entre eles os provocados por doenças, que podem incidir sobre as plantas e provocar variações nas propriedades de refletância. Atualmente não há possibilidade de se indentificar qual é a fonte específica do estresse tomando por base as medidas de refletância, mas em muitos casos pode-se detectá-lo antes do que seria possível se fossem utilizados métodos convencionais (Nilsson, 1995).

O nitrogênio e a água do solo têm uma grande influência na característica espectral do dossel. Seus efeitos são frequentemente grandes e podem mascarar efeitos de doenças em baixa intensidade. Portanto, o controle destes dois fatores é importante no sensoriamento remoto aplicado à fitopatometria. Diferenças no crescimento e desenvolvimento entre cultivares podem também mascarar efeitos de doenças em baixa intensidade. Cultivares com porte e arquitetura diferentes possuem diferentes características espectrais (Nilsson, 1995).

A detecção das condições de estresse toma por base a redução da área foliar total, por perda direta de folhas, mudança de sua orientação, ou ainda supressão do crescimento da planta (Moreira, 1997). Nestes casos, a refletância do infravermelho próximo tende a ser reduzida relativamente mais do que a do visivel, por causa da redução do realce do infravermelho próximo ou por aumento da exposição do solo (Knipling, 1970).

Para aplicações de medidas de refletância na fitopatologia devem ser realizados estudos de material vegetal, primeiramente em dosséis sadios, então suplementados com dados de dosséis com diferentes níveis de severidade (Nilsson, 1995). A avaliação de doenças ou estresses usando sensoriamento remoto é, por enquanto, uma comparação primária de dados da áreas com estresse e áreas com dossel sadio (Nilsson, 1995).

Como visto, há uma série de fatores que podem influenciar a refletância da folhagem de uma cultura. Uma alternativa para eliminar grande parte da variação e viabilizar o uso de medidas de refletância em manejo de doença é o uso da parcela controle sensu Lopes et al. (1994), para comparações instantâneas com determinada situação de produção. 


\subsubsection{2 Índices de vegetação}

Índices de vegetação auxiliam no uso das informações contidas na refletância nos vários comprimentos de onda. São resultado de transformações lineares do fator de refletância, obtido em duas ou mais bandas espectrais, envolvendo soma, razão, diferença ou qualquer outra combinação (Wiegand et al., 1991). Algumas vezes é suficiente analisar somente o decréscimo da refletância no infravermelho próximo. Entretanto, melhores informações podem ser obtidas se forem combinados dados de várias faixas do espectro.

A literatura cita numerosas utilizações dos índices de vegetação, que se relacionam com: índice da área føliar verde (Asrar et al., 1984; Hatfield et al., 1985; Clevers, 1989), fitomassa (Tucker, 1979), radiação fotossinteticamente ativa absorvida (Asrar et al., 1984; Hatfield et al., 1984; Seller, 1985). O emprego de índices de vegetação em culturas agrícolas apresenta duas grandes vantagens: a) reduz a dimensão das informações multiespectrais a um simples número, além de minimizar o impacto das condições de iluminação (Moreira, 1997) e b) fornece um número altamente correlacionável com parâmetros agronômicos (Wiegand et al., 1991).

Apesar da melhor correlação com parâmetros agronômicos, os índices de vegetação são obtidos a partir de medidas de refletância e portanto, sujeitos às influências dos mesmos fatores que atuam nas propriedades óticas do dossel agrícola (Moreira, 1997). Entre eles as propriedades ópticas da folha, a influência do solo e a posição do sol e nebulosidade.

A maioria dos indices de vegetação utilizam medidas de refletância nas faixas espectrais do vermelho e infravermelho próximo (Huete \& Jackson, 1988). O motivo para que isto ocorra na radiometria de campo é que estas duas faixas contêm mais de 90\% da informação espectral da vegetação (Baret et al.; 1989). Os principais índices de vegetação utilizados em trabalhos na área de fitopatologia são o índice de vegetação (infravermelho próximo/vermelho), relacionado com mudanças no índice da área foliar $(\mathrm{LAI})$, e a diferença normalizada (normalized difference $=$ (infravermelho próximo - 
vermelho) / (infravermelho próximo + vermelho)), mais apropriada para relações com a interceptação de radiação fotossinteticamente ativa (Nilsson, 1995).

\subsubsection{Radiometria}

Radiometria, ou espectrorradiometria de campo pode ser definida como técnica de sensoriamento remoto empregada para medir a radiação solar refletida de objetos na superficie terrestre, em determinadas faixas ou bandas espectrais (Deering, 1989). Os sistemas para medição desta radiação refletida são denominados radiômetros (Steffen et al., 1981). Alguns trabalhos buscam relações entre medidas de campo com imagens de satélites (sensoriamento remoto orbital), neste caso as informações registradas no campo devem estar em sincronismo com a passagem do satélite pela área de estudos (Silva, 1995).

As medições de campo são feitas posicionando-se o radiômetro sobre a cultura. Algumas características das medidas radiométricas obtidas no campo foram destacadas por Epiphanio (1989): a) os dados são obtidos próximo à superficie com influência mínima da atmosfera; b) os radiômetros são sensores que, geralmente, possuem um número maior de bandas espectrais do que os sensores a bordo de satélites; c) devido à proximidade alvo-sensor pode-se controlar melhor as relações entre as medidas espectrais e as variáveis biofĩsicas; d) possibilidade de grande número de medidas ao longo do ciclo da cultura.

\subsubsection{Trabalhos desenvolvidos com radiometria aplicados à fitopatologia}

Os primeiros relatos do uso de radiômetros na fitopatologia são relativamente recentes (Pederson \& Gudmestad, 1977; Nilsson, 1980; Pederson \& Fiechtner, 1980). As boas relações entre doença e refletância demonstradas por Nutter Jr. \& Cunfer (1988) e 
Nutter Jr. (1989) estimularam o estudo do assunto. Ultimamente os principais trabalhos têm usado medidas de refletância para quantificar a área foliar e assim avaliar indiretamente o efeito das doenças (Aquino et al., 1992; Nutter Jr. et al., 1990; 1993; Nutter Jr. \& Littrell, 1996). Boas revisões sobre o assunto podem ser encontradas em Bergamin Filho et al. (1995), Gaunt (1995) e Nilsson (1995). 


\section{RELAÇÕES ENTRE ÁREA FOLIAR, PRODUÇÃO, MEDIDAS DE REFLETÂNCIA E SEVERIDADE DA MANCHA ANGULAR DO FEIJOEIRO.}

\subsection{RESUMO}

Foram conduzidos experimentos com feijoeiro, em folhas destacadas e em dossel sob condições de campo, com o objetivo de testar as relações entre as variáveis derivadas da área foliar, produção, medidas de refletância e severidade da mancha angular (Phaeoisariopsis griseola (Sacc.) Ferraris). As refletâncias do dossel em infravermelho (IR), $810 \mathrm{~nm}\left(\mathrm{R}_{810}\right)$ e vermelho $(\mathrm{R}), 660 \mathrm{~nm}\left(\mathrm{R}_{660}\right)$ e $610 \mathrm{~nm}\left(\mathrm{R}_{610}\right)$, foram usadas para calcular as diferenças normalizadas $\mathrm{ND}_{810,660}$ e $\mathrm{ND}_{810,610}$, onde $\mathrm{ND}=(\mathrm{IR}$ $R) /(I R+R)$. Em folhas destacadas, quanto maior o nível de severidade maior foi a refletância nos comprimentos de onda de 460, 510, 560, 660 e 710 nm e menor em 760 e $810 \mathrm{~nm}$. Não houve um comprimento de onda ou um índice vegetativo que pudesse ser usado para estimar apenas a severidade de doença a nível de campo. A curva da refletância em $810 \mathrm{~nm}$ apresentou um formato bem semelhante à curva do índice da área foliar (LAI), para os dois cultivares, as duas épocas de plantio e os dois tratamentos de controle da mancha angular. As melhores relações com índice da área foliar sadia (HLAI) foram obtidas com a refletância em $810 \mathrm{~nm}\left(\mathrm{R}_{810}\right)\left(\mathrm{R}^{2}=84,7 \%\right)$ e com a diferença normalizada, usando 810 e $660 \mathrm{~nm}\left(\mathrm{ND}_{810,660}\right)\left(\mathrm{R}^{2}=86,6 \%\right)$. A absorção da área foliar sadia (HRI), apresentou melhor relação com a $\mathrm{ND}_{810,610}\left(\mathrm{R}^{2}=82,6 \%\right)$. O ajuste do modelo monomolecular nas relações $\mathrm{R}_{810} \times$ HLAI e $\mathrm{ND}_{810,660} \times$ HLAI foi significativamente diferente $(\mathrm{P}<0,05)$ para parcelas com e sem tratamento fungicida. Na relação $\mathrm{ND}_{810,610} \times$ HRI, o ajuste foi significativamente diferente $(\mathrm{P}<0,05)$ para as épocas de plantio. Apresentou-se um modelo para estimar a HLAI em função da $\mathrm{ND}_{810,660}$. As medidas de duração e absorção da área foliar sadia correlacionaram-se bem com a produção $\left(\mathrm{R}^{2}=62,7 \%\right.$ e $73,5 \%$, respectivamente) e com a diferença normalizada da refletância $\left(\mathrm{R}^{2}=86,6 \%\right.$ e $82,6 \%$, respectivamente), indicando o potencial deste tipo de medida para relações com danos e uso no manejo de doenças em feijoeiro. 


\subsection{INTRODUÇÃO}

A quantificação de danos provocados por patógenos é um dos componentes essenciais em sistemas de manejo integrado. Geralmente, para se quantificar e estimar danos são utilizadas avaliações visuais de severidade da doença. Uma nova abordagem apresentada por Waggoner \& Berger (1987) relaciona produtividade à quantidade da área foliar sadia remanescente na cultura, o que permite a obtenção dos danos indiretamente. A viabilização prática desta abordagem exige estimativas da área foliar, uma tarefa árdua se realizada pelos métodos tradicionais de avaliação e muitas vezes inviável de ser executada sem se destruir a amostra (Bergamin Filho \& Amorim, 1996).

A literatura cita trabalhos que utilizam o sensoriamento remoto para estimar o índice da área foliar de culturas (Asrar et al., 1984; Aquino et al., 1992; Schuld, 1996). O sensoriamento remoto envolve métodos de mensuração de propriedades de um objeto sem contato fisico entre o instrumento de medida e o objeto. Estas medidas não destroem e não alteram as propriedades do objeto e este pode ser analisado muitas vezes sem ser danificado. Medidas de refletância são o principal exemplo do sensoriamento remoto aplicado à fitopatologia.

Propriedades específicas da vegetação, tais como se está sadia ou doente, influenciam a quantidade e qualidade da radiação emitida e refletida pelo dossel (Nilsson, 1995). Medições radiométricas da vegetação possuem como característica um incremento drástico na refletância entre 680 e $750 \mathrm{~nm}$ (Figura 1). Esta característica é única para vegetação verde, permitindo avaliações de comportamento da clorofila e do índice da área foliar, independentemente de variações na cobertura do solo, sendo particularmente úteis para detecção precoce de estresse na vegetação (Nilsson, 1995), entre os quais as doenças encontram-se incluídas.

Índices de vegetação auxiliam no uso das informações contidas na refletância nos vários comprimentos de onda. Algumas vezes é suficiente analisar o decréscimo da refletância na faixa do infravermelho. Entretanto, melhores informações podem ser obtidas se forem combinados dados de várias faixas do espectro. $O$ índice de vegetação 
(infravermelho/vermelho) é relacionado com mudanças no índice da área foliar (LAI), enquanto a diferença normalizada ((infravermelho - vermelho) / (infravermelho + vermelho)) é mais apropriada para relações com a interceptação de radiação fotossinteticamente ativa (Hatfield, 1990).

Informações obtidas em folhas individuais fornecem dados básicos sobre os mecanismos das transformações ocorridas dentro da planta, mas para se obter alguma aplicação prática necessita-se extendê-la para o nivel do dossel em condições de campo. A refletância de uma folha individual é o principal fator que influencia a refletância do dossel (Major et al., 1993). Conjuntos de folhas ou o dossel exibem as mesmas propriedades refletivas de folhas individuais, porém há uma série de variáveis que devem ser consideradas. A orientação das folhas, isto é, o arranjo das folhas em relação ao caule e orientação em relação ao sol, provocam variações entre leituras feitas em folhas individuais e no dossel (Hatfield, 1990).

O objetivo do presente estudo foi verificar se medidas de refletância em vários comprimentos de onda e combinações destas medidas entre si são capazes de estimar área foliar, severidade da mancha angular e produção em feijoeiro, bem como testar se há variação em leituras de refletância de acordo com o cultivar, época de plantio, severidade da mancha angular e estádio da cultura. 


\subsection{MATERIAL E MÉTODOS}

\subsubsection{Experimento com folhas destacadas de feijoeiro}

Diversas folhas destacadas de feijoeiro, com o mesmo nivel de severidade da mancha angular foram posicionadas de forma contínua, procurando simular uma grande folha. As folhas com sintomas da doença foram obtidas de plantas do cultivar 'Carioca', inoculadas aos 10 dias após a emergência com uma suspensão de $1,5 \times 10^{5}$ conídios $/ \mathrm{ml}$ de Phaeoisariopsis griseola e mantidas em câmara úmida por 48 horas. As plantas permaneceram em câmaras de crescimento (Conviron modelo E7), sob fotoperíodo de 12 horas, com temperaturas variáveis entre as câmaras, para favorecer a obtenção de folhas com uma ampla gama de níveis severidade (Dalla Pria, 1997).

Após 20 dias em câmara de crescimento, algumas folhas foram selecionadas e separadas, de acordo com o nível de severidade da doença (Godoy et al., 1997), em quatro classes: a) sadias; b) $1,5 \%$ a $2,5 \%$; c) $8 \%$ a $12 \%$,d) $25 \%$ a $35 \%$. Descartaram-se, com auxílio de tesoura, as áreas das folhas que não se enquadravam em sua classe de severidade. As folhas de cada classe foram arranjadas sobre um tecido áspero, que permitia sua fixação, de modo a formar uma superfície plana e uniforme com a severidade da mancha angular desejada. Este procedimento foi repetido 4 vezes, para cada classe de severidade, para que fosse estimada a refletância. No momento da leitura, um radiômetro de múltiplo espectro (Cropscan Inc., modelo MSR87) foi posicionado a uma altura de $16 \mathrm{~cm}$ sobre a superficie de folhas, resultando numa área amostrada de $50,3 \mathrm{~cm}^{2}$, em forma de círculo, sendo executada 5 leituras para cada arranjo das folhas. Todos os passos foram realizados com grande agilidade para evitar a perda de água dos tecidos. A parte de preparo do material foi executada na sombra, sob temperatura de $21^{\circ} \mathrm{C}$. O teste foi executado no dia 27/07/96, sob luz solar, sem nebulosidade nem sombreamento sobre a superfície de folhas. 


\subsubsection{Experimento de campo}

Os experimentos de campo foram executados no Campo Demonstrativo e Experimental da Cooperativa Agropecuária Castrolanda Ltda., em Castro-PR. Foram conduzidos dois ensaios, com os mesmos tratamentos, semeados em 20/12/95 e 15/01/96. O delineamento experimental adotado fatorial com 4 tratamentos e 4 repetições, totalizando 16 parcelas. Os tratamentos eram compostos pelos cultivares de feijão Carioca e Iapar 44, com e sem aplicação de fungicidas. Nas parcelas tratadas com fungicida foram feitas 4 aplicações: aos 20, 30, 40 e 50 dias após a emergência, com 250 $\mathrm{g}$ i.a /ha de benomil $+187,5 \mathrm{~g}$ i.a./ha de tebuconazole, $200 \mathrm{~g}$ i.a./ha de fentin hidróxido, $200 \mathrm{~g}$ i.a./ha de fentin hidróxido $+75 \mathrm{~g}$ i.a./ha de tebuconazole e $200 \mathrm{~g}$ i.a./ha de fentin hidróxido, respectivamente.

As parcelas possuíam $5,00 \mathrm{~m}$ de comprimento por $1,60 \mathrm{~m}$ de largura e foram divididas em duas partes. Na primeira metade, fizeram-se leituras de refletância e na segunda, as avaliações de severidade de doença. Isto para evitar interferências da movimentação das plantas nas leituras de refletância. Utilizou-se espaçamento de $0,40 \mathrm{~m}$ entre linhas, mantendo-se 10 e 12 plantas por metro linear, para os cultivares Carioca e Iapar 44, respectivamente. Adubou-se no sulco de plantio com $250 \mathrm{~kg} / \mathrm{ha}$ da fórmula 08 30-20, a base de N-P-K. O controle de pragas e ervas daninhas foi feito quando necessário, para manter a área livre da interferência destes fatores.

\subsubsection{Crescimento de plantas, severidade da doença e produtividade}

As avaliações de crescimento de plantas e severidade da mancha angular foram feitas em 6 plantas por parcela, marcadas com fita plástica, totalizando 96 plantas por ensaio. As avaliações iniciaram-se aos 15 dias após a emergência, prosseguindo numa periodicidade de 6 a 8 dias, até o fim do ciclo da cultura. 
A área foliar (LA, em $\mathrm{cm}^{2}$ ) de todas as folhas das plantas marcadas foi estimada medindo-se com uma régua a largura máxima do folíolo central de cada folha $(\mathrm{L}, \mathrm{cm})$. Usou-se a relação empírica (Schuld, 1996): $\mathrm{LA}=2,1 \times \mathrm{L}^{2}$. As avaliações de severidade da mancha angular foram realizadas com o auxilio de uma escala diagramática (Godoy et al., 1997), simultaneamente com as avaliações da área foliar, estimando-se a severidade média, em porcentagem, para os três folíolos de cada folha, em todas as plantas marcadas.

A colheita no primeiro ensaio foi realizada aos 79 dias após a emergência (DAE) nas parcelas sem tratamento fungicida e aos $96 \mathrm{DAE}$ nas parcelas com tratamento fungicida. No segundo ensaio a colheita foi realizada aos 87 DAE. A produção foi determinada colhendo-se as duas linhas centrais de cada parcela, em uma área de 3,20 $\mathrm{m}^{2}$. Mediu-se a umidade dos grãos e padronizou-se os resultados para $13 \%$ de umidade. Contou-se o número de plantas na área útil da parcela, no momento da colheita, para estimativa da densidade de plantas por metro quadrado. Optou-se por trabalhar com a produção da parcela (método da parcela experimental) ao invés da produção por planta (método da planta individual) (Bergamin Filho \& Amorim, 1996) para que fosse possivel estabelecer relações desta variável com medidas de refletância.

\subsubsection{Variáveis integrais}

O valor da área sob a curva de progresso da doença (AUDPC) para cada parcela foi calculado por integração trapezoidal (Shaner \& Finney, 1977):

$$
\mathrm{AUDPC}=\sum_{i=1}^{n-1}\left[\left(X_{i}+X_{i+1}\right) / 2\right]\left(t_{i+1}-t_{i}\right)
$$

onde $X$ é a severidade média da doença por parcela (porcentagem), $X_{\mathrm{i}}=X\left(t_{i}\right), n$ é o número de avaliações e $\left(t_{i+1}-t_{i}\right)$ é o intervalo entre duas avaliações consecutivas.

Os valores de índice da área foliar (LAI) de cada parcela foram obtidos pela multiplicação da área foliar média por planta $\left(\mathrm{m}^{2}\right)$ pela densidade de plantas por $\mathrm{m}^{2}$ 
observada no dia da colheita. A duração da área foliar sadia (HAD) para cada parcela foi calculada pela fórmula

$$
\mathrm{HAD}=\sum_{i=1}^{n-1}\left\{\left[L A I_{l}\left(1-X_{\imath}\right)+L A I_{i+1}\left(1-X_{i+1}\right)\right] / 2\right\}\left(t_{i+1}-t_{i}\right)
$$

onde $\operatorname{LAI}_{\mathrm{i}}=\operatorname{LAI}\left(\boldsymbol{t}_{i}\right)$. O valor do índice da área foliar sadio (HLAI) para cada data de avaliação foi calculado como HLAI $=\operatorname{LAI}(1-X)$.

Os valores de radiação interceptada $\left(\mathrm{RI}_{\mathrm{i}}\right) \mathrm{em} \mathrm{MJ} \mathrm{m}^{-2}$ foram calculados como:

$$
\mathrm{RI}_{i}=I_{i}\left[1-\exp \left(-k \mathrm{LAI}_{i}\right)\right]
$$

em que $I_{i}$ é a média de radiação solar incidente $\left(\mathrm{MJ} \mathrm{m}^{-2}\right)$ no período $\left(t_{i+1}-t_{i}\right)$ e $k$ é o coeficiente de extinção; usou-se $k=0,7$ (Bergamin Filho et al., 1997). O valor da absorção da área foliar sadia (HAA) em $\mathrm{MJ} \mathrm{m}^{-2}$ para cada parcela foi calculado como $\mathrm{HAA}=\sum_{i=1}^{n-1} I_{i}\left(\left\{\left(1-X_{i}\right)\left[1-\exp \left(-k L . A I_{l}\right)\right]+\left(1-X_{l+1}\right)\left[1-\exp \left(-k L . A I_{l+1}\right)\right]\right\} / 2\right)\left(t_{l+1}-t_{l}\right)$

Os valores de HRI $\left(\mathrm{MJ} \mathrm{m}^{-2}\right)$ para cada data de avaliação foram calculados pela fórmula HRI $=$ RI $(1-X)$. A radiação solar incidente $(I)$ foi medida por uma estação meteorológica computadorizada situada a $100 \mathrm{~m}$ da área experimental.

\subsubsection{Medidas de refletância}

As leituras de refletância foram feitas desde um dia antes até um dia após as avaliações da área foliar. Usou-se um radiômetro de múltiplo espectro portátil CropScan, modelo MSR87, que armazenou a porcentagem de luz refletida pelo dossel em oito comprimentos de onda $(460,510,560,610,660,710,760$ e $810 \mathrm{~nm})$. O sensor foi montado em uma barra e um armazenador de dados ("data logger") conectado ao sensor, automaticamente gravou os dados de todos os canais. Durante a leitura a barra permanecia em um ângulo de $45^{\circ}$, com o sensor a uma altura de $1,60 \mathrm{~m}$ sobre o solo. Foram feitas 3 leituras por parcela, e a área medida foi a de um círculo com diâmetro igual à metade da altura do sensor, centralizado no intervalo entre as duas linhas mais 
internas da parcela. Todas as medidas de refletância foram feitas no periodo da tarde. entre uma e duas horas após o meio dia solar.

As medidas de refletância foram usadas para calcular os índices vegetativos IR/R e diferença normalizada (ND), onde ND = (IR-R)/(IR+R) (Nilsson, 1995). Usaram-se três combinações para os comprimentos de onda infravermelho (IR) e vermelho (R). Para o IR, usaram-se sempre 810 nanômetros $(\mathrm{nm})$ e para o R, 610,660 e $710 \mathrm{~nm}$. resultando nas combinações IR/R610, IR/R $\mathrm{R}_{660}, \mathrm{IR} / \mathrm{R}_{710}, \mathrm{ND} \mathrm{D}_{810.610}, \mathrm{~N} \mathrm{D}_{810.660}$ e $\mathrm{N} \mathrm{D}_{810.710}$.

Para cada comprimento de onda e para os índices vegetativos, foram calculados por integração trapezoidal os valores da área sob a curva das medidas de refletância (AUR) para cada parcela, pela fórmula:

$$
\mathrm{AUR}=\sum_{i=1}^{n-1}\left[\left(R_{t}+R_{t+1}\right) / 2\right]\left(t_{t+1}-t_{j}\right)
$$

onde $R$ é a medida de refletância em cada comprimento de onda (porcentagem), $R_{\mathrm{i}}=$ $R\left(t_{i}\right), n$ é o número de avaliações e $\left(t_{i+1}-t_{i}\right)$ é o intervalo entre duas avaliações consecutivas.

\subsubsection{Análise dos dados}

O experimento com folhas destacadas seguiu o delineamento de blocos ao acaso, com 4 tratamentos e 12 repetições. Os resultados obtidos foram submetidos à análise de variância pelo teste $F$, e as diferenças entre as médias, quando significativas, foram comparadas pelo teste de Tukey ao nivel de $5 \%$ de probabilidade, utilizando-se 0 software PlotIT for Windows (Scientific Programming Enterprises, Haslett, MI).

Nos ensaios de campo, as relações entre produtividade, HAD, HAA, medidas de refletância e severidade da doença foram examinadas pelos métodos de regressão linear usando-se o programa STATISTICA (StatSoft, Tulsa, OK). As relações entre LAI, HLAI e HRI com refletância foram pesquisadas considerando-se as 32 parcelas isoladamente. O modelo monomolecular (Campbell \& Madden, 1990) $\left[Y=B_{J}\left(1-B_{2} \exp \left(-B_{3} X\right)\right)\right.$, onde $Y$ 
eram as medidas de refletância e $X$ as variáveis representativas da área foliar] foi ajustado à totalidade dos dados por regressão não-linear. Após, os dados foram separados de acordo com o cultivar (Carioca e Iapar 44), ajustados novamente ao modelo monomolecular e com o erro padrão (SE) dos três parâmetros obtidos testou-se se havia diferença estatística para refletância da área foliar entre os cultivares (Campbell \& Madden, 1990). O mesmo foi feito para época de plantio (1 e 2), tratamento fungicida (com e sem) e o estádio da cultura (até metade do ciclo e após metade do ciclo). 


\subsection{RESULTADOS E DISCUSSÃO}

\subsubsection{Comportamento do índice da área foliar, severidade da mancha angular e refletância durante o ciclo da cultura}

O comportamento do índice da área foliar (LAI), da severidade da mancha angular e da refletância em infravermelho na faixa de $810 \mathrm{~nm}\left(\mathrm{R}_{810}\right)$ foi analisado durante o ciclo da cultura, em ambos os ensaios, para os dois cultivares e os dois tratamentos (Figura 2). Os primeiros sintomas da mancha angular foram observados aos 36 dias após a emergência (DAE) na época 1 e aos 24 DAE na época 2. Nas duas épocas de plantio, a doença apresentou alta severidade nas parcelas sem controle (até 23,7\%), o que provocou grande variação na quantidade de doença entre as parcelas com e sem tratamento. Isto permitiu avaliar o comportamento das medidas de refletância em situações de muita e de pouca doença.

O comportamento do índice da área foliar (LAI) foi semelhante para as duas épocas de plantio. Os tratamentos com controle da doença apresentaram um LAI máximo maior e uma maior duração do LAI que os tratamentos sem controle. A diferença entre LAI das parcelas com e sem controle ficou evidente a partir de 44 DAE para a época 1 e a partir de $39 \mathrm{DAE}$ para época 2. A data em que a diferença ficou perceptível coincidiu com o aumento da severidade da mancha angular. A severidade média nestas datas, nas parcelas sem tratamento, era 0,5\% na época 1 e 0,7\% na época 2 , enquanto nas parcelas tratadas era $0,1 \%$. A diferença de LAI entre os tratamentos poderia ter sido provocada pelo aumento da área foliar doente ou pela redução do crescimento das plantas associado à desfolha, nas parcelas sem tratamento. Apesar de não estar representado graficamente, o indice da área foliar sadio (HLAI) apresentou comportamento muito semelhante ao LAI, principalmente nas fases iniciais do ciclo, quando a severidade da doença era baixa. 
A curva da refletância em $810 \mathrm{~nm}$ apresentou um formato bem semelhante à curva do LAI, inclusive, para o momento em que as diferenças entre as parcelas tratadas e não tratadas tornaram-se perceptíveis. A refletância na faixa do infravermelho havia sido citada por Hatfield (1990) como um ótimo indicativo do índice da área foliar das culturas. Observações das mudanças nos valores da refletância durante a estação de cultivo feitas pelo mesmo autor demonstraram um incremento com o desenvolvimento do dossel e uma queda mais lenta durante a senescência (efeito "hysteresis"), devido à permanência de material vegetal sobre o solo, o qual tem propriedades refletivas diferentes do solo.

Em relação às parcelas tratadas e não tratadas, o cultivar Iapar 44 apresentou maior diferença para o LA.I máximo do que para a refletância máxima. Isto está associado ao hábito de crescimento ereto do cultivar. Assim, ele precisa de um maior LAI para proporcionar a mesma cobertura do solo, que na verdade é a variável relacionada à refletância. Deve-se lembrar que a refletância pode sofrer influência de fatores externos tais como: horário de leitura, umidade do solo, umidade sobre a superfície das folhas e temperatura dos sensores (Nilsson, 1995). Isto indica uma dificuldade em se obter modelos transportáveis baseados simplesmente em medidas de refletância e estimula o uso de uma "parcela controle", sensu Lopes et al. (1994), para comparar com situações de produção e ser aplicada no manejo integrado da doença.

A hora da leitura de refletância pode provocar grandes variações nos resultados. Em dias sem nebulosidade ao meio dia solar observou-se que as folhas do feijoeiro assumem um posicionamento mais ereto e consequentemente a refletância em infravermelho é menor, para um mesmo LAI, pois as folhas permanecem perpendiculares em relação ao solo. Isto foi observado apenas em um curto período do dia, ao redor do meio dia e apenas em dias com alta intensidade solar. Portanto, recomenda-se que as leituras devem ser executadas sempre no mesmo horário, sob as mesmas condições de insolação. Outro ponto a ser lembrado é que a intensidade de radiação solar mais intensa exige que o radiômetro esteja calibrado para esta condição. 


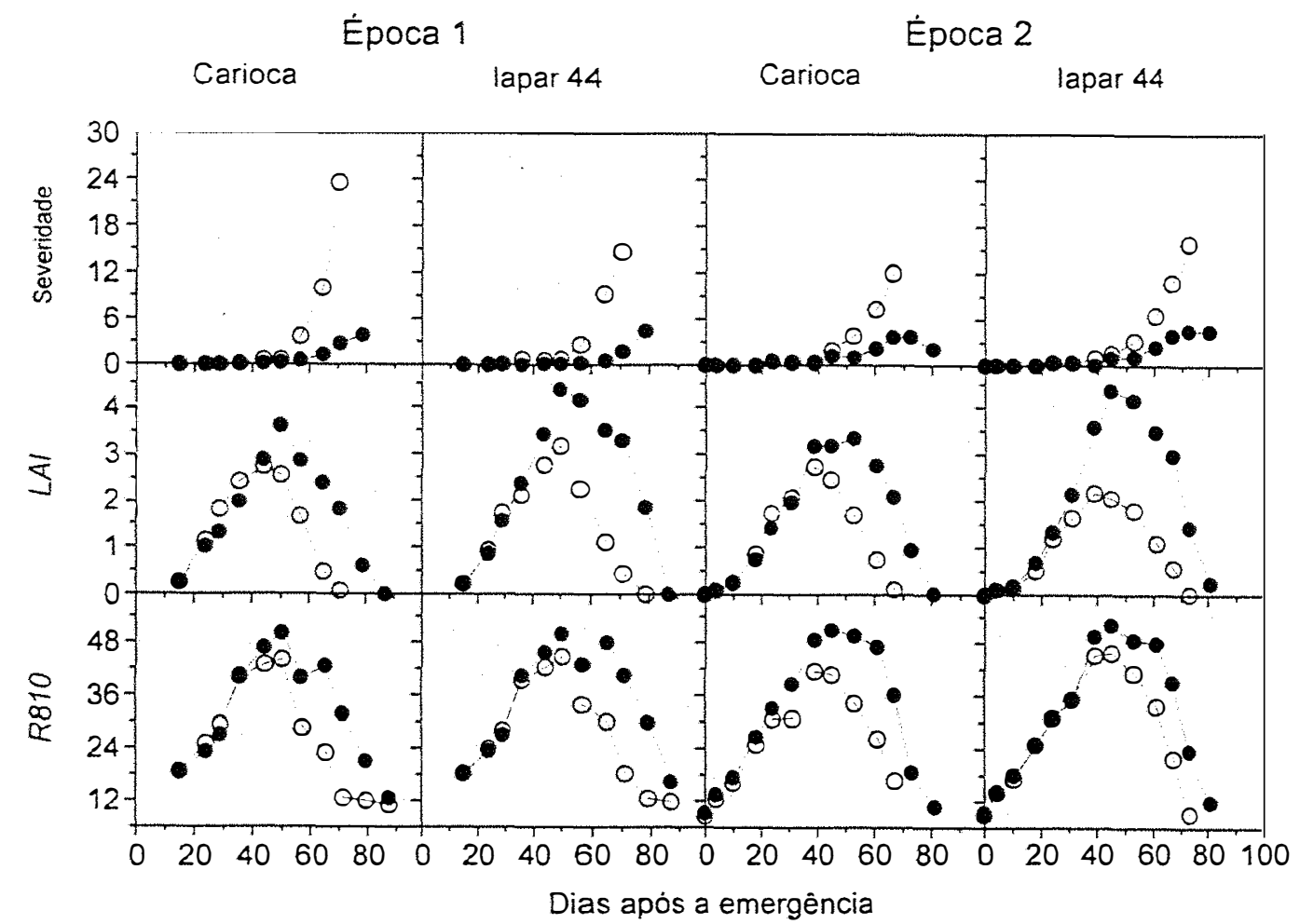

Figura 2 - Severidade da mancha angular, índice da área foliar ( $L A I)$ e refletância em 810 $\mathrm{nm}\left(R_{\delta 10}\right)$ observados em feijoeiro cultivares Carioca e Iapar 44 , em duas épocas de plantio, em parcelas com controle (círculos cheios) e sem controle (ćrculos vazios) da doença. Para severidade e LAI cada ponto representa a média de 24 plantas. Para refletância, cada ponto representa a média de 12 amostragens.

As parcelas doentes apresentaram menor índice da área foliar e maior severidade da mancha angular. Assim, não se pode afirmar qual dos dois fatores colaborou em maior intensidade na variação das leituras de refletância. Em função da literatura (Hatfield, 1990; Aquino et al., 1992; Nilsson, 1995) conclui-se que o LAI foi o principal responsável, mas permanece a dúvida quanto à sensibilidade de medidas de refletância para detectar niveis de severidade da mancha angular. 


\subsubsection{Relaçōes entre severidade da doença e refletância}

Mediu-se a refletância em folhas destacadas de feijoeiro sadias e em três niveis de severidade da mancha angular e houveram regressões significativas para a maioria dos comprimentos de onda (Figura 3). Entre folhas sadias e com $2 \%$ de severidade não foram constatadas diferenças significativas para a refletância em azul (460 nm) (Figura 3A) e no infravermelho próximo (760 e $810 \mathrm{~nm}$ ) (Fig. 3G,H). Na faixa do vermelho (660 $\mathrm{nm}$ ) (Figura $3 \mathrm{E}$ ) não se observou diferença significativa entre os níveis 0 e $2 \%$ e entre 2 e 10\%. Também no vermelho, em $710 \mathrm{~nm}$ (Figura 3F), as diferenças nâo foran significativas entre os niveis 2 e $10 \%$. Os menores coeficientes de variação foram observados para o comprimento de onda infravermelho próximo, em 760 e $810 \mathrm{~nm}$, indicando maior precisão para avaliações executadas nesta faixa do espectro.

De forma geral, quanto maior o nivel de severidade, maior foi a refletância nos comprimentos de onda de 460,510,560, 660 e $710 \mathrm{~nm}$ e menor nos comprimentos de 760 e $810 \mathrm{~nm}$. Em $610 \mathrm{~nm}$ os resultados foram peculiares, mas com tendência de aumento na refletância com o aumento da severidade. Os comportamentos observados foram semelhantes ao relatado por Nilsson (1995). O autor descreve que, quando a vegetação sofre algum tipo de estresse, no caso da doença, há um incremento na refletância na faixa do vermelho e azul, e em muitos casos, no amarelo também. Além disto, há um decréscimo na refletância na faixa do infravermelho.

Os resultados indicaram que as medidas de refletância na faixa do infravermelho, onde está incluído $810 \mathrm{~nm}$, foram pouco sensiveis para detectar pequenas diferenças na severidade de doença, por exemplo entre os niveis 0 e $2 \%$. Isto confirma a maior relaçâo das medidas de refletância em $810 \mathrm{~nm}$ com o LAI, quando a severidade é baixa. Como visto na Figura 2, quando houve diferença entre as parcelas tratadas e não tratadas, a diferença entre os niveis de severidade era de apenas $0,4 \%$ o que dificilmente seria captado pela refletância em $810 \mathrm{~nm}$. As medidas de refletância foram capazes de detectar variações nos níveis de severidade da mancha angular nas condições em que foi realizado o experimento, mas sob condições de campo as folhas, com lesões nem sempre 
estão visiveis, isto é, ficam sobrepostas por folhas sadias e não estão disponiveis para serem avaliadas pelo radiômetro. Além disto, nem sempre há $100 \%$ de cobertura vegetal, havendo, portanto, interferência da refletância do solo nas avaliações.

Para verificar a influência da severidade da doença nas leituras de refletância sob condições de campo foram selecionadas medidas tomadas em parcelas com LAI igual ou superior a 3,6; isto é, onde praticamente não havia interferência da refletância do solo nas avaliações. Entre todos os comprimentos de onda e combinações testadas, a única medida de refletância que apresentou relação $(\mathrm{P}<0,001)$ com a severidade de doença no campo foi a $\mathrm{ND}_{810,610}$ (Figura $\left.4 \mathrm{~B}\right)\left(\mathrm{R}^{2}=55,6 \%\right)$. Os demais comprimentos de onda não apresentaram relação devido ao baixo nivel de severidade observado, pouco mais que $2 \%$ em avaliações de planta toda e como visto na Figura 3, a maioria dos comprimentos de onda não apresentou variação significativa até este nível de severidade.

Os dados de severidade em folhas destacadas foram tabulados de forma a se verificar o comportamento espectral de folhas sadias e folhas com elevada severidade da mancha angular comparados a um fundo preto com a mínima quantidade possivel de refletância (Figura 4A). O comportamento observado foi semelhante ao relatado por Nilsson (1995). O autor cita que medições de refletância em folhas sadias detectam uma sutil refletância na faixa do azul (450-480 nm) e do vermelho $(600-700 \mathrm{~nm})$, um pouco mais no verde (500-550 nm) e substancialmente mais no infravermelho entre 750 e 1100 $\mathrm{nm}$ e qualquer tipo de estresse, incluindo doenças, provocam maiores refletâncias no azul e vemelho e menores no infravermelho.

Verificou-se que não houve um comprimento de onda ou um índice vegetativo que pudesse ser usado para estimar apenas a severidade de doença a nível de campo. Mas conforme Waggoner e Berger (1987), medições da área foliar sadia são mais úteis aos propósitos de manejo da doença do que medidas de severidade de doença. Portanto, procuraram-se relações entre medidas de refletância com as variáveis representativas da área foliar. 


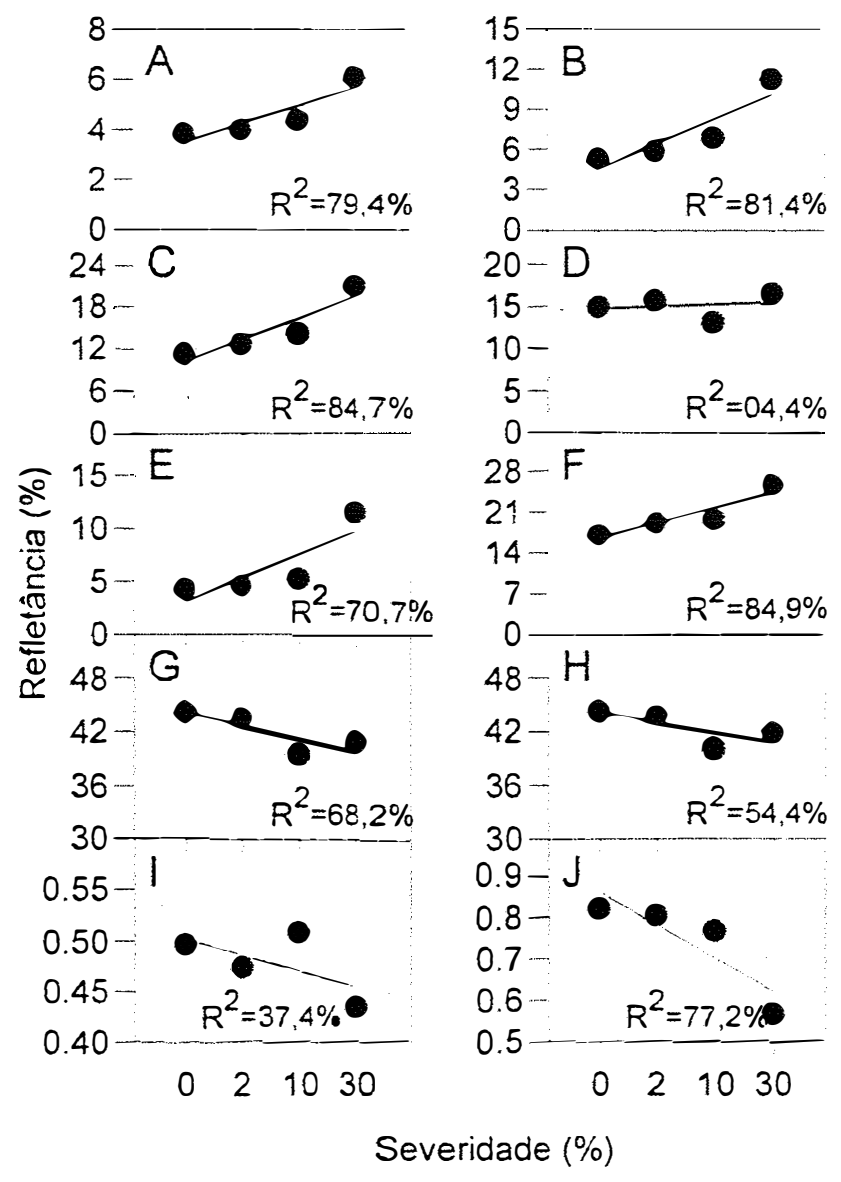

Figura 3 - Refletância observada em folhas de feijoeiro destacadas, sem sintomas da mancha angular (0) e com severidades entre $1,5 \%$ e $2,5 \%$ (2), $8 \%$ e $12 \%(10)$ e $25 \%$ e $35 \%$ (30), nos comprimentos de onda das cores azul, em $460 \mathrm{~nm}(\mathrm{~A})$, verde, em $510 \mathrm{~nm}$ (B), amarelo, em $560 \mathrm{~nm}$ (C), laranja, em $610 \mathrm{~nm}$ (D), vermelho, em $660 \mathrm{~nm}$ (E) e $710 \mathrm{~nm}$ (F) e infravermelho, em $760 \mathrm{~nm}$ (G) e $810 \mathrm{~nm}(\mathrm{H})$ e nos índices vegetativos $(810-610) /(810+610)(\mathrm{I})$ e $(810-660) /$ $(810+660)(J)$. 

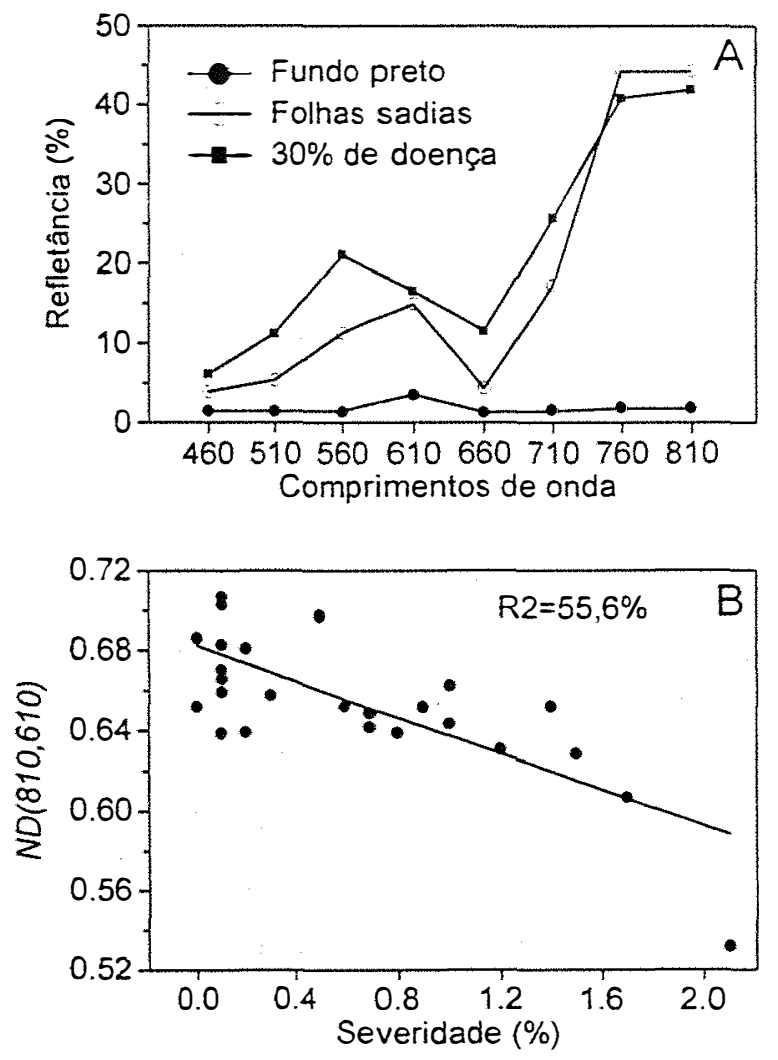

Figura 4 - A) Comportamento espectral de camada de folhas de feijoeiro sadias (círculos vazios), camada de folhas com $30 \%$ da mancha angular (quadrado cheio) e camada de tecido preto opaco (círculos cheios). B) Severidade da mancha angular versus a refletância, representada pela diferença normalizada $\left(N D_{(810.610)}\right)$ utilizando os comprimentos de onda 810 e $610 \mathrm{~nm}$, observadas para dossel de feijoeiro com índice da área foliar superior a 3,6.

\subsubsection{Relações entre refletância e variáveis da área foliar}

Procuraram-se relações entre todos os comprimentos de onda avaliados (460, $510,560,610,660,710,760$ e $810 \mathrm{~nm}$ ) e todos os índices vegetativos (IR/R $R_{610}, I R / R_{660}$, IR/R $R_{710}, \mathrm{ND}_{810,610}, \mathrm{ND}_{810,660}$ e $\mathrm{ND}_{810,710}$ ) com as variáveis derivadas da área foliar LAI, 
HLAI e HRI. Foram usadas as avaliações semanais realizadas nos dois ensaios, para os dois cultivares e os dois tratamentos, totalizando 336 pontos. Os melhores resultados estão apresentados na Figura 5. Todos os dados ajustaram-se ao modelo monomolecular e as melhores relaçōes com LAI foram obtidas com refletância em $810 \mathrm{~nm}\left(\mathrm{R}_{810}\right)$ $\left(\mathrm{R}^{2}=84,7 \%\right)$ e com a diferença normalizada, usando 810 e $660 \mathrm{~nm}(\mathrm{ND} 810.660)$ $\left(\mathrm{R}^{2}=87,2 \%\right)$. O mesmo foi observado para HLAI com $\mathrm{R}^{2}$ igual a $84,7 \%$ e $86,6 \%$, para $\mathrm{R}_{810}$ e $\mathrm{ND}_{810.660}$, respectivamente. Não houve grande diferença de resultados de ajuste entre LAI e HLAI, apesar dos altos índices observados para severidade da mancha angular, ou seja, a principal influência da doença deu-se na diminuição da área foliar total e não na redução da área foliar sadia pelas lesões.

Para HRI, o ajuste obtido com o uso da $\mathrm{ND}_{810,610}\left(\mathrm{R}_{2}=82,6 \%\right)$ foi bem melhor que o observado para $R_{810}(69,6 \%)$, confirmando o exposto por Hatfield (1990), ou seja, a diferença normalizada (ND) se relaciona bem com a interceptação de radiação fotossinteticamente ativa, enquanto a refletância na faixa do infravermelho apresenta melhor relação com o índice da área foliar.

O coeficiente de determinação observado para relação HLAI x ND $\mathrm{N}_{810,660}$ foi um pouco maior que para a relação HLAI x $R_{810}$, porém a curva de ajuste tendeu a estabilizar para valores superiores a 3 (Figura 5). O mesmo não foi observado para a relação HLAI x $R_{810}$. A distribuição dos pontos apresentou desuniformidade para valores entre 0,5 e 2,5, tanto para a relação HLAI x $\mathrm{ND}_{810,660}$ como para HLAI $\times \mathrm{R}_{810}$ e é justamente neste intervalo que há necessidade de maior precisão para estimativas de HLAI para uso em programa de manejo da doença. Em razão disto procurou-se identificar quais eram as fontes desta variação, se a época de plantio, o cultivar, o tratamento para controle da doença ou até mesmo o estádio da cultura em que eram feitas as leituras, pois a refletância para a HLAI em final do ciclo pode sofrer influência das folhas que já caíram sobre o solo (Schuld, 1996). 


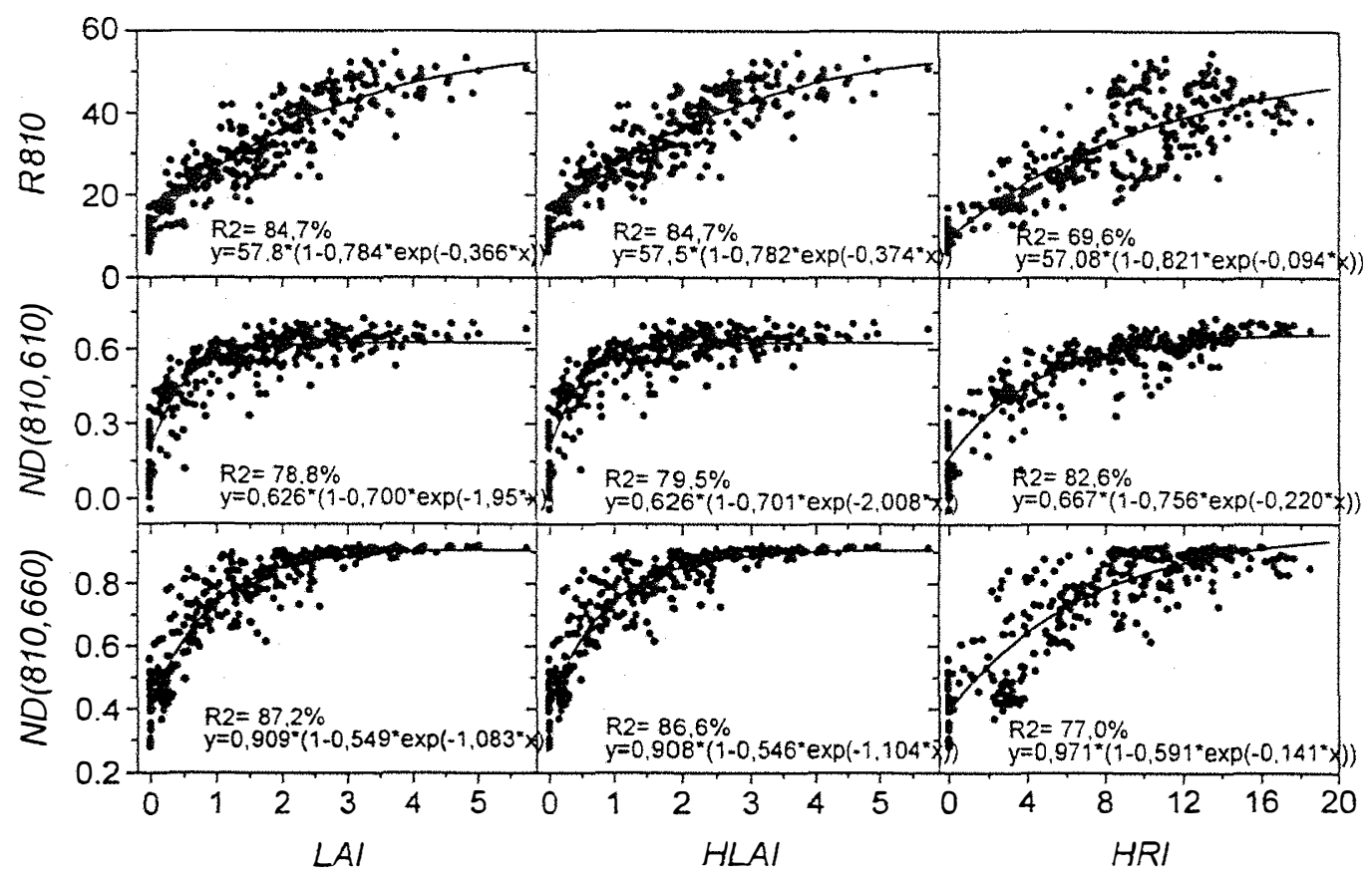

Figura 5 - Relações entre as variáveis derivadas da área foliar: índice da área foliar (LAI), índice da área foliar sadio (HLAI) e absorção da área foliar sadia (HRI), com a refletância em $810 \mathrm{~nm}\left(\mathrm{R}_{810}\right)$, a diferença normalizada usando $810 \mathrm{e}$ $610 \mathrm{~nm}\left(\mathrm{ND}_{810,610}\right)$ e a diferença normalizada usando 810 e $660 \mathrm{~nm}$, observada para dossel de feijoeiro cultivares Carioca e Iapar 44, com e sem tratamento fungicida em duas épocas de plantio.

Foram feitos testes, recomendados por Campbell \& Madden (1990), para verificar se havia diferença significativa $(P<0,05)$ entre os parâmetros da equação de ajuste do modelo monomolecular, para os dados de refletância contra as variáveis da área foliar, com os dados tabulados separadamente para cada uma das fontes de variação (cultivar, época de plantio, tratamento e estádio de crescimento). O principal parâmetro de comparação foi o $B_{3}$, responsável pela inclinação da curva de ajuste, onde $Y=B_{1}{ }^{*}(1$ - 
$\mathrm{B}_{2} * \exp \left(-\mathrm{B}_{3}^{*} \mathrm{X}\right) . \mathrm{O} \mathrm{B}_{1}$ indicava o valor de estabilização da curva e o $\mathrm{B}_{2}$ o valor de início. $O R^{2}$ deu uma idéia da interação com as demais fontes de variação. Por exemplo, se para análise do cultivar os parâmetros fossem diferentes significativamente, mas $\circ R^{2}$ dos modelos para os dados separados fosse igual ou inferior ao $\mathrm{R}^{2}$ obtido para os dados em conjunto, havia interação do cultivar com outras fontes de variação, tais como época de plantio, tratamento fungicida ou estágio da cultura.

A relação do $\mathrm{R}_{810}$ com LAI e HLAI demonstrou que a refletância na faixa de 810 $\mathrm{nm}$ sofreu influência do tratamento fungicida, apresentando diferença significativa para os três parâmetros da equação (Tabela 1 e 2). Isto significa que o HLAI de parcelas sadias apresentou uma refletância em $810 \mathrm{~nm}$ diferente de um mesmo valor de HLAI de parcelas doentes. Porém, a separação dos dados de acordo com o tratamento não incrementou o $\mathrm{R}^{2}$, sugerindo interação com as outras fontes de variação. Esta diferença de refletância em $810 \mathrm{~nm}$ para parcelas com e sem tratamento fungicida pode estar associada à cobertura do solo, ou seja, parcelas sem tratamento, mas com um mesmo HLAI de parcelas com tratamento, apresentavam maior quantidade de folhas no solo, influenciando as propriedades de refletância. Outra possivel causa pode ter sido os próprios fungicidas utilizados, que, na superfície das folhas, provocaram mudança nas propriedades de refletância, ou a própria diferença na severidade da doença entre tratamentos.

A ND $D_{10,660}$, quando relacionada com HLAI, também sofreu influência do ciclo e do tratamento, ou seja, da quantidade de doença (Tabela 2). Na maioria das vezes, o $R^{2}$ para os dados separados foi superior ao $\mathrm{R}^{2}$ apresentado para a totalidade dos dados, estimulando a obtenção de um novo modelo que considerasse ou eliminasse estas influências. A influência do estádio da cultura foi eliminada pelo descarte das avaliações realizadas no final do ciclo, as quais não apresentam importância na tomada de decisão para manejo da doença, e a severidade da doença entrou como uma nova variável na equação do modelo monomolecular. Assim, obteve-se o modelo:

$\mathrm{ND}_{810,660}=0,904 *(1-0,588 * \exp (-1 * \mathrm{HLAI}))+0,035 *$ Severidade, com um $\mathrm{R}^{2}$ igual a $91,1 \%$. 
A $\mathrm{ND}_{810,610}$ quando relacionada à HLAI sofreu influência significativa da época de plantio, entretanto o $R^{2}$ dos dados tabulados separadamente foi inferior ao $R^{2}$ dos

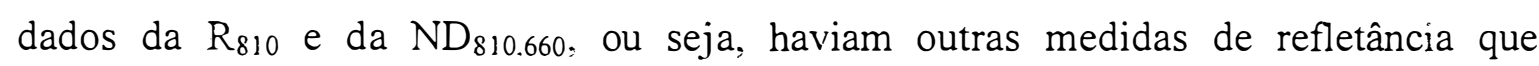
apresentaram melhor relação com HLAI.

Para relações com HRI, os melhores resultados foram apresentados pelo índice vegetativo $\mathrm{ND}_{810,610}$. Os resultados sofreram influência da época de plantio, com diferenças significativas para os 3 parâmetros da equação do modelo monomolecular (Tabela 3). Quando os dados foram tabulados separadamente o $\mathrm{R}^{2}$ subiu de $82,6 \%$ para $83,2 \%$ e $85,6 \%$, para a época 1 e 2 , respectivamente. Isto indica que houve variação entre estações de cultivo, dificultando a obtenção de um modelo transportável para estimar HRI. Era esperada a variação entre épocas de plantio, pois a absorção da área foliar sadia (HRI) depende da radiação solar incidente ( $I$, que varia entre as estações de cultivo.

\subsubsection{Modelo para estimar HLAI}

A HRI é a variável que melhor se relaciona com a produção (Bergamin Filho et al., 1997), portanto seria a mais indicada para uso em programas de manejo de doenças. Porém, a HRI depende da radiação solar incidente $(I)$ e esta pode variar entre estações de cultivo. Assim, procurou-se obter um modelo para estimar HLAI, que pudesse, juntamente com dados de radiação solar incidente, ser utilizado para calcular a HRI. A variável de refletância utilizada para o modelo foi o índice vegetativo $\mathrm{ND}_{810.660}$, que havia demonstrado boa relação com HLAI. Para obtenção do modelo foram utilizados dados apenas até a metade do ciclo da cultura, evitando-se a influência dos estágios finais na refletância. $\mathrm{O}$ modelo obtido está representado na Figura $6 . \mathrm{O} \mathrm{R}^{2}$ obtido $(80,8 \%)$ foi menor que o $\mathrm{R}^{2}$ da relação HLAI $\times \mathrm{ND}_{810,660}(86,6 \%)$ devido à diferença entre as equações utilizadas, exponencial para o primeiro e monomolecular para o segundo. 
Tabela 1 - Parâmetros estimados $B_{1}, B_{2}, B_{3}$ ( \pm erro padrão) e coeficiente de determinação $\left(\mathrm{R}^{2}\right)$ do modelo monomolecular ajustado aos valores de refletância plotados contra o índice da área foliar (LAI), para dois cultivares (Carioca e lapar 44), duas épocas de plantio ( 1 e 2), dois tratamentos fungicidas (com e sem) e dois períodos do ciclo da cultura (até a metade e após a metade do ciclo). Diferenças significativas entre pares de dados $(\mathrm{P}<$ $0,05)$ estão marcadas com * .

\begin{tabular}{|c|c|c|c|c|}
\hline & $B_{1}$ & $B_{2}$ & $B_{3}$ & $\mathrm{R}^{2}$ \\
\hline \multicolumn{5}{|l|}{$\mathrm{R}_{810}$} \\
\hline cv. Carioca & $67,7 \pm 30,1$ & $0,815 \pm 0, \bullet 6$ & $0,282 \pm 0,23$ & 83,6 \\
\hline cv. Iapar44 & $52,7 \pm 2,9$ & $0,764 \pm 0,02$ & $0,462 \pm 0,07$ & 83,0 \\
\hline Época 1 & $58,7 \pm 6,1$ & $0,765 \pm 0,02$ & $0,329 \pm 0,08$ & 80,1 \\
\hline Época 2 & $53,9 \pm 3,1$ & $0,794 \pm 0,01$ & $0,484 \pm 0,07$ & 86,6 \\
\hline Com fungicida & $60,8 \pm 5,2 *$ & $0,801 \pm 0,02 *$. & $0,333 \pm 0,07 *$ & 84,6 \\
\hline Sem fungicida & $43,8 \pm 2,6^{*}$ & $0,735 \pm 0,02 *$ & $0,767 \pm 0,14 *$ & 79,6 \\
\hline Até metade do ciclo & $64,3 \pm 8,6$ & $0,771 \pm 0,02$ & $.0,295 \pm 0,09$ & 79,0 \\
\hline Após metade do Ciclo & $54,3 \pm 2,8$ & $0,799 \pm 0,02$ & $0,450 \pm 0,06$ & 88,2 \\
\hline \multicolumn{5}{|l|}{$\mathrm{ND}_{(810,610)}$} \\
\hline cv. Carioca & $0,626 \pm 0,01$ & $0,697 \pm 0,02$ & $1,809 \pm 0,21$ & 82,9 \\
\hline cv. Iapar44 & $0,630 \pm 0,01$ & $0,713 \pm 0,03$ & $2,186 \pm 0,34$ & 75,0 \\
\hline Época 1 & $0,670 \pm 0,01 *$ & $0,564 \pm 0,02 *$ & $1,213 \pm 0,13^{*}$ & 82,3 \\
\hline Época 2 & $0,597 \pm 0,01 *$ & $0,805 \pm 0,03^{*}$ & $2,728^{*} \pm 0,34 *$ & 81,6 \\
\hline Com fungicida & $0,642 \pm 0,01$ & $0,652 \pm 0,04$ & $1,324 \pm 0,22 *$ & 68,7 \\
\hline Sem fungicida & $0,622 \pm 0,01$ & $0,713 \pm 0,02$ & $2,475 \pm 0,29 *$ & 84,6 \\
\hline Até metade do ciclo & $0,659 \pm 0,01$ & $0,471 \pm 0,02 *$ & $1,334 \pm 0,13$ & 83,2 \\
\hline Após metade do Ciclo & $0,647 \pm 0,01$ & $0,743 \pm 0,02 *$ & $1,063 \pm 0,12$ & 85,0 \\
\hline \multicolumn{5}{|l|}{$\mathrm{ND}_{(810,660)}$} \\
\hline cv. Carioca & $0,921 \pm 0,02$ & $0,539 \pm 0,01$ & $0,964 \pm 0,10$ & 86,7 \\
\hline cv. Iapar44 & $0,899 \pm 0,01$ & $0,573 \pm 0,01$ & $1,286 \pm 0,11$ & 87,9 \\
\hline Época 1 & $0,912 \pm 0,01$ & $0,575 \pm 0,01$ & $1,020 \pm 0,09$ & 87,1 \\
\hline Época 2 & $0,909 \pm 0,01$ & $0,539 \pm 0,01$ & $1,182 \pm 0,09$ & 88,3 \\
\hline Com fungicida & $0,929 \pm 0,01 *$ & $0,575 \pm 0,01$ & $0,882 \pm 0,06^{*}$ & 90,6 \\
\hline Sem fungicida & $0,883 \pm 0,01 *$ & $0,540 \pm 0,01$ & $1,509 \pm 0,15^{*}$ & 85,9 \\
\hline Até metade do ciclo & $0,908 \pm 0,01$ & $0,625 \pm 0,02 *$ & $1,155 \pm 0,08$ & 90,1 \\
\hline Após metade do Ciclo & $0,896 \pm 0,01$ & $0,527 \pm 0,01 *$ & $1,468 \pm 0,14$ & 89,0 \\
\hline
\end{tabular}


Tabela 2 - Parâmetros estimados $B_{1}, B_{2}, B_{3}$ ( \pm erro padrão) e coeficiente de determinação $\left(\mathrm{R}^{2}\right)$ do modelo monomolecular ajustado aos valores de refletância plotados contra o índice da área foliar sadia (HLAI), para dois cultivares (Carioca e Iapar 44), duas épocas de plantio (1 e 2), dois tratamentos fungicidas (com e sem) e dois períodos do ciclo da cultura (até a metade e após a metade do ciclo). Diferenças significativas entre pares de dados $(\mathrm{P}<0,05)$ estão marcadas com * .

\begin{tabular}{|c|c|c|c|c|}
\hline & $B_{1}$ & $B_{2}$ & $B_{3}$ & $\mathrm{R}^{2}$ \\
\hline \multicolumn{5}{|l|}{$\mathrm{R}_{810}$} \\
\hline cv. Carioca & $66,8 \pm 23,6$ & $0,811 \pm 0,05$ & $0,291 \pm 0,19$ & 83,5 \\
\hline cv. Iapar44 & $52,5 \pm 2,79$ & $0,762 \pm 0,02$ & $0,474 \pm 0,07$ & 83,2 \\
\hline Época 1 & $58,4 \pm 5,86$ & $0,763 \pm 0,02$ & $0,336 \pm 0,08$ & 80,3 \\
\hline Época 2 & $53,7 \pm 3,06$ & $0,792 \pm 0,01$ & $0,495 \pm 0,07$ & 86,6 \\
\hline Com fungicida & $60,6 \pm 4,90^{*}$ & $0,802 \pm 0,02 *$ & $0,340 \pm 0,06 *$ & 85,0 \\
\hline Sem fungicida & $43,2 \pm 2,38 *$ & $0,731 \pm 0,02 *$ & $0,817 \pm 0,15^{*}$ & 79,6 \\
\hline Até metade do ciclo & $64,2 \pm 8,58$ & $0,771 \pm 0,02$ & $0,297 \pm 0,09$ & 78,9 \\
\hline Após metade do Ciclo & $53,6 \pm 2,57$ & $0.793 \pm 0,01$ & $0,476 \pm 0,06$ & 88,4 \\
\hline \multicolumn{5}{|l|}{$N D_{(810,610)}$} \\
\hline cv. Carioca & $0,626 \pm 0,01$ & $0,697 \pm 0,02$ & $1,86 \pm 0,21$ & 83,4 \\
\hline cv. lapar44 & $0,630 \pm 0,01$ & $0,715 \pm 0,03$ & $2,24 \pm 0,33$ & 75,8 \\
\hline Época 1 & $0,670 \pm 0,01^{*}$ & $0,564 \pm 0,02 *$ & $1,24 \pm 0,13 *$ & 83,3 \\
\hline Época 2 & $0,597 \pm 0,01 *$ & $0,805 \pm 0,03^{*}$ & $2,78 \pm 0,34 *$ & 82,1 \\
\hline Com fungicida & $0,643 \pm 0,01$ & $0,654 \pm 0,04$ & $1,32 \pm 0,22 *$ & 69,7 \\
\hline Sem fungicida & $0,623 \pm 0,01$ & $0,714 \pm 0,02$ & $2,58 \pm 0,28 *$ & 85,3 \\
\hline Até metade do ciclo & $0,660 \pm 0,01$ & $0,471 \pm 0,02 *$ & $1,33 \pm 0,13$ & 83,2 \\
\hline Após metade do Ciclo & $0,644 \pm 0,01$ & $0,739 \pm 0,02 *$ & $1,13 \pm \bullet, 13$ & 84,8 \\
\hline \multicolumn{5}{|l|}{$\mathrm{ND}_{(810,660)}$} \\
\hline cv. Carioca & $0,920 \pm 0,02$ & $0,535 \pm 0,01$ & $0,98 \pm 0,10$ & 86,1 \\
\hline cv. Iapar44 & $0,899 \pm 0,01$ & $0,570 \pm 0,02$ & $1,32 \pm 0,11$ & 87,4 \\
\hline Época 1 & $0,912 \pm 0,01$ & $0,570 \pm 0,01$ & $1,03 \pm 0,10$ & 86,6 \\
\hline Época 2 & $0,908 \pm 0,01$ & $0,536 \pm 0,01$ & $1,21 \pm 0,10$ & 87,7 \\
\hline Com fungicida & $0,929 \pm 0,01 *$ & $0,575 \pm 0,01$ & $0,89 \pm 0,06^{*}$ & 90,6 \\
\hline Sem fungicida & $0,880 \pm 0,01 *$ & $0,536 \pm 0,01$ & $1,58 \pm 0,16^{*}$ & 85,2 \\
\hline Até metade do ciclo & $0,908 \pm 0,01$ & $0,625 \pm 0,02 *$ & $1,16 \pm 0,08^{*}$ & 90,0 \\
\hline Após metade do Ciclo & $0,894 \pm 0,01$ & $0,524 \pm 0,01 *$ & $1,59 \pm 0,15^{*}$ & 88,8 \\
\hline
\end{tabular}


Tabela 3 - Parâmetros estimados $\mathrm{B}_{1}, \mathrm{~B}_{2}, \mathrm{~B}_{3}$ ( \pm erro padrão) e coeficiente de determinação $\left(\mathrm{R}^{2}\right)$ do modelo monomolecular ajustado aos valores de refletância plotados contra a abosorção da área foliar sadia (HRI), para dois cultivares (Carioca e Iapar 44), duas épocas de plantio (1 e 2), dois tratamentos fungicidas (com e sem) e dois períodos do ciclo da cultura (até a metade e após a metade do ciclo). Diferenças significativas entre pares de dados $(\mathrm{P}<0,05)$ estão marcadas com *.

\begin{tabular}{|c|c|c|c|c|}
\hline & $B_{1}$ & $B_{2}$ & $B_{3}$ & $\mathrm{R}^{2}$ \\
\hline \multicolumn{5}{|l|}{$\mathrm{R}_{810}$} \\
\hline cv. Carioca & $51,7 \pm 6,62$ & $0,812 \pm 0,03$ & $0,097 \pm 0,03$ & 67,3 \\
\hline cv. Iapar44 & $50,4 \pm 4,49$ & $0,826 \pm 0,03$ & $0,115 \pm 0,03$ & 69,4 \\
\hline Época 1 & $52,5 \pm 7,74$ & $0,787 \pm 0,03$ & $0,086 \pm 0,03$ & 62,7 \\
\hline Época 2 & $56,9 \pm 9,20$ & $0,853 \pm 0,02$ & $0,094 \pm 0,03$ & 74,7 \\
\hline Com fungicida & $54,5 \pm 6,47$ & $0,904 \pm 0,04^{*}$ & $0,106 \pm 0,03$ & 63,4 \\
\hline Sem fungicida & $42,2 \pm 2,61$ & $0,759 \pm 0,02 *$ & $0,151 \pm 0,03$ & 72,1 \\
\hline Até metade do ciclo & $46,0 \pm 2,91$ & $0,973 \pm 0,09$ & $0,164 \pm 0,04$ & 55,8 \\
\hline Após metade do Ciclo & $52,6 \pm 5,49$ & $0,814 \pm 0,02$ & $0,115 \pm 0,03$ & 75,7 \\
\hline \multicolumn{5}{|l|}{$N D_{(810,610)}$} \\
\hline cv. Carioca & $0,677 \pm 0,02$ & $0,747 \pm 0,02$ & $0,199 \pm 0,02$ & 85,0 \\
\hline cv. Iapar44 & $0,659 \pm 0,01$ & $0,782 \pm 0,03$ & $0,262 \pm 0,03$ & 79,8 \\
\hline Época 1 & $0,721 \pm 0,02 *$ & $0,632 \pm 0,02 *$ & $0,153 \pm 0,02 *$ & 83,2 \\
\hline Época 2 & $0,627 \pm 0,01 *$ & $0,848 \pm 0,02 *$ & $0,291 \pm 0,03 *$ & 85,6 \\
\hline Com fungicida & $0,677 \pm 0,02$ & $0,836 \pm 0,04$ & $0,210 \pm 0,03$ & 75,1 \\
\hline Sem fungicida & $0,653 \pm 0,01$ & $0,743 \pm 0,02$ & $0,271 \pm 0,03$ & 86,6 \\
\hline Até metade do ciclo & $0,694 \pm 0,01$ & $0,642 \pm 0,03^{*}$ & $0,196 \pm 0,02$ & 81,1 \\
\hline Após metade do Ciclo & $0,698 \pm 0,03$ & $0,775 \pm 0,02 *$ & $0,166 \pm 0,03$ & 82,8 \\
\hline \multicolumn{5}{|l|}{$N D_{(810,660)}$} \\
\hline cv. Carioca & $0,996 \pm 0,05$ & $0,579 \pm 0,02$ & $0,122 \pm 0,02$ & 75,2 \\
\hline cv. Iapar44 & $0,941 \pm 0,02$ & $0,617 \pm 0,02$ & $0,179 \pm 0,02$ & 79,7 \\
\hline Época 1 & $0,949 \pm 0,03$ & $0,626 \pm 0,02$ & $0,155 \pm 0,02$ & 78,9 \\
\hline Época 2 & $1,011 \pm 0,05$ & $0,584 \pm 0,02$ & $0,129 \pm 0,02$ & 76,8 \\
\hline Com fungicida & $0,996 \pm 0,03$ & $0,668 \pm 0,02 *$ & $0,139 \pm 0,02$ & 76,7 \\
\hline Sem fungicida & $0,916 \pm 0,03$ & $0,556 \pm 0,02 *$ & $0,190 \pm 0,03$ & 77,0 \\
\hline Até metade do ciclo & $0,914 \pm 0,02$ & $0,924 \pm 0,06^{*}$ & $0,242 \pm 0,02$ & 78,9 \\
\hline Após metade do Ciclo & $0,911 \pm 0,02$ & $0,543 \pm 0,01 *$ & $0,249 \pm 0,03$ & 86,3 \\
\hline
\end{tabular}




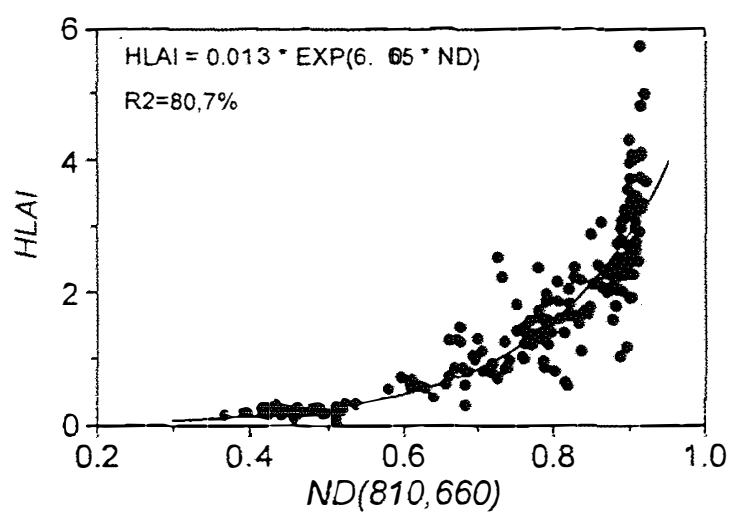

Figura 6 - Modelo para estimativa do índice da área foliar sadia (HLAI) em função da refletância representada pelo índice vegetativo ND, calculado pela fórmula $\left(\mathrm{R}_{810}-\mathrm{R}_{660}\right) /\left(\mathrm{R}_{810}+\mathrm{R}_{660}\right)$.

O modelo apresentado necessita ser validado para que possa ser recomendado para outras situações de cultivo. Schuld (1996) encontrou variação em medidas de refletância de acordo com variedade e estação de cultivo e vários fatores podem influenciar os dados espectrais, tais como quantidade de pigmentos (clorofila), ângulo das folhas, textura da superficie das folhas, doenças e outros estresses, estádio de crescimento das plantas, condição de cultivo, ângulo do sol, tipo de solo e outras condições mensuráveis (Nilsson, 1995). E também deve-se lembrar que qualquer modelo, para que tenha aplicação, deve ser validado com dados diferentes daquele que 0 originou (Kranz \& Royle, 1978). 


\subsubsection{Relações da produção com variáveis da área foliar, doença e refletância}

A produção correlacionou-se bem com as variáveis representativas da área foliar, confirmando a possibilidade de uso destas variáveis para estimar danos provocados pela mancha angular (Lopes et al., 1994; Godoy, 1995; Bergamin Filho et al., 1997; Silva: 1997). A duração da área foliar sadia (HAD) apresentou um $\mathrm{R}^{2}=62,7 \%$ e a absorção da área foliar sadia (HAA) um $\mathrm{R}^{2}=73,5 \%$ (Figura 7A,B,F,G). A HAD apresentou diferenciação na distribuição dos pontos em relação aos cultivares (Figura $7 F$ ). $O$ cultivar Carioca apresentou maior incremento na produção com o incremento da HAD. ou seja, este cultivar foi mais sensivel à redução na duração da área foliar do que o cultivar Iapar 44. Para o HAA houve diferenciação apenas para o cultivar Iapar 44 na época 2 (Figura 7B).

A área sob a curva de progresso da doença (AUDPC), variável geralmente utilizada para relações com danos (Bergamin Filho \& Amorim, 1996), apresentou o menor coeficiente de determinação $\left(\mathrm{R}^{2}=53,3 \%\right)$ na relação com a produção. A integral da refletância em $810 \mathrm{~nm}\left(\mathrm{AUR}_{810}\right)$ não foi tão boa quanto a integral do índice vegetativo $N D\left(A U R_{N D}\right)$ para relações com a produção. Isto está de acordo com o exposto por Hatfield (1990), ou seja, a diferença normalizada (ND) se relaciona bem com a interceptação de radiação fotossinteticamente ativa e consequentemente com a produção. A $A \mathrm{AR}_{810}$ apresentou uma nítida diferenciação na distribuição dos pontos de acordo com a época de plantio (Figura 7D), enquanto a $A \mathrm{R}_{\mathrm{ND}}$ apresentou uma distribuição uniforme.

Conforme os resultados encontrados, a integral da diferença normalizada (ND) para os comprimentos de onda 810 e $610 \mathrm{~nm}$ apresentou a melhor relação com a produção e, conseqüentemente, a melhor possibilidade de estimar danos provocados pela doença, apesar do inconveniente de ser uma medida integral. 

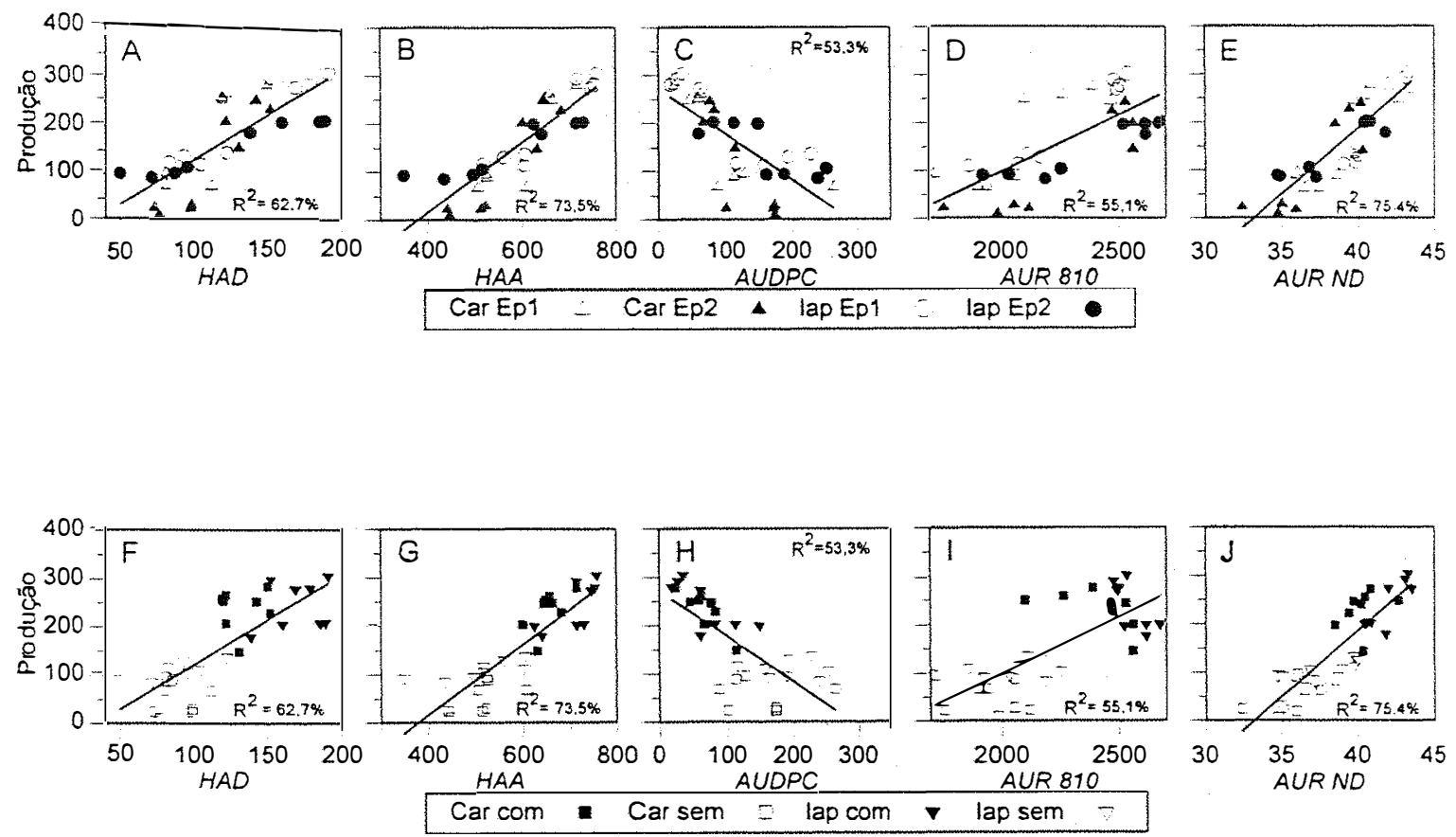

Figura 7 - Relações da produção $\left(\mathrm{g} \mathrm{m}^{-2}\right)$ com duração da área foliar sadia (HAD), absorção da área foliar sadia (HAA), área sob a curva de progresso da doença (AUDPC), integral da refletância em $810 \mathrm{~nm}\left(\right.$ AUR $\left._{810}\right)$ e integral da diferença normalizada ( $A U R_{N D}$ ), utilizando os comprimentos de onda de 810 e $610 \mathrm{~nm}$. O coeficiente $R^{2}$ refere-se ao coeficiente de determinação da regressão representada pela reta cheia. Dados apresentados em relação a época de plantio (A,B,C,D,E) e em relação ao tratamento (F,G,H,I,J) 


\section{MEDIDAS DE REFLETÂNCIA COMO PARÂMETRO DE TOMADA DE DECISÃO PARA MANEJO DA MANCHA ANGULAR DO FEIJOEIRO}

\subsection{RESUMO}

Foi conduzido um experimento com feijoeiro cultivar Carioca, com diferentes épocas de início de aplicação de fungicidas para controle da mancha angular, em Castro, PR. O objetivo do ensaio foi testar se medidas de refletância detectavam variações na área foliar e na produção de feijoeiro, para poderem ser usadas como ferramentas no manejo da doença. As leituras de refletância foram feitas em 8 comprimentos de onda, de $460 \mathrm{~nm}$ a $810 \mathrm{~nm}$ em intervalos de $50 \mathrm{~nm}$. Calculou-se a diferença normalizada (ND), onde $\mathrm{ND}=(810-660) /(810+660)$. A produção se relacionou significativamente $(\mathrm{P}<0,01)$, de forma linear, com as variáveis Duração da área foliar sadia (HAD) $\left(R^{2}=40,2 \%\right)$, Absorção da área foliar sadia (HAA) $\left(\mathrm{R}^{2}=44,8 \%\right)$, Área sob a curva de progresso da doença (AUDPC) $\left(\mathrm{R}^{2}=31,4 \%\right)$ e Integral da diferença normalizada (AUR $\mathrm{ND}$ ) $\left(R^{2}=50,1 \%\right)$. Ficaram implícitas diferenças na eficiência fotossintética de parcelas com mesmo nível de HAD e diferentes severidades da mancha angular. Não houve diferenças significativas (Tukey, $\mathrm{P}<0,05$ ) entre os tratamentos para medidas de HAD, HAA e refletância. Pulverizações de fungicida iniciadas aos 30 dias após a emergência (DAE) apresentaram eficiência de $67,8 \%$, e $0 \%$ quando iniciadas aos 62 DAE. A ND demonstrou relação com HLAI $\left(\mathrm{R}^{2}=89,7 \%\right)$ e com a HRI $\left(\mathrm{R}^{2}=87,7 \%\right)$. A sensibilidade das medidas de ND foi suficiente para captar variações menores que o limiar de dano econômico (LDE). Assim, a ND apresentou potencial para ser usada para estimar a HLAI e ser usada, juntamente com avaliações de severidade de doenças, para tomada de decisão baseada em LDE em programas de manejo da mancha angular do feijoeiro. 


\subsection{INTRODUÇÃO}

A produção de uma cultura está intimamente relacionada com a porção de radiação que as plantas conseguem aproveitar (Waggoner \& Berger, 1987). Esta radiação capturada é função da duração da área foliar e da absorção da área foliar, variáveis estas dependentes do índice da área foliar observado durante o ciclo da cultura (Bergamin Filho et al., 1995). Desta forma, quando se pretende estimar o dano provocado por uma determinada doença, pode-se avaliar a alteração que ela provoca na área foliar do hospedeiro ao invés de avaliar somente a quantidade da área com sintomas, a qual está relacionada indiretamente à produção (Lopes et al., 1994).

Os patógenos podem influenciar a produção de duas formas: a) alteração na interceptação de radiação solar (Waggoner \& Berger, 1987; Madeira et al., 1988; Rossing et al., 1992); b) interferência na eficiência do uso da radiação (Rabbinge et al., 1985; Bastiaans, 1991; Rossing et al., 1992). No primeiro caso, para se quantificar a influência da doença, basta subtrair a área foliar doente da área foliar para se obter a duração da área foliar sadia (HAD). Do mesmo modo pode-se calcular a absorção da área foliar sadia (HAA) em $\mathrm{MJ} \mathrm{m}^{-2}$ (Waggoner \& Berger, 1987).

Para as doenças que provocam interferência no uso da radiação, pode-se utilizar a proposta de Bastiaans (1991), que permite classificar os patógenos de acordo com sua habilidade em afetar a eficiência de conversão de seus hospedeiros. $O$ autor propõe uma relação entre lesão visual (proporção da área foliar visualmente doente) e lesão virtual (proporção da área foliar imaginária, igual ou superior à visual, dependendo do efeito do patógeno na taxa de eficiência de conversão). Assim, conforme sugerido por Johnson (1987), a produtividade de uma cultura será função da interceptação da radiação solar $\left(\mathrm{MJ} \mathrm{m}^{-2}\right)$ pelo dossel da cultura e da eficiência do uso da radiação $\left(\mathrm{g} \mathrm{MJ}^{-1}\right)$.

Medições de HAD e HAA têm mostrado maior eficiência na determinação de danos provocados por doenças (Amorim et al., 1995; Bergamin Filho, 1995; Bergamin Filho et al., 1995; Carneiro, 1995; Godoy, 1995; Iamauti, 1995; Bergamin Filho et al., 1997; Carneiro et al., 1997; Silva, 1997), mas são métodos muito mais trabalhosos 
quando comparados a medições de intensidade de doença (Canteri \& Giglioti, 1996). Enquanto, para a primeira, necessita-se conhecer a área foliar das plantas, geralmente medindo-se folha a folha, na segunda, pode-se utilizar escalas diagramáticas para fazer estimativas (Bergamin Filho \& Amorim, 1996). Para viabilizar o uso de HAD e HAA no cálculo de danos, técnicas de sensoriamento remoto têm demonstrado potencial para execução de estimativas rápidas e precisas do índice da área foliar, principalmente sob condições de campo (Asrar et al. 1984; Nilsson, 1995; Nutter Jr. \& Littrell, 1996).

O método mais conhecido é aquele em que se utiliza um radiômetro portátil de múltiplo espectro para quantificar a radiação refletida pela copa do hospedeiro (Nilsson, 1995; Canteri et al., 1996). Nutter Jr. \& Cunfer (1988) e Nutter Jr. (1989) determinaram uma estreita correlação entre a refletância da copa em $800 \mathrm{~nm}$ e a área foliar sadia, nos patossistemas cevada-Rhynchosporium secalis e amendoim-Cercosporidium personatum-Puccinia arachidis, respectivamente. Aquino et al. (1992) encontraram excelente relação entre a porcentagem de radiação refletida e a área foliar sadia de amendoim atacado por $C$. personatum, com $\mathrm{R}^{2}$ de até 0,95 . A rapidez e a facilidade de execução deste método foram demonstradas por Nutter Jr. et al. (1990). Os autores demonstraram que o tempo gasto para avaliações com radiômetro ocupou menos de 3\% do tempo necessário para avaliações de severidade com escalas diagramáticas no patossistema amendoim-C. personatum.

A mancha angular (Phaeoisariopsis griseola (Sacc.) Ferraris) é um dos principais problemas da cultura do feijão no Brasil, chegando a provocar reduções de até $45 \%$ na produção (Sartorato \& Rava, 1992). Entretanto, ainda não há um sistema adequado e eficaz de manejo da doença que utilize os recentes princípios de HAD e HAA.

O objetivo do presente trabalho foi verificar se medidas de refletância apresentam relação com a duração da área foliar sadia (HAD), absorção da área foliar sadia (HAA) e produção em feijoeiro, e também determinar se a mancha angular influencia a eficiência fotossintética das plantas sob condições de campo, para servir de base a um futuro sistema de manejo da mancha angular. 


\subsection{MATERIAL E MÉTODOS}

\subsubsection{Experimento de campo}

O experimento foi conduzido no Campo Demonstrativo e Experimental da Cooperativa Agropecuária Castrolanda Ltda., em Castro-PR. A época de semeadura foi escolhida de acordo com a época de ocorrência de maiores epidemias da mancha angular, observada em anos anteriores (Canteri et al., 1997). A semeadura, com o cultivar Carioca, foi realizada em 14/01/97 e a emergência das plantas ocorreu em 21/01/97. As parcelas eram compostas por 6 linhas de 5,00 m, espaçadas $0,40 \mathrm{~m}$, com 12 plantas por metro linear, mantidas por desbaste. O ensaio foi composto por oito tratamentos com quatro repetições, totalizando 32 parcelas. Foram feitas aplicações de fungicidas em diferentes épocas, visando monitorar o efeito do controle da doença na área foliar e produção das parcelas. Foi mantido um tratamento sem aplicação de fungicida, tratamento 08 . No tratamento 03 foi feita aplicação de cartap (500 g i.a./ha) aos 30, 42, 55 e 69 dias após a emergência (DAE), visando controlar somente a ferrugem. A mistura fungicida utilizada para controle da mancha angular foi trifenil hidróxido de estanho (200 g i.a./ha) + tebuconazole ( $80 \mathrm{~g}$ i.a./ha). No tratamento 01 , considerado "parcela controle", sensu Lopes et al. (1994), a aplicação foi executada aos 30, 42, 55 e $69 \mathrm{DAE}$, visando manter as plantas livres da mancha angular. No tratamento 02 aplicou-se aos 30 e $42 \mathrm{DAE}$, no tratamento 04 aos 42, 55 e $69 \mathrm{DAE}$, no tratamento 05 aos 48 e 62 DAE, no tratamento 06 aos 55 e 69 DAE e no tratamento 07 aos $62 \mathrm{DAE}$.

\subsubsection{Crescimento de plantas, severidade da mancha angular e produtividade}

O crescimento de plantas, a severidade da mancha angular e a produtividade foram avaliadas nas quatro linhas centrais de cada parcela, mantendo-se uma bordadura 
de $0,50 \mathrm{~m}$ no final de cada linha. Avaliaram-se seis plantas por parcela, marcadas com fita plástica, totalizando 216 plantas para todo o ensaio.

A área foliar $\left(\mathrm{LA}, \mathrm{cm}^{2}\right)$ de todas as folhas das plantas marcadas foi estimada aos $30,39,44,51,58,64,72$ e 79 DAE. Mediu-se com uma régua a largura máxima do folíolo central de cada folha ( $\mathrm{L}, \mathrm{cm})$ e para o cálculo da LA usou-se a relação empírica (Schuld, 1996):

$$
\mathrm{LA}=2,1 \times \mathrm{L}^{2} ; \quad\left(\mathrm{R}^{2}=0,98\right)
$$

As avaliações de severidade da mancha angular foram realizadas com o auxilio de uma escala diagramática (Godoy et al., 1997), simultaneamente com as avaliações da área foliar, estimando-se a severidade média, em porcentagem, para os três foliolos de cada folha, em todas as plantas marcadas. Em cada avaliação determinou-se o estádio de crescimento de acordo com a escala descritiva de Van Schoonhoven \& Pastor-Corrales (1987): V0 = germinação; V1 = emergência; V2 = abertura de folhas primárias; V3 = primeira folha trifoliolada; $\mathrm{V} 4=$ terceira folha trifoliolada; $\mathrm{R} 5$ = pré-floração; $\mathrm{R} 6=$ floração; R7 = formação de vagens; R8 = enchimento de vagens; $R 9$ = maturação fisiológica.

A colheita foi realizada 85 dias após a emergência. A produção foi determinada colhendo-se as quatro linhas centrais de cada parcela, em uma área de $6,40 \mathrm{~m}^{2}$. Mediu-se a umidade dos grãos e padronizaram-se os resultados para $13 \%$ de umidade. Contou-se o número de plantas na área útil da parcela no momento da colheita para estimativa da densidade de plantas por metro quadrado. Optou-se por trabalhar com a produção da parcela (método da parcela experimental) ao invés da produção por planta (método da planta individual - Bergamin Filho \& Amorim, 1996) para que fosse possivel estabelecer relações desta variável com medidas de refletância. 


\subsubsection{Variáveis integrais}

O valor da área sob a curva de progresso da doença (AUDPC) para cada parcela foi calculado por integração trapezoidal (Shaner \& Finney, 1977):

$$
\operatorname{AUDPC}=\sum_{i=1}^{n-1}\left[\left(X_{1}+X_{i+1}\right) / 2\right]\left(t_{t+1}-t_{1}\right)
$$

onde $X$ é a severidade média da doença por parcela (porcentagem), $X_{\mathrm{i}}=X\left(t_{i}\right), n$ é o número de avaliações e $\left(t_{i+\jmath}-t_{i}\right)$ é o intervalo entre duas avaliações consecutivas.

Os valores de indice da área foliar (LAI) de cada parcela foram obtidos pela multiplicação da área foliar média por planta $\left(\mathrm{m}^{2}\right)$ pela densidade de plantas por $\mathrm{m}^{2}$ observada no dia da colheita. A duração da área foliar sadia (HAD) para cada parcela foi calculada pela fórmula

$$
\mathrm{HAD}=\sum_{i=1}^{n-1}\left\{\left[L A I_{i}\left(1-X_{i}\right)+L A I_{i+1}\left(1-X_{t+1}\right)\right] / 2\right\}\left(t_{l+1}-t_{i}\right)
$$

onde $\mathrm{LAI}_{\mathrm{i}}=\operatorname{LAI}\left(t_{i}\right)$. O valor do indice da área foliar sadio (HLAI) para cada data de avaliação foi calculado como HLAI $=\operatorname{LAI}(1-X)$.

Os valores de radiação interceptada $\left(\mathrm{RI}_{\mathrm{i}}\right)$ em $\mathrm{MJ} \mathrm{m}^{-2}$ foram calculados como:

$$
\mathrm{RI}_{i}=I_{i}\left[1-\exp \left(-k \mathrm{LAI}_{i}\right)\right]
$$

em que $I_{i}$ é a média de radiação solar incidente $\left(\mathrm{MJ} \mathrm{m}^{-2}\right)$ no periodo $\left(t_{i+l}-t_{i}\right)$ e $k$ é o coeficiente de extinção; usou-se $k=0,7$ (Bergamin Filho et al., 1997). O valor da absorção da área foliar sadia (HAA) em $\mathrm{MJ} \mathrm{m}^{-2}$ para cada parcela foi calculado como $\mathrm{HAA}=\sum_{i=1}^{n-1} I_{i}\left(\left\{\left(1-X_{1}\right)\left[1-\exp \left(-k L A I_{i}\right)\right]+\left(1-X_{i+1}\right)\left[1-\exp \left(-k L A I_{i+1}\right)\right]\right\} / 2\right)\left(t_{i+1}-t_{i}\right)$

Os valores de HRI $\left(\mathrm{MJ} \mathrm{m}^{-2}\right)$ para cada data de avaliação foram calculados pela fórmula $\mathrm{HRI}=\mathrm{RI}(1$ - X). A radiação solar incidente $(I)$ foi medida por uma estação meteorológica computadorizada situada ao lado da área experimental.

Calculou-se a eficiência do uso da radiação (RUE, em $\mathrm{g} \mathrm{MJ}^{-1}$ ) para cada parcela pela divisão da produção $\left(\mathrm{g} \mathrm{m}^{-2}\right)$ pela HAA $\left(\mathrm{MJ} \mathrm{m}^{-2}\right)$. 


\subsubsection{Medidas de refletância}

As medidas de refletância foram feitas com um radiômetro de múltiplo espectro portátil CropScan, modelo MSR87, aos 30, 41, 44, 51, 58, 64, 72 e 79 DAE. Em cada data de avaliação foram feitas três leituras por parcela, sempre no período da tarde, até duas horas após o meio dia solar. A área medida foi um círculo com diâmetro igual à metade da altura do sensor, centralizado no intevalo entre as duas linhas mais internas da parcela. O sensor foi montado em uma barra a uma altura de 1,60 m sobre o solo. A quantidade de luz difusa refletida (refletância) do dossel do feijoeiro foi medida em oito comprimentos de onda simultaneamente $(460,510,560,610,660,710,760$ e 810 nanômetros).

As medidas de refletância foram usadas para calcular os índices vegetativos IR $R$ e ND (diferença normalizada), onde $N D=(I R-R) /(I R+R)$ (Nilsson, 1995). Usaram-se três combinações para os comprimentos de onda infravermelho (IR) e vermelho (R). Para o IR usaram-se sempre 810 nanômetros (nm) e, para o R, 610, 660 e $710 \mathrm{~nm}$.

Para cada comprimento de onda e para os índices vegetativos foram calculados, por integração trapezoidal, os valores da área sob a curva das medidas de refletância (AUR), para cada parcela, pela fórmula:

$$
\mathrm{AUR}=\sum_{i=1}^{n-1}\left[\left(R_{i}+R_{t+1}\right) / 2\right]\left(t_{i+1}-t_{i}\right)
$$

onde $R$ é a medida de refletância em cada comprimento de onda (porcentagem), $R_{\mathrm{j}}=$ $R\left(t_{i}\right), n$ é o número de avaliações e $\left(t_{i+1}-t_{i}\right)$ é o intervalo entre duas avaliações consecutivas.

\subsubsection{Análise dos dados}

A eficiência dos tratamentos foi examinada por análise de variância usando-se o programa PlotIT for Windows (Scientific Programming Enterprises, Haslett, MI). As 
relações entre produtividade e HAD e HAA, entre produtividade e medidas de refletância e entre medidas de refletância e HAD e HAA foram examinadas por regressão linear, usando-se o programa STATISTICA (StatSoft, Tulsa, OK). Para a análise dos resultados de HAD, HAA e refletância foram consideradas as 36 parcelas isoladamente. 


\subsection{RESULTADOS E DISCUSSÃO}

Os primeiros sintomas da mancha angular ( $P$. griseola) foram observados aos 30 dias após a emergência (DAE). A severidade da ferrugem e de antracnose foi desprezível e a mancha angular logo se tornou a doença predominante. A epidemia da mancha angular não foi severa; a AUDPC máxima foi 52,5 e o nível máximo de severidade observado em avaliações de toda a planta até o estádio R8 foi 6,05\%.

\subsubsection{Comparação entre parcelas sem e com controle da doença}

A relação entre severidade da mancha angular, HLAI, HRI e refletância em 810 nm foi investigada pela comparação entre parcelas com e sem controle químico da doença (Figura 8). Para os dois casos foram selecionadas parcelas com grande diferença no indice da área foliar sadio (HLAI). No caso das parcelas sem controle, pode-se observar que, apesar dos niveis semelhantes de severidade, a variação da HLAI influenciou a absorção da área foliar sadia (HRI) e a refletância. O mesmo foi observado para as parcelas com controle químico, onde, apesar da baixa severidade da doença foram observadas variações para HRI e refletância em função da variação da HLAI.

A queda da HRI observada aos 58 dias após a emergência (DAE), para todas as parcelas (Figura 8), foi devida à baixa radiação incidente (I) no período, $10,9 \mathrm{MJ} \mathrm{m}^{-2}$ contra $13,5 \mathrm{MJ} \mathrm{m}^{-2}$ de média para os demais periodos.

A produção observada foi $286,8 \mathrm{~g} \mathrm{~m}^{-2}$ para a parcela sem controle e com maior HLAI e $264,9 \mathrm{~g} \mathrm{~m}^{-2}$ para parcela sem controle e com menor HLAI. Para as parcelas com controle, a produção foi $304,8 \mathrm{~g} \mathrm{~m}^{-2}$ para o maior HLAI e $278,8 \mathrm{~g} \mathrm{~m}^{-2}$ para a menor HLAI. Assim, mesmo quando a HLAI era semelhante, constatou-se tendência de menor produção para as parcelas com maior severidade da doença, quando comparadas às parcelas com menos doença. Isto dá um indicativo de variação na eficiência fotossintética de plantas com mesma HLAI. 

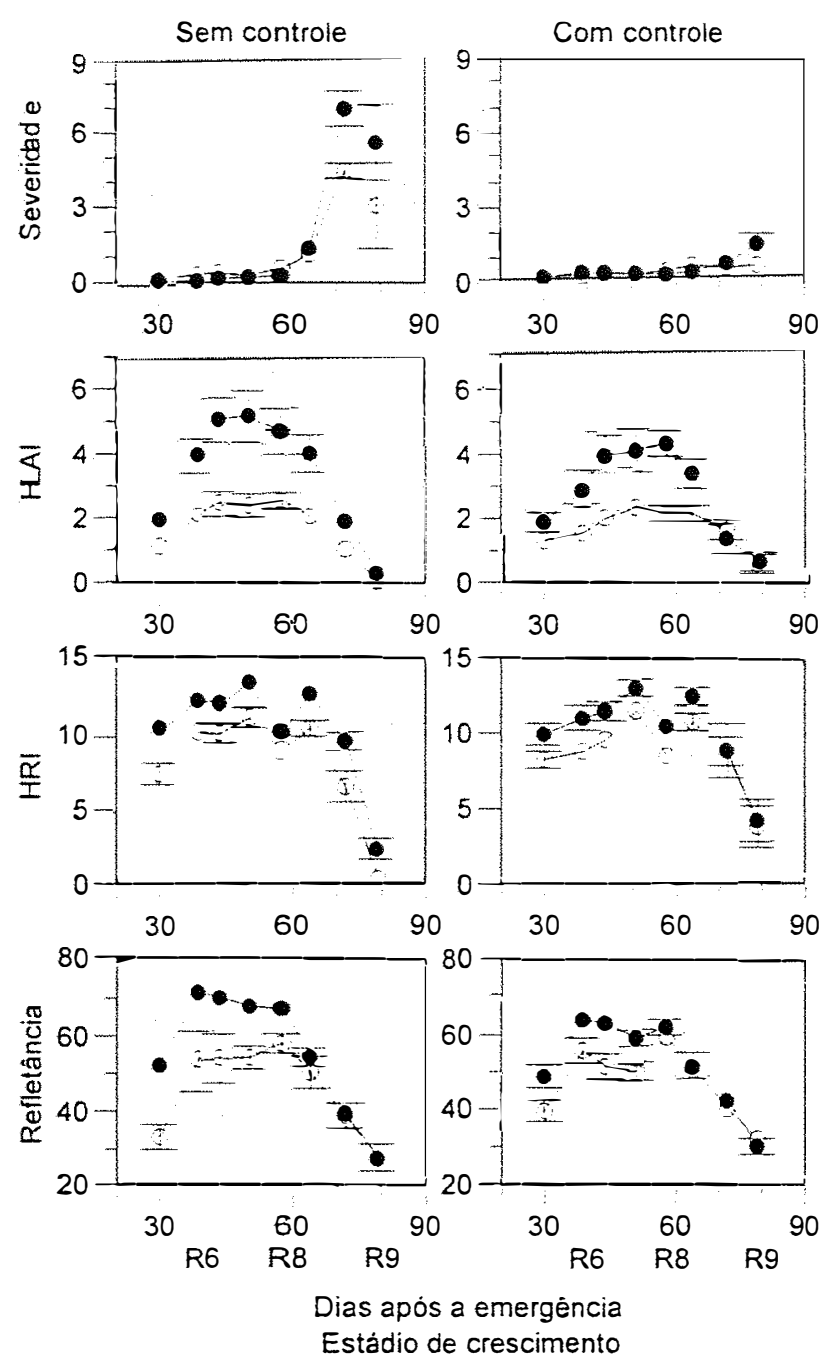

Figura 8 - Severidade (porcentagem) da mancha angular em feijoeiro, indice da área foliar sadia (HLAI), radiação interceptada pela área foliar sadia (HRI), em MJ $\mathrm{m}^{-2}$ e medidas de refletância em $810 \mathrm{~nm}$ versus o tempo, observados em parcelas com controle e sem controle químico da mancha angular. Para severidade, HLAI e HRI cada ponto representa a média de 6 plantas, para refletância cada ponto representa a média de 3 leituras. Círculos cheios representam parcelas com maior área foliar e círculos vazios parcelas com menor área foliar. Barras verticais representam o erro padrão. 


\subsubsection{Relações da produção com HAD, HAA, AUDPC e refletância}

A produção $\left(\mathrm{g} \mathrm{m}^{-2}\right)$, apresentou incremento linear $(\mathrm{P}<0,01)$ com o incremento da HAD e também com o incremento da HAA (Figura 9), confirmando a possibilidade de uso destas variáveis para estimar danos provocados pela mancha angular (Lopes et al., 1994; Godoy, 1995; Bergamin Filho et al., 1997; Silva, 1997). A equação para relação produção-HAA foi: Produção $=97,2+0,29$ HAA $\left(\mathrm{R}^{2}=44,8 \%\right)$, e para HAD foi: Produção $=216,0+0,44 \mathrm{HAD}\left(\mathrm{R}^{2}=40,2 \%\right)$. Os $\mathrm{R}^{2}$ encontrados não foram tão altos quanto aqueles observados por Carneiro (1995), Godoy (1995) e Bergamin Filho et al. (1997).

A relação linear entre HAD e produção para mancha angular já havia sido constatada por Bergamin Filho et al. (1997). No mesmo trabalho os autores sugerem que para elevados HLAI, a relação produção-HAA é exponencial, porém no presente trabalho, apesar dos elevados HLAI, a relação foi linear $\left(\mathrm{R}^{2}=44,8 \%\right)$ e não exponencial $\left(\mathrm{R}^{2}=43,8 \%\right)$.

A AUDPC apresentou relação linear negativa $(\mathrm{P}<0,01)$ com a produção (Figura 9). A avaliação da severidade de doença mostrou potencial para ser usada para estabelecer relações com danos, pela equação: Produção $=304,5-0,92$ AUDPC $\left(R^{2}=\right.$ $31,4 \%)$. A relação entre produção e AUDPC para mancha angular em feijoeiro é um tanto controversa, alguns trabalhos não relatam relação e, naqueles em que esta é encontrada, as equações que a representam são distintas, variando de acordo com o local e a estação de cultivo (Bergamin Filho \& Amorim, 1996). Uma representação desta controvérsia está em Bergamin Filho et al. (1997). Os autores encontraram relação entre produção e AUDPC apenas para 1 entre 5 ensaios conduzidos. Os autores sugerem que a ocorrência de relação produção x AUDPC está associada à quantidade máxima de HLAI observada. Nos seus experimentos, os valores de HLAI máximo eram menores que 3 , com exceção para um dos ensaios, que possuía HLAI máximo próximo a 5, justamente o mesmo ensaio em que foi observada a relação entre produção e AUDPC. No presente 
trabalho foram constatadas HLAI de até 5,2, confirmando a suposição levantada por Bergamin Filho et al. (1997).

Segundo Bergamin Filho et al. (1997) A explicação para a ocorrência da relação entre produção e AUDPC, quando constatados elevados HLAI, é o fato de que plantas com alto HLAI parecem ser menos sujeitas à desfolha e assim, as folhas doentes permanecem nas plantas. Como a desfolha é reduzida, a produção se relaciona com a severidade da doença, estimada com auxílio de escalas diagramáticas. No presente ensaio não foi medida a desfolha e portanto não há como comprovar a afirmativa.

A relação entre produção e medidas de refletância foi significativa $(\mathrm{P}<0,01)$, com $\mathrm{R}^{2}=38,0 \%$ para a Integral da refletância em $810 \mathrm{~nm}\left(\mathrm{AUR}_{810}\right)$ e $\mathrm{R}^{2}=57,0 \%$ para a Integral da diferença normalizada $\left(A_{U} R_{N D}\right)$ (Figura 9), valores estes bem menores que os encontrados para o patossistema Cercosporidium personatum-Sphacelloma arachidis /amendoim $\left(\mathrm{R}^{2}=84,0 \%\right)$ (Canteri et al., 1996). A AUR $\mathrm{ND}_{\mathrm{N}}$ mostrou-se mais eficiente em correlações com a produção do que a $A U R_{810}$. Outros autores já haviam sugerido o uso da diferença normalizada (ND) por apresentar melhores relações com produção (Asrar et al. 1984; Nilsson, 1995; Schuld, 1996). No presente trabalho, o comprimento de onda na faixa do vermelho que forneceu melhores resultados na equação da ND foi $660 \mathrm{~nm}$.

Os baixos valores de $\mathrm{R}^{2}$ encontrados para as relações com produção têm duas explicações: i) a pouca amplitude dos valores da produção; ii) o alto HLAI observado. A produção variou entre 238,7 a $314,7 \mathrm{~g} \mathrm{~m}^{-2}$, diferentemente dos dados apresentados por Bergamin Filho et al. (1997), onde a produção variou de quase 0 até mais de $500 \mathrm{~g} \mathrm{~m}^{-2}$. A pouca variação da produção deve-se ao uso de uma área homogênea, com elevada fertilidade e a adoção do método da "parcela experimental" ao invés da "planta individual". Os altos valores de HLAI (até 5,2) foram função da alta fertilidade da área experimental e dos baixos niveis de severidade, apesar do experimento ter sido implantado em uma época de ocorrência histórica de severas epidemias da mancha angular (Canteri et al. 1997).

Comparativamente aos dados apresentados por Bergamin Filho et al. (1997), a produção apresentada foi alta. A produção média do presente ensaio foi $279,1 \pm 2,5 \mathrm{~g}$ 
$\mathrm{m}^{-2}$, enquanto que, para os referidos autores foi $185,4 \mathrm{~g} \mathrm{~m}^{-2}$ nos 4 ensaios em que não houve relação entre produção com AUDPC e $302,5 \mathrm{~g} \mathrm{~m}^{-2}$ no ensaio que apresentou a relação, evidenciando novamente a influência de elevados HLAI.
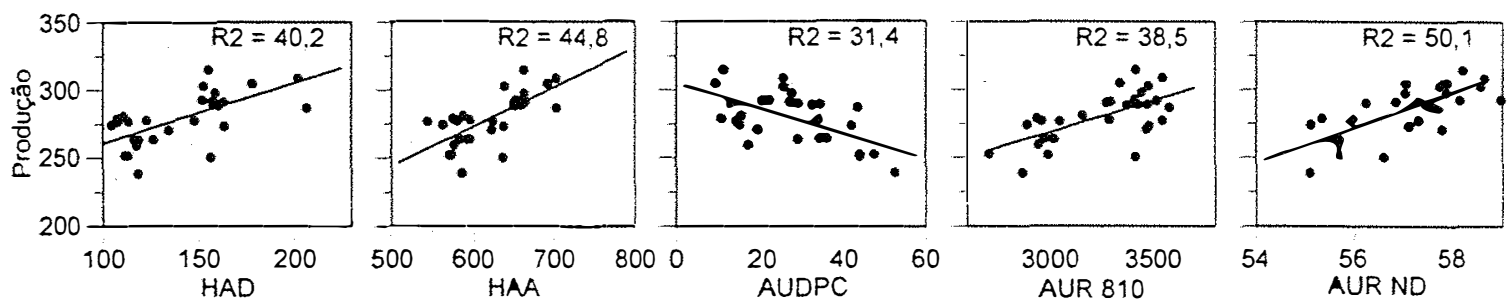

Figura 9 - Relações da produção $\left(\mathrm{g} \mathrm{m}^{-2}\right)$ com duração da área foliar sadia (HAD), absorção da área foliar sadia (HAA), área sob a curva de progresso da doença (AUDPC), integral da refletância em $810 \mathrm{~nm}\left(\mathrm{AUR}_{810}\right)$ e integral da diferença normalizada $\left(A U R_{N D}\right)$, utilizando os comprimentos de onda de 810 e $660 \mathrm{~nm}$, observadas em parcelas com diferentes tratamentos fungicidas para controle da mancha angular.

\subsubsection{Eficiência fotossintética}

A possibilidade de diminuição da eficiência fotossintética provocada por $P$. griseola foi investigada após observar-se que parcelas com valores semelhantes de HAD e de HAA apresentavam diferentes produtividades para diferentes valores de AUDPC (Figura 10). Houve relação entre produção, em $\mathrm{g} \mathrm{m}^{-2}$, $\operatorname{HAD}$ e $\operatorname{AUDPC}\left(\mathrm{R}^{2}=74,8 \%\right)$, representada pela equação: Produção $=244,7-0,91 \mathrm{AUDPC}+0,42 \mathrm{HAD}$. Isto indica que, para uma mesma HAD, a produção pode variar em função da AUDPC, ou seja a mancha angular, representada pela AUDPC, interfere na eficiência fotossintética da área foliar sadia. Resultados semelhantes foram obtidos quando se utilizou HAA ao invés de $\mathrm{HAD}\left(\mathrm{R}^{2}=74,7 \%\right)$, para a equação: Produção = 134,5 - 0,78 AUDPC + 0,27 HAA. 
Para confirmar a interferência na eficiência fotossintética provocada pela mancha angular, calculou-se a eficiência do uso da radiação para produção de grãos (RUE), em g $\mathrm{MJ}^{-1}$, para os 8 tratamentos. Não foi possivel utilizar a abordagem tradicional (Bergamin Filho et al. 1997), onde é analisado o coeficiente angular da equação da regressão linear entre Produção-HAA, pois haveria somente 4 pontos para cada análise. Assim, fez-se uma estimativa da RUE, dividindo-se a produção $\left(\mathrm{g} \mathrm{m}^{-2}\right)$ pela HAA ( $\left.\mathrm{MJ} \mathrm{m}^{-2}\right)$ para cada tratamento (Tabela 4). A maior RUE foi observada para o tratamento $1(0,46 \pm 0,01 \mathrm{~g}$ $\left.\mathrm{MJ}^{-1}\right)$ e a menor RUE para o tratamento $7\left(0,41 \pm 0,01 \mathrm{~g} \mathrm{MJ}^{-1}\right)$. Mesmo assim, não foi constatada diferença significativa $(\mathrm{P}<0,05)$ entre os tratamentos. Os resultados foram consistentes, isto é, o tratamento com melhor controle da doença apresentou a maior RUE. Apesar das evidências, somente medições diretas das taxas de fotossíntese de plantas sadias e doentes podem mostrar se, realmente, há variação na RUE (van Oijen, 1990).

Bassanezi (1995), trabalhando em condições controladas com um analisador de $\mathrm{CO}_{2}$ infravermelho, encontrou uma redução significativa na RUE em plantas atacadas por P. griseola. Em condições de campo, Bergamin Filho et al. (1997) não constataram variações significativas da RUE entre parcelas doentes e sadias para ensaios com HLAI máximo próximo a 3, mas verificaram grande variação na RUE para o ensaio com HLAI máximo próximo a 5 . No presente ensaio, com HLAI máximo próximo a 5 , não foi constatada variação significativa $(\mathrm{P}<0,01)$ para $R U E$, mas houve relação Produção $\mathrm{x}$ AUDPC x HAA (Figura 10). Talvez a pouca variação da RUE se deva à reduzida intensidade da doença. A AUDPC máxima observada foi próximo a 40, enquanto, para Bergamin Filho et al. (1997) foi maior que 250.

Com estes resultados constata-se a importância em medir não apenas a área foliar para correlacionar com danos, mas também a quantidade de doença, para procurar conhecer qual foi a redução na eficiência fotossintética da área foliar remanescente na cultura. 

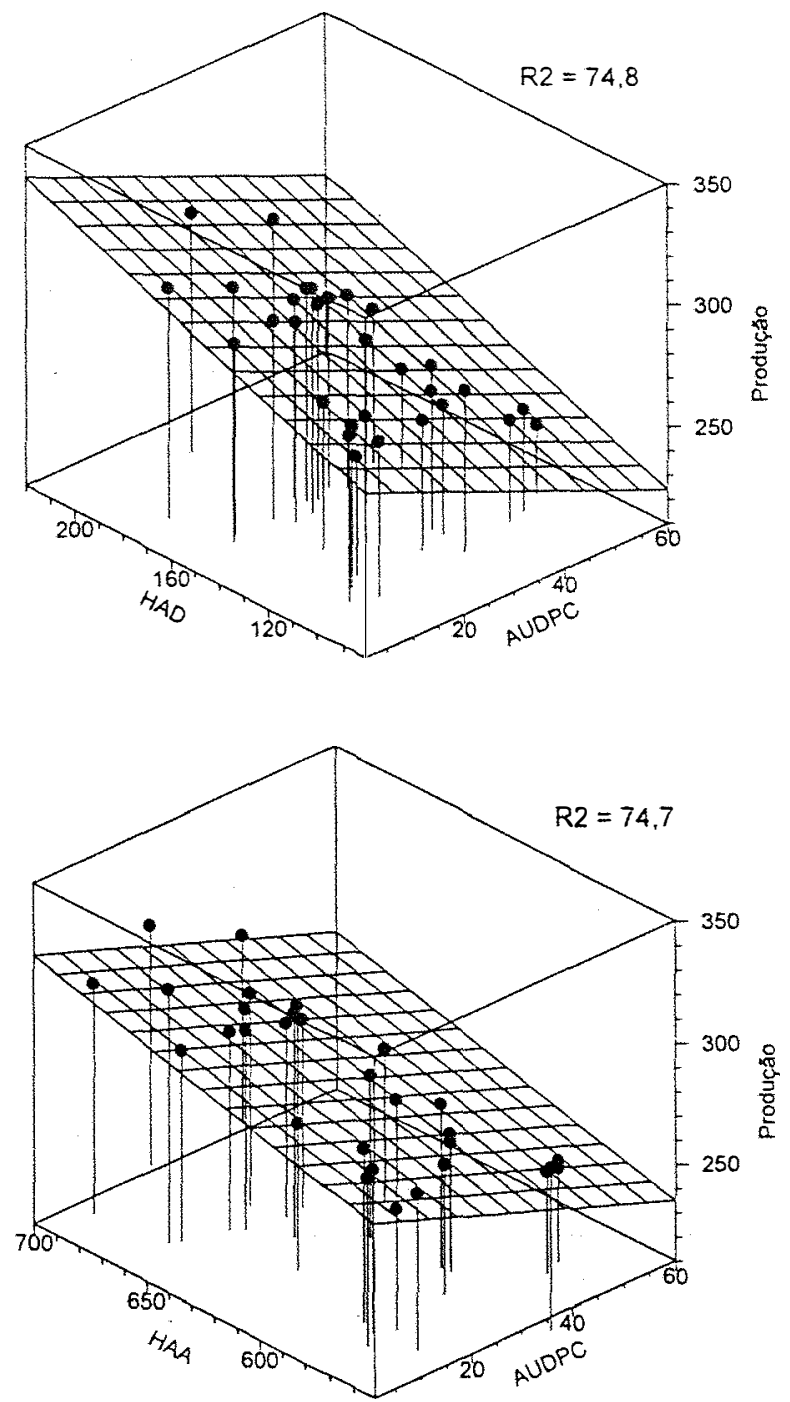

Figura 10 - Relações entre duração da área foliar sadia (HAD) e absorção da área foliar sadia (HAA) com a área sob a curva de progresso da doença (AUDPC) e a produção $\left(\mathrm{g} \mathrm{m}^{-2}\right)$, observadas em parcelas com diferentes tratamentos fungicidas para controle da mancha angular em feijoeiro. 


\subsubsection{Eficiência dos tratamentos}

Os oito tratamentos utilizados foram definidos buscando-se uma ampla gama de niveis de severidade da mancha angular e conseqüentemente, variações na área foliar e na produção. Entretanto, não houveram diferenças significativas para absorção da área foliar sadia (HAA), nem para a integral das medidas de refletância em $810 \mathrm{~nm}\left(\mathrm{AUR}_{810}\right)$, pelo teste de Tukey $(\mathrm{P}<0,05)$ (Tabela 4$)$. O coeficiente de variação observado para as variáveis $\mathrm{HAA}$ e $\mathrm{AUR}_{810}$ foi baixo, entre 7,5\% e 9,2\%, respectivamente, demonstrando uma alta precisão para o experimento (Gomes, 1987). A ausência de diferenças significativas para estas variáveis pode ser explicada pelo pouco efeito da quantidade de doença sobre a área foliar neste ensaio.

O efeito dos tratamentos fungicidas pode ser observado na AUDPC (Tabela 4). As variações foram consistentes e de acordo com o esperado, ou seja, menores níveis da mancha angular para os tratamentos com início de aplicações em estágios iniciais do ciclo da cultura. Também foram constatadas diferenças significativas entre os tratamentos nas avaliações aos 64, 72 e 79 DAE, com coeficiente de variação para análise de variância igual a 35,9\%,29,3\% e 56,1\%, respectivamente.

A avaliação da severidade de doença mostrou-se um bom parâmetro para classificar os tratamentos fungicidas de acordo com sua eficiência para controle da doença (Tabela 4), mas, como discutido anteriormente, nem sempre é uma boa variável para estimar danos (Bergamin Filho \& Amorim, 1996). A maior porcentagem de controle foi observada para o tratamento 01 (67,8\%), com 4 aplicações, mas não diferiu estatisticamente do tratamento 02 (65,6\%), com apenas duas aplicações no início do ciclo. Já o tratamento 05, também com 2 aplicações, feitas no final do ciclo, teve eficiência menor $(38,5 \%)$.

Quanto mais tarde se iniciaram as aplicações, menor foi a porcentagem de controle (PC) da mancha angular. Quando se iniciaram as aplicações aos 30 DAE houve eficiência de $67,8 \%$, e quando iniciaram-se aos 62 DAE não se constatou eficiência alguma. A relação entre época de início da aplicação (EI), em DAE, e a PC foi linear e 
negativa $\left(R^{2}=95,7 \%\right)$, representada pela equação: $P C=127,3-1,946$ EI. Estes resultados são semelhantes aos apresentados por Forcelini (1997) para diversas doenças foliares. O autor comprovou que aplicações com fungicidas de contato em intervalos constantes. começando no início da epidemia, eram mais eficientes em controlar a doença.

Tabela 4. Absorção da área foliar sadia (HAA), área sob a curva de progresso da mancha angular (AUDPC), eficiência fotossintética (RUE) para produção de grãos, área sob a curva de refletância na faixa de $810 \mathrm{~nm}\left(\mathrm{AUR}_{810}\right)$ e produtividade do feijoeiro, observadas para tratamentos com diferentes épocas de aplicação de fungicidas em dias após a emergência (DAE).

\begin{tabular}{|c|c|c|c|c|c|c|}
\hline \multicolumn{2}{|r|}{ Tratamentos } & \multirow{2}{*}{$\begin{array}{l}\text { Área foliar } \\
\text { HAA }\left(\mathrm{MJ} \mathrm{m}^{-2}\right) \\
\text { média } \pm \mathrm{SE} *\end{array}$} & \multirow{2}{*}{$\begin{array}{l}\text { Doença } \\
\text { AUDPC } \\
\text { média } \pm \text { SE }\end{array}$} & \multirow{2}{*}{$\begin{array}{l}\text { RUE } \\
g_{M J^{-1}} \\
\text { média } \pm S E\end{array}$} & \multirow{2}{*}{$\begin{array}{l}\text { Refletância } \\
\text { AURR }_{810} \\
\text { média } \pm S E\end{array}$} & \multirow{2}{*}{$\begin{array}{l}\text { Produtividade } \\
\qquad\left(\mathrm{g} \mathrm{m}^{-2}\right) \\
\text { média } \pm \mathrm{SE}\end{array}$} \\
\hline & $\begin{array}{c}\text { Época de } \\
\text { aplicaçâo(DAE) }\end{array}$ & & & & & \\
\hline 01 & $30,42,55,69$ & $614,2 \pm 19,8 a$ & $12,0 \pm 1,3 \mathrm{a}$ & $0,46 \pm 0,010 a$ & $3221,3 \pm 114,5 \mathrm{a}$ & $282,9 \pm 2,2 \mathrm{ab}$ \\
\hline 02 & 30,42 & $628,3 \pm 29,0 \mathrm{a}$ & $12,8 \pm 1,7 \mathrm{a}$ & $0,46 \pm 0,010 a$ & $3165,4 \pm 123,6 a$ & $288,9 \pm 12,7 \mathrm{ab}$ \\
\hline $03^{\circ}$ & $30,42,55,69$ & $595,1 \pm 17,5 \mathrm{a}$ & $37,0 \pm 1,8 \mathrm{c}$ & $0,45 \pm 0,01 \bullet a$ & $3144,1 \pm 150,4 \mathrm{a}$ & $269,8 \pm 3,4 a b$ \\
\hline 04 & $42,55,69$ & $622,8 \pm 26,9 a$ & $20,1 \pm 2,6 \mathrm{ab}$ & $0,46 \pm 0,020 \mathrm{a}$ & $3211,9 \pm 219,2 \mathrm{a}$ & $284,5 \pm 4,8 \mathrm{ab}$ \\
\hline 05 & 48,62 & $654,6 \pm 17,2 \mathrm{a}$ & $22,9 \pm 1,4 \mathrm{abc}$ & $0,46 \pm 0,010 \mathrm{a}$ & $3407,2 \pm 75,7 a$ & $303.3 \pm 3.9 \mathrm{~b}$ \\
\hline 06 & 55,69 & $614,0 \pm 20,8 \mathrm{a}$ & $27,8 \pm 4,7 \mathrm{abc}$ & $0,46 \pm 0,010 \mathrm{a}$ & $3199,5 \pm 172,6 a$ & $282,9 \pm 5,1 \mathrm{ab}$ \\
\hline 07 & 62 & $619,6 \pm 15,1 \mathrm{a}$ & $37,4 \pm 6,6 \quad c$ & $0,41 \pm 0,010 \mathrm{a}$ & $3165,7 \pm 118,1 \mathrm{a}$ & $257,0 \pm 11,3 \mathrm{a}$ \\
\hline 08 & sem fungicida & $601,6 \pm 34,9 \mathrm{a}$ & $38,2 \pm 4,4 \quad c$ & $0,45 \pm 0,020 \mathrm{a}$ & $3087,3 \pm 180,8 a$ & $269,7 \pm 7.6 \mathrm{ab}$ \\
\hline & C.V & $7,62 \%$ & $25,54 \%$ & $05 \%$ & $9,27 \%$ & $5.53 \%$ \\
\hline
\end{tabular}

médias seguidas de mesma letra não diferem estatisticamente entre si pelo teste de Tukey $(\mathrm{P}<0,05)$.

* tratamento com cartap (500 g i.a./ha), demais tratamentos com trifenil hidróxido de estanho (200 g i.a.ha) + tebuconazole ( 80 g i.a. $/$ ha).

** $\mathrm{SE}=$ erro padrão da amostra. 
A produtividade apresentou diferença significativa $(\mathrm{P}<0,05)$ apenas entre os tratamentos 05 e 07 . Esta diferença esteve mais ligada a variação na HAA, em função da fertilidade natural do solo, do que à intensidade da mancha angular. A integral de medidas de refletância na faixa do infravermelho $\left(\mathrm{AUR}_{810}\right)$ apresentou um comportamento semelhante à produtividade $\left(\mathrm{g} \mathrm{m}^{-2}\right)$ e a HAA $\left(\mathrm{MJ} \mathrm{m}^{-2}\right)$, indicando maior relação com estas variáveis do que com a severidade da mancha angular ou à AUDPC.

A quantidade de doença observada não afetou significativamente a HAD e HAA, assim, as diferenças de produção foram função da variação das condições edafoclimáticas da área experimental e também da redução da eficiência fotossintética na área foliar remanescente nas parcelas doentes.

\subsubsection{Medidas de refletância e relações com HLAI e HRI}

A viabilização do uso da HLAI e HRI em modelos de danos necessita de um método rápido e eficiente para estimá-las. No patossistema amendoim-Cescosporidium personatum foram encontradas boas relações entre refletância, em $810 \mathrm{~nm}$, e HLAI ( $\mathrm{R}^{2}$ entre 77 e 95\%) (Aquino et al. 1992). No presente ensaio, os melhores resultados para relações de refletância com HLAI e HRI foram obtidos com o uso da diferença normalizada (ND - relação entre os comprimentos de onda 810 e $660 \mathrm{~nm}$ - Asrar et al. 1984) (Figura 11). Os comprimentos de onda na faixa do infravermelho próximo (760 e $810 \mathrm{~nm}$ ) e IR/R também se correlacionaram com HLAI e HRI, entretanto os resultados não foram tão bons quanto os apresentados pela ND.

Os $\mathrm{R}^{2}$ observados foram $89,7 \%$ para a relação ND-HLAI e $87,7 \%$ para ND-HRI, ambas ajustadas pelo modelo monomolecular. Schuld (1996), trabalhando com a mancha angular em feijoeiro, também obteve melhores resultados com o uso da diferença normalizada (ND) para correlações com o índice da área foliar (LAI). O autor, entretanto, usou os comprimentos de onda 810 e $610 \mathrm{~nm}$ para o cálculo da ND. No mesmo trabalho, sugere-se que leituras na faixa do infravermelho se relacionam com a 
área foliar sadia (HLAI) e não simplesmente com o índice da área foliar (LAI). As relações encontradas sofreram variação de acordo com cultivares e com a estação de cultivo. Outro fator que pode influenciar a relação refletância-HLAI é a calibração do radiômetro (Nilsson, 1995).
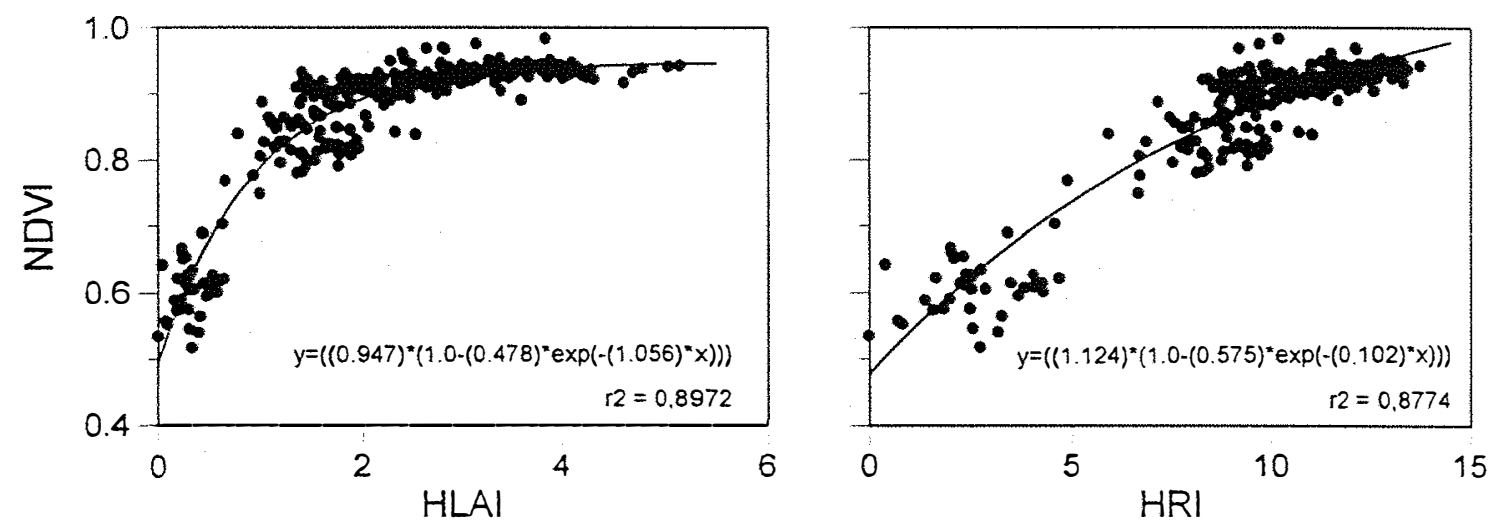

Figura 11 - Índice da área foliar sadia (HLAI) e radiação interceptada pela área foliar sadia (HRI) em $\mathrm{MJ} \mathrm{m}^{-2}$ versus a refletância, representada pela diferença normalizada do índice de vegetação (ND), utilizando os comprimentos de onda 660 e $810 \mathrm{~nm}$ para vermelho e infravermelho, respectivamente, observados para dossel de feijoeiro entre os estádios R5 (pré-floração) e R9 (maturação fisiológica). Cada ponto representa a média de 3 leituras de refletância.

Um dos problemas para uso de medidas de refletância para estimar HLAI é o fato de que as medidas tendem a se estabilizar a partir de HLAI superiores a 3 (Figura 11), para qualquer um dos comprimentos de onda. Isto significa que, em ensaios onde a HLAI é superior a 3, as estimativas de HLAI baseadas em refletância podem não ser precisas. Já em estimativas de HRI, a relação não tende a estabilizar, demonstrando bom 
potencial para uso, pois a integral da HRI (HAA) apresenta melhor relação com produção do que a integral da HLAI (HAD). Vale lembrar, entretanto, que há possibilidade de variação na relação ND-HRI entre diferentes estações de cultivo, pois HRI não depende exclusivamente de HLAI, mas também da radiação incidente (I). A I varia de estação para estação e pode exercer forte influência nos resultados da HRI, conforme pode ser visto na Figura 8, o que influenciaria um sistema de manejo baseado nesta variável.

As medidas de refletância, representadas por $\mathrm{ND}$, apresentaram boa correlação com HLAI e HRI. Em função disto testou-se o uso da integral da refletância $\left(\mathrm{AUR}_{810} \mathrm{e}\right.$ AUR $_{N D}$ ) em substituição aos valores de HAD e HAA, do mesmo modo que se fez na Figura 10, buscando-se relações entre refletância $x$ produção $x$ doença. Os $R^{2}$ encon ados, 68,6\% e 66,4\%, respectivamente para $\mathrm{AUR}_{810}$ e $A U R_{N D}$, foram menores do que aqueles observados para HAD e HAA (74,8\% e 74,7\%). A diminuição do $\mathrm{R}^{2}$ pode estar relacionada a dois fatores: i) as medidas de refletância sofreram influência da quantidade de doença; ii) HLAI superiores a 3 têm influência na produção, que não são captadas pelas medidas de refletância.

Valores de HLAI acima de 3 têm pouca influência na HRI, que, efetivamente é a variável que melhor se correlaciona com produção (Waggoner \& Berger, 1987). Isto ocorre porque a relação entre as duas variáveis é exponencial. Portanto, como prova a literatura (Nilsson, 1995), a integral de medidas de refletância tomadas durante o ciclo da cultura relaciona-se com a produção. A dúvida, porém, permanece quanto à utilidade destas medições em programas de manejo de doenças do feijoeiro.

Como citado anteriormente, medições de refletância sofrem influência da estação de cultivo e da variedade (Schuld, 1996) e podem sofrer influência da calibração do aparelho, da umidade e tipo de solo e do horário de leitura (Nilsson, 1995). Estas variáveis dificultam a obtenção de modelos transportáveis baseados em refletância para estimar danos e orientar o manejo das doenças (Bouman, 1995). Assim, a adoção da "parcela controle", sugerida por Lopes et al. (1994) e ratificada por Bergamin Filho \& Amorim (1996) e Bergamin Filho et al. (1997), parece ser a alternativa viável para 
implementação de um programa de manejo da doença em feijoeiro baseado em HAD e HAA.

Se a variação entre a parcela controle e a situação de produção ocorrer antes de atingido um HLAI maior ou igual a 3, então as medidas de refletância estarão aptas a captar a variação. Senão, resta apenas a esperança de que a doença interfira de forma significativa nas leituras de refletância para direcionar o manejo. Vale lembrar que as leituras de refletância também sofrem variação com a quantidade de doença na cultura (Nutter Jr., 1989; Nilsson, 1995; Canteri et al., 1996). No presente ensaio, a pouca severidade da mancha angular impediu que se provasse a variação na refletância provocada pela doença no patossistema $P$. griseola-feijoeiro.

Modelos usados para calcular HLAI e HRI em função de medidas de refletância não devem ser usados em outros dados antes de ser feita sua validação. Afinal, outros trabalhos indicam que pode haver variação nos modelos de acordo com variedade e estação de cultivo (Schuld, 1996) e qualquer modelo, para que tenha aplicação, deve ser validado com dados diferentes daquele que o originou (Kranz \& Royle, 1978).

\subsubsection{Sensibilidade de medidas de refletância para detectar variações em HLAI e HRI}

Bergamin Filho et al. (1997) apresentaram uma estimativa aproximada para o grau de sensibilidade com que a HRI deve ser determinada no processo de tomada de decisão. Seguindo a mesma linha de raciocínio, no presente trabalho, foi calculada a inclinação da reta de regressão linear (com origem forçada em zero) para a relação entre $\mathrm{HRI}\left(\mathrm{MJ} \mathrm{m}^{-2}\right)$ e produção $\left(\mathrm{g} \mathrm{m}^{-2}\right)$, para as avaliações realizadas entre 30 e 72 dias após a emergência. Obteve-se o valor médio de $26,9 \mathrm{~g} \mathrm{MJ}^{-1}$, com erro padrão (SE) igual a 1,41, valores estes muito semelhantes àqueles obtidos no referido trabalho. Este valor significa que cada unidade de HRI representa um incremento de $269 \mathrm{~kg} \mathrm{ha}^{-1}$. Assim, se for considerado o custo de controle de $P$. griseola como $\$ 40 \mathrm{ha}^{-1}$ (equivalente a 
aproximadamente $96 \mathrm{~kg}$ de feijão) pode-se estimar o limiar de dano econômico (LDE) em $96 / 269=0,36$, ou aproximadamente $1 / 3$ de uma unidade de HRI.

Esta estimativa aproximada do limiar de dano econômico (LDE), igual a 1/3 de HRI, significa que a diferença entre "parcela controle" e a "situação de produção" não poderia atingir 1/3 de uma unidade de HRI. Bergamin Filho et al. (1997) estimaram também o LDE èm função da HLAI, que é a variável efetivamente quantificada no campo e encontraram os valores $1 / 20$ de HLAI quando o HLAI no campo for igual a 0,2; $1 / 10$ para 1,$2 ; 1 / 5$ para 2,$2 ; 1 / 3$ para 2,$9 ; 1 / 2,5$ para 3,$2 ; 1 / 2$ para 3,5 e $1 / 1$ para 4,5 .

Para verificar se medidas de refletância seriam aptas em captar a variação de HLAI com acuidade suficiente para detectar o LDE, foi calculada a variação de HLAI observada no campo e de HLAI estimada via medidas de refletância (Tabela 5). Os resultados indicaram que, entre 30 e $64 \mathrm{DAE}$, período crítico da cultura no campo (Sartorato \& Rava, 1992), a variação encontrada entre o HLAI máximo e o HLAI mínimo estimados, sempre foi superior aos valores do LDE. Por exemplo, dos 44 aos 58 DAE o valor do HLAI médio observado foi próximo a 3,2, portanto o LDE era 0,4 $(1 / 2,5)$ e a variação observada entre HLAI máximo e mínimo estimados foi 1,36 , 1,32 e 1,73, respectivamente aos 44, 51 e 58 DAE. Assim, constata-se que medidas de refletância são suficientemente sensíveis para serem usadas em estimativas de HLAI.

O coeficiente de variação pode dar uma idéia da precisão das avaliações de HLAI e das avaliações de refletância, via HLAI estimado. Com exceção da avaliação aos 30 $\mathrm{DAE}$, o coeficiente de variação $(\mathrm{CV})$ do $\mathrm{HLAI}$ estimado sempre foi menor que o $\mathrm{CV}$ para os dados observados, indicando que as medidas de refletância sofrem menos variações que leituras da área foliar.

Os testes acima foram feitos em relação aos valores máximos e mínimos encontrados nas parcelas, não significando que havia diferença superior ao LDE entre os tratamentos. Para viabilizar o uso das medidas de refletância em programas de manejo deve-se trabalhar com as médias dos tratamentos para evitar variações de HLAI e de refletância devido a condições edafo-climáticas. Testes para verificar se os tratamentos atingiram o LDE estão representados na Figura 12. 
Tabela 5. Variação da duração da área foliar sadia (HLAI) observada (obs.) e estimada (est.) e coeficiente de variação para várias épocas de avaliação, em dias após a emergência (DAE), de parcelas com diferentes tratamentos fungicidas para controle da mancha angular em feijoeiro. O HLAI estimado foi calculado pela fórmula HLAI $=0,00435 \exp (6,999 \mathrm{ND}), \operatorname{com} \mathrm{R}^{2}=71,8 \%$, onde $\mathrm{ND}=(\mathrm{R} 810$ $\mathrm{R} 660)$ / ( $\mathrm{R} 810+\mathrm{R} 660)$, sendo $\mathrm{R} 810$ e $\mathrm{R} 660$ a refletância observada em $810 \mathrm{~nm}$ e $660 \mathrm{~nm}$, respectivamente.

\begin{tabular}{lccccccccccccc}
\hline & \multicolumn{2}{c}{$30 \mathrm{DAE}$} & \multicolumn{2}{c}{$39 \mathrm{DAE}$} & \multicolumn{2}{c}{$44 \mathrm{DAE}$} & \multicolumn{2}{c}{$51 \mathrm{DAE}$} & \multicolumn{2}{c}{ 58 DAE } & \multicolumn{2}{c}{ 64 DAE } \\
& \multicolumn{2}{c}{ HLAI } & \multicolumn{2}{c}{ HLAI } & \multicolumn{2}{c}{ HLAI } & \multicolumn{2}{c}{ HLAI } & \multicolumn{2}{c}{ HLAI } & \multicolumn{2}{c}{ HLAI } \\
& obs. & est. & obs. & est. & obs. & est. & obs. & est. & obs. & est. & obs. & est. \\
\hline Média & 1,41 & 2.14 & 2.59 & 2.80 & 3.17 & 2.78 & 3.22 & 3.10 & 3.04 & 2.97 & 2.77 & 2.67 \\
Máximo & 1.96 & 2.98 & 4.16 & 3.30 & 5.06 & 3.25 & 5.18 & 3.88 & 4.71 & 4.27 & 4.62 & 2.99 \\
Mínimo & 0.78 & 1.00 & 1.55 & 1.95 & 2.01 & 1.89 & 2.21 & 2.56 & 2.04 & 2.54 & 1.94 & 2.35 \\
\hline C.V.(\%) & 21.2 & 25.0 & 29.0 & 14.8 & 25.4 & 13.0 & 23.6 & 11.7 & 23.4 & 12.7 & 19.9 & 6.3 \\
\hline
\end{tabular}

\subsubsection{Limiar de dano econômico (LDE)}

Considerando-se o exposto até agora, deduz-se que modelos de estimativa de danos em função de HLAI e HRI são mais eficientes do que aqueles que usam severidade de doença, hipótese compartilhada por outros autores (Waggoner \& Berger, 1987; Lopes et al., 1994; Bergamin Filho et al., 1995; Bergamin Filho \& Amorim, 1996). Além disto, leituras de refletância apresentam sensibilidade suficiente para detectar variações nestas variáveis. Baseado nestas afirmações, foram feitos alguns cálculos para verificar se os vários tratamentos do experimento haviam atingido o LDE. Cada tratamento foi considerado como uma "situação de produção", sendo que o tratamento 01 foi considerado a "parcela controle" (Lopes et al., 1994). A diferença entre os valores de HRI da "parcela controle" e das respectivas "situações de produção" 
(Bergamin Filho \& Amorim, 1996) foi transformada em porcentagem, em relação ao HRI da "parcela controle", obtendo-se o DeltaHRI.

O DeltaHRI, em porcentagem, para dados observados e dados estimados em função de medidas de refletância, para os vários tratamentos, pode ser visualizado na Figura 12. O LDE, vale lembrar, é apenas uma estimativa e também foi calculado em porcentagem, em função do HLAI, de acordo com os valores apresentados acima, apenas entre 30 e 60 DAE. Aos 30 DAE iniciaram-se os tratamentos na "parcela controle" e a partir de 62 DAE não foi constatada eficiência dos fungicidas no controle da mancha angular (Tabela 4). Apesar de apresentar tendência exponencial, dos 30 aos 60 DAE, o LDE pode ser representado linearmente, pois apresenta um bom ajuste a uma reta neste intervalo (Figura 12). Devido à influência de fatores edafo-climáticos na LAI e consequentemente nos danos provocados pela mancha angular, pode-se no futuro, determinar diferentes retas de LDE; uma para cada situação de fertilidade do solo, ou até mesmo de época de plantio.
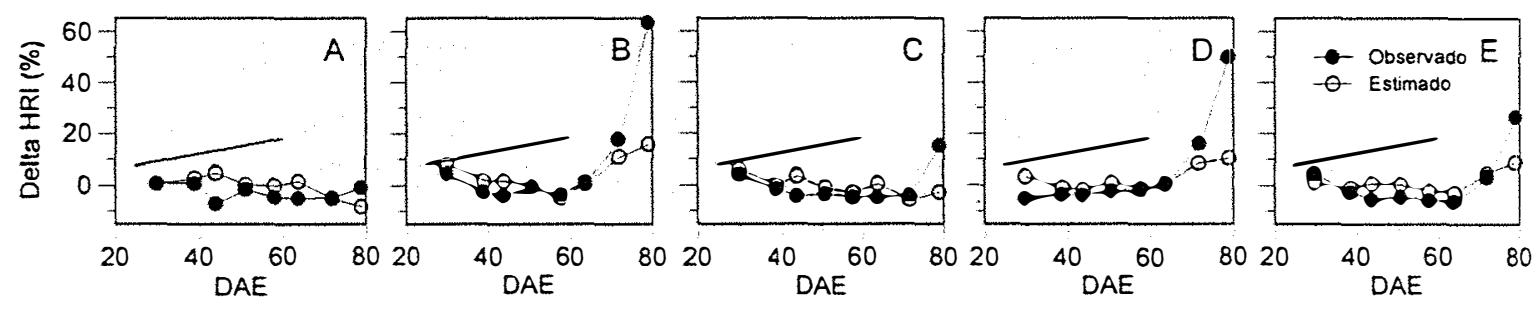

Figura 12 - Diferença percentual de absorção da área foliar sadia (Delta HRI) em relação ao tratamento controle (01) para os tratamentos 02 (A), 03 (B), 04 (C), 06 (D) e 08 (E). Círculos cheios representam dados observados (média de 24 plantas), círculos vazios representam dados èstimados (média de 12 amostragens) e a linha tracejada representa um suposto limiar de dano econômico. A HRI estimada foi calculada pela fórmula $\mathrm{HRI}=0,395 \exp (3,599 \mathrm{ND})$, com $\mathrm{R}^{2}=81,9 \%$, onde $\mathrm{ND}=(\mathrm{R} 810-\mathrm{R} 660) /(\mathrm{R} 810+\mathrm{R} 660)$, sendo $\mathrm{R} 810$ e $\mathrm{R} 660$ a refletância observada em $810 \mathrm{~nm}$ e $660 \mathrm{~nm}$, respectivamente. 
Os tratamentos 03 e 04 atingiram o LDE, na avaliação aos $30 \mathrm{DAE}$ (Figuras 5B,C). Entretanto, isto pode ser desconsiderado, pois os tratamentos fungicidas na "parcela controle" só foram iniciados aos 30 DAE. Portanto, a coincidência dos valores de LDE e DeltaHRI foi função de diferenças naturais na área foliar dos tratamentos. Para que isto não venha a ocorrer em aplicações futuras, sugere-se iniciar os tratamentos na parcela controle aos $20 \mathrm{DAE}$, e também usar um fator de correção, baseado na diferença do DeltaHRI constatada na primeira avaliação, ou seja, se a diferença percentual da primeira avaliação era $5 \%$, isto seria considerado nas avaliações subsequentes.

Nenhuma situação de produção atingiu o suposto LDE, mesmo naqueles tratamentos que não receberam controle da mancha angular (Figuras. 5B, E). Nestes tratamentos o DeltaHRI incrementou apenas no final do ciclo da cultura. O tratamento com aplicação fungicida a partir de $55 \mathrm{DAE}$ (Figura 12D) apresentou comportamento semelhante aos tratamentos sem controle da doença (Figuras 5B, E), comprovando a pouca, ou quase nenhuma eficiência de aplicações fungicidas após $55 \mathrm{DAE}$. Quando as aplicações do fungicida iniciaram aos 30 (Figura 12A) ou aos 42 DAE (Figura 12C) não houve grande variação do DeltaHRI, comprovando a eficiência de medidas de controle em períodos iniciais do ciclo da cultura.

O comportamento do Delta HRI para dados observados e estimados foi muito semelhante, exceto em medições aos $79 \mathrm{DAE}$, quando não há utilidade para a tomada de decisão para controle. Isto indica novamente a potencialidade de uso das medidas de refletância em estimativas de HRI e HLAI.

\subsubsection{Tomada de decisão}

De acordo com os resultados apresentados, é possível elaborar um modelo de danos que seja transportável, usando-se HAA e medidas de refletância para estimá-la. Porém, muitos pontos ainda necessitam ser esclarecidos para que a abordagem de danos possa ser utilizada no contexto de manejo de doenças do feijoeiro. 
O primeiro ponto é a melhor definição do LDE baseado em absorção da área foliar sadia (HRI). O presente ensaio, devido à pouca influência da quantidade de doença na área foliar e conseqüente pouca influência na produção, não permitiu resultados conclusivos quanto ao LDE. A reta representativa do LDE, mostrada na Figura 12, pode sofrer variação com a fertilidade do solo ou com outros fatores edafo-climáticos que influenciem o LAI. Também há necessidade de estudos sobre a influência da eficiência fotossintética para condições de elevado LAI, que podem influenciar o LDE. Ainda para melhor definição do LDE, necessita-se conhecer mais sobre a eficiência dos tratamentos fungicidas para controle da mancha angular. O presente trabalho demonstrou relação entre porcentagem de controle e época de início dos tratamentos.

Outro ponto a ser esclarecido é a validação dos modelos que relacionam medidas de refletância-HLAI, ou seja, saber da aplicabilidade destes modelos sob outras condições de cultivo. Também, buscar saber se a relativa estabilidade de leituras de refletância para HLAI superiores a 3 influenciará a tomada de decisão em futuros modelos. Forcelini (1997) conseguiu controlar de forma eficaz doenças foliares em diversos patossistemas quando executou pulverizações nas fases iniciais das epidemias, até mesmo usando doses menores do fungicida. Geralmente as epidemias iniciam nos primeiros estágios do ciclo da cultura e no caso do feijoeiro, justamente no periodo em que medidas de refletância são mais sensíveis para captar variações na HLAI. Assim, a combinação das duas abordagens pode trazer grandes benefícios no manejo da mancha angular do feijoeiro. 


\section{CONCLUSŌES}

De acordo com os objetivos propostos e a análise dos resultados obtidos chegouse as seguintes conclusões:

- As medidas de refletância se relacionaram com a severidade da mancha angular em condições de folha destacada, mas não houve um comprimento de onda ou índice vegetativo com boa correlação com a severidade da doença a nível de campo durante todo o ciclo da cultura.

- As melhores relações com o índice da área foliar sadia foram obtidas com medidas de refletância na faixa de $810 \mathrm{~nm}$ e com o índice vegetativo que usa os comprimentos de onda de $810 \mathrm{~nm}$ e $660 \mathrm{~nm}$.

- As melhores relações com a absorção da área foliar sadia foram obtidas com o índice vegetativo, que usa os comprimentos de onda de $810 \mathrm{~nm}$ e $610 \mathrm{~nm}$.

- A produção se relacionou com as integrais das variáveis derivadas da área foliar e com a integral do índice vegetativo e em menor grau com a área sob a curva de progresso da doença.

- Houve efeito da mancha angular na eficiência fotossintética das plantas no campo.

- As medidas de refletância apresentaram sensibilidade suficiente para captar variações no índice da área foliar sadia e serem utilizadas em programas de manejo da mancha angular baseados nos conceitos de duração e absorção da área foliar sadia. 


\section{REFERÊNCIAS BIBLIOGRÁFICAS}

AMORIM, L.; BERGAMIN FILHO, A.; GODOY, C.V.; IAMAUTI, M.T.; NUNES, W.M.; CARNEIRO, S.M.T.P.G. Avaliação de danos na cultura do feijoeiro. Summa Phytopathologica, v.21, p.82-84, 1995.

AQUINO, V.M.; SHOKES, F.M.; BERGER, R.D.; GOBERT, D.W.; KUCHAREK, T.A. Relationships among late leafspot, healthy leaf area duration, canopy reflectance, and pod yield of peanut. Phytopathology, v. 82, p.546-552, 1992.

ASRAR, G.; KANEMASU, E.T.; JACKSON, R.D.; PINTER Jr., P.J. Estimation of total above ground phytomass production using remote sensed data. Remote Sensing of Environment, v.17, p.211-220, June. 1985.

ASRAR, G.; FUCHS, M.; KANEMASU, E.T.; HATFIELD, J.L. Estimating absorbed photosynthetic radiation and leaf area index from spectral reflectance in wheat. Agronomy Journal, v.76, p.300-306, 1984.

ASSUNÇÃO, G.V. Sensoriamento remoto na agricultura: conceitos básicos, metodologia e aplicações. São José dos Campos: Instituto Nacional de Pesquisas Espaciais - INPE, 1989 (INPE-4806-MD/39).

BASSANEZI, R.B. Interações entre o mosaico-em-desenho do feijoeiro e duas doenças fúngicas, ferrugem e mancha angular, em plantas de feijoeiro. Piracicaba, 1995. 122p. Dissertação (M.S.) - Escola Superior de Agricultura "Luiz de Queiroz", Universidade de São Paulo. 
BASTIAANS, L. Ratio between virtual and visual lesion size as a measure to describe reduction in leaf photosynthesis of rice due to leaf blast. Phytopathology, v.81, p.611-615, 1991.

BASTIAANS, L.; RABBINGE, R.; ZADOKS, J.C. Understanding and modeling leaf blast effects on crop physiology and yield. In: ZEIGLER, R.S., LEONS, S.A., TENG, P.S. (Ed.) Rice blast disease. Wallingford-UK: Cab Intemational, 1994. p.357-379.

BAUER, M.E. The role of remote sensing in determining the distribution and yield of crops. West Lafayette, Laboratory for Applications of Remote Sensing, 1975. (LARS Technical Report 122075).

BEEBE, S.E.; PASTOR-CORRALES, M. Breeding for disease resistance. In: SCHOONHOVEN A. van; VOYSEST, O. (Ed.) Common beans: research for crop improvement. Wallingford: CAB International, 1991. cap.10, p.561-618.

BERGAMIN FILHO, A. Avaliação de danos e perdas. In: BERGAMIN FILHO, A.; KIMATI, H.; AMORIM, L. (Ed.) Manual de fitopatologia: princípios e conceitos. 3.ed. São Paulo: Ceres, 1995. cap.33, p.672-690.

BERGAMIN FILHO, A.; AMORIM, L. Doenças de plantas tropicais: epidemiologia e controle econômico. São Paulo: Ceres, 1996. 299p.

BERGAMIN FILHO, A.; CARNEIRO, S.M.T.P.G.; GODOY, C.V.; AMORIM, L.; BERGER, R.D.; HAU, B. Angular leaf spot of Phaseolus beans: relationships between disease, healthy leaf area, and yield. Phytopathology, v.87, p.506-515, 1997.

BERGAMIN FILHO, A.; LOPES, D.B.; AMORIM, L.; GODOY, C.V.; BERGER, R.D. Avaliação de danos causados por doenças de plantas. Revisão Anual de Patologia de Plantas, v.3, p.133-184, 1995. 
BIANCHINI, A.; MENEZES, J.R.; MARNGONI, A.C. Doenças e seu controle. In: IAPAR, O feijão no Paraná. Londrina, IAPAR, 1989. Circular 63. p.189-216.

BOOTE, K.J.; JONES, J.W.; SMERAGE, G.H.; BARFIELD, C.S. Photosynthesis of peanut canopies as affected by leafspot and artificial defoliation. Agronomyc Journal, v.72, p.247-252, 1980.

BOUMAN, B.A.M. Crop modelling and remote sensing for yield prediction. Netherlands Journal of Agricultural Science, v.43, p.143-161, 1995.

CAMPBELL, C.L.; MADDEN, L.V. Crop loss assessment and modeling. In: CAMPBELL, C.L.; MADDEN, L.V. (Ed.) Introduction to plant disease epidemiology. New York: John Wiley \& Sons, 1990. p. 393-422.

CANTERI, M.G.; DALLA PRIA, M.; AMORIM, L.; BERGAMIN FILHO, A. Uso de radiômetro de múltiplo espectro para quantificar danos. Fitopatologia Brasileira, v.21, p.433, 1996.

CANTERI, M.G.; DALLA PRIA, M.; TESSMANN, D.J.; MOLIN, R. Efeito de épocas de semeadura sobre níveis de doenças do feijoeiro sob condições naturais de infecção na região dos Campos Gerais do Paraná. Summa Phytopathologica, v.23, p.54, 1997.

CANTERI, M.G.; GIGLIOTI, E.A. Software para seleção e treinamento de avaliadores de severidade de doenças em cana de açúcar. Publicatio UEPG-Ciências Exatas e da Terra, v.2, p.57-69, 1996.

CARNEIRO, S.M.T.P.G. Quantificação de danos causados por Phaeoisariopsis griseola em feijoeiro (Phaseolus vulgaris L.) no município de Londrina - PR. Piracicaba, 1995. 102p. Dissertação (M.S.) - Escola Superior de Agricultura "Luiz de Queiroz", Universidade de São Paulo. 
CARNEIRO, S.M.T.P.G.; AMORIM, L.; BERGAMIN FILHO, A. Avaliação de dano provocado pela mancha angular em feijoeiro: relação entre severidade, área foliar e componentes de produção. Fitopatologia Brasileira, v.22, p.427-431, 1997.

CASTRO, J.L.; DUDIENAS, C.; ITO, M.F.; IGUE, T. Eficiência de fungicidas no controle das doenças do feijoeiro (Phaseolus vulgaris L.). Summa Phytopathologica, v.15, p.145-155, 1989.

CLEVERS, J.G.P.W. The application of a weighted infrared-red vegetation index for estimating leaf area index by correcting for soil moisture. Remote Sensing Environment, v.29, p.25-37, July, 1989.

COSTA, A.S. Investigações sobre as moléstias do feijoeiro no Brasil. In: SIMPÓSIO BRASILEIRO DO FEIJÃO, 1. Campinas, 1971. Anais. Viçosa: Imprensa Universitária, 1972. p.305-384.

DAUGHTRY, C.S.T.; VANDERBILT, V.C.; POLLARA, V.J. Variability of reflectance measurements with sensor altitude and canopy type. Agronomy Journal, v.74, p.744-751, July/Aug. 1982.

DEERING, D.W. Field measurements of bidirectional reflectance. In: ASRAR, G. (Ed.) Theory and applications of optical remote sensing. New York: John Wiley \& Sons. 1989. cap.2, p.14-61.

EPIPHANIO, J.C.N. Metodologia de aquisição de dados ao nível terrestre. In: ASSUNÇÃO, G.V. Sensoriamento remoto na agricultura: conceitos básicos, metodologia e aplicações. São José dos Campos: Instituto Nacional de Pesquisas Espaciais-INPE, 1989. p.53-73.

FORCELINI, C.A. Use of Low Rates of Fungicides to Suppress Initial Waves of Plant Disease and to Manage Epidemics. Gainesville, 1997. Thesis (Ph.D.) - University of Florida. 
FORMAGGIO, A.R. Características agronômicas e espectrais para sensoriamento remoto de trigo e de feijão. Piracicaba, 1989. 161 p. Tese (Doutorado) - Escola Superior de Agricultura "Luiz de Queiroz", Universidade de São Paulo.

GAUNT, R.E. Empirical disease-yield loss models. In: Crop loss assessment in rice. Manila: International Rice Research Institute, 1990. p.185-191.

GAUNT, R.E. New technologies in disease measurement and yield loss appraisal. Canadian Journal of Plant Pathology, v.17, p.185-189, 1995a.

GODOY, C.V. Danos causados pela mancha angular em feijoeiro, no município de Piracicaba. Piracicaba, 1995. 72p. Dissertação (M.S.) - Escola Superior de Agricultura "Luiz de Queiroz", Universidade de São Paulo.

GODOY, C.V.; CARNEIRO, S.M.T.P.G.; IAMAUTI, M.T.; DALLA PRIA, M.; AMORIM, L.; BERGAMIN FILHO, A.; BERGER, R.D. Diagramatic scales for foliar diseases of beans: development and validation. Zeitschrift für Pflanzenkrankheiten und Pflanzenschutz, v.104, p.336-345, 1997.

GOMES, F.P. Curso de estatística experimental. 2. ed. Piracicaba: Nobel, 1987. 467p.

GOULART, A.C.P. Eficiência de fungicidas no controle de doenças foliares do feijoeiro. Fitopatologia Brasileira, v.15, p.86-88, 1990.

HATFIELD, D.L. Remote detection of crop stress: application to plant pathology. Phytopathology, v.80, p.37-39, 1990.

HATFIELD, D.L., ASRAR, G., KANEMAŚU, E.T. Intercepted photosynthetically active radiation estimated by spectral reflectance. Remote Sensing of Environment, v.14, p.65-75, Jan. 1984.

HATFIELD, D.L.; KANEMASU, E.T.; ASRAR, G.; JACKSON, R.D.; PINTER JUNIOR, P.J.; REGINATO, R.J.; IDSO, S.B. Leaf area estimates from spectral 
measurements over various planting data of wheat. International Journal of Remote Sensing, v.6, p.167-175, Jan.1985.

HAU, B.; KRANZ, J.; DENGEL, H.J. On the development of loss assessment methods in the tropics. In: TENG, P.S.; KRUPA, S.V. (Ed) Crop loss assessment. St. Paul: University of Minnesota, 1980. p.254-261.

HAVERKORT, A.J.; BICAMUMPAKA, M. Correlation between intecepted radiation and yield on potato crops infested by Phytophthtora infestans in central Africa. Netherlands Journal of Plant Pathology, v.92, p.239-247, 1986.

HOFFER, R.M. Biological and physical considerations in applying computer-aided analysis techniques to remote sensing data. In: SWAIN, P.H.; DAVIS, S.M. (Ed.) Remote sensing the quantitative approach. New York: McGraw Hill, 1978. cap.5, p.228-289.

HUETE, A.R., JACKSON, R.D. Soil and atmosphere influences on the spectra of partial canopies. Remote Sensing of Environment, v.25, p.89-105, June. 1988.

IAMAUTI, M.T. Avaliação de danos causados por Uromyces appendiculatus no feijoeiro. Piracicaba, 1995. 85p. Tese (Doutorado) - Escola Superior de Agricultura "Luiz de Queiroz", Universidade de São Paulo.

ISSA, E.; SINIGAGLIA, C.; OLIVEIRA, D.A. Controle químico da "mancha angular" da folha, Isariopsis griseola Sacc., do feijoeiro, Phaseolus vulgaris L. O Biológico, v.48, p.299-303, 1982.

JACKSON, R.D. Remote sensing of biotic and abiotic plant stress. Annual Review of Phytopathology, v.24, p.265-287, 1986.

JOHNSON, K.B. Defoliation, disease, and growth: a reply. Phytopathology, v.77, p.1495-1497, 1987. 
KNIPLING, E.B. Physical and physiological bases for the reflectance of visible and near-infrared radiation from vegetation. Remote Sensing of Environment, v.1, p.155-159, 1970.

KOFFLER, N.F. Identificação da cultura da cana-de-açúcar (Saccharum spp.) através de fotografias aéreas infravermelhas coloridas e dados multiespectrais do satélite LANDSAT. Piracicaba, 1995. 234p. Tese (Doutorado) - Escola Superior de Agricultura "Luiz de Queiroz", Universidade de São Paulo.

KOLLENKARK, J.C., VANDERBILT, V.C., BAUER, M.E., HOUSLEY, T.L. Effect of cultural practices on agronomic and reflectance characteristics of soybean canopy. Agronomy Journal, v.74, p.751-758, July/Aug. 1982.

KRANZ, J.; ROYLE, J. Perspectives in mathematical modeling of plant disease epidemics. In: SCOTT, P.R. \& BAINBRIDGE, A. (Ed.) Plant disease epidemiology. Oxford: Blackwell, 1978. p.111-119.

LIM, L.G.; GAUNT, R.E. The effect of powdery mildew (Erisiphe graminis f. sp. hordei) and leaf rust (Puccinia hordei) on spring barley in New Zealand. I. Epidemic development, green leaf area and yield. Plant Pathology, v.35, p. 44-53, 1986.

LOPES, D.B.; BERGER, R.D.; BERGAMIN FILHO, A. Absorção da área foliar sadia (HAA): uma nova abordagem para a quantificação de dano e para o manejo integrado de doença. Summa Phytopathologica, v.20, p.143-151, 1994.

MADEIRA, L.V.; CLARK, J.A.; ROSSALL, S. Growth, light interception and disease in field bean (Vicia faba): the effect of late infection by Ascochyta fabae. Annals of Applied Biology, v.112, p.587-595, 1988. 
MAJOR, D.J., McGINN, S.M., GILLESPIE, T.J., BARET, F. A technique for determination of single leaf reflectance and transmittance in field studies. Remote Sensing of Environment, v.43, p.209-215, 1993.

MENEZES, J.R. Manejo integrado de doenças do feijoeiro irrigado. In: SEMINÁRIO SOBRE PRAGAS, DOENÇAS E PLANTAS DANINHAS DO FEIJOEIRO, 5. Piracicaba, 1994. Anais. Piracicaba: FEALQ, 1994. p.112-122.

MOREIRA, M.A. Déficit hídrico na cultura do trigo e o impacto na resposta espectral e em parâmetros agronômicos. Piracicaba, 1997. 142 p. Tese (Doutorado) - Escola Superior de Agricultura "Luiz de Queiroz", Universidade de São Paulo.

MYERS, V.I. Soil, water, plant relationships. In: Remote sensing with spectral reference to agriculture and forestry. Washington: National Academy of Science, 1970. p.253-79.

NILSSON, H-E. Application of remote sensing and image analysis at macroscopic and microscopic levels in plant pathology. In: Teng, P.S., Krupa, S.V. (Ed.). Crop loss assessment. St. Paul: University of Minnesota, 1980. p.77-84.

NILSSON, H-E. Remonte sensing and image analysis in plant pathology. Annual Review of Phytopathology, v.33, p.489-527, 1995.

NUTTER Jr., F.W. Detection and measurement of plant disease gradients in peanut with a multispectral radiometer. Phytopathology, v.79, p.958-963, 1989.

NUTTER Jr., F.W., GLEASON, M.L., JENCO, J.H., CHRISTIANS, N.C. Assessing the accuracy, intra-rater repeatability, and inter-rater reliability of disease assessment systems. Phytopathology, v.83, p.806-812, 1993. 
NUTTER Jr., F.W.; LITTRELL, R.H. Relationships between defoliation, canopy reflectance and pod yield in the peanut-late leafspot pathosystem. Crop Protection, v.15, p.135-142, 1996.

NUTTER Jr., F.W.; LITTRELL, R.H.; BRENNEMAN, T.B. Utilization of a multispectral radiometer to evaluate fungicide efficacy to control late leaf spot in peanut. Phytopathology, v.80, p.102-108, 1990.

NUTTER, Jr., F.W.; CUNFER, B.M. Quantification of barley yield losses caused by Rhyncosporium secalis using visual versus remote sensing assessment methods. Phytopathology, v.78, p.1530, 1988.

OLIVEIRA, S.H.F.; BARROS, B.C.; CASTRO, J.L. Avaliação do efeito de fungicidas no controle de doenças da parte aérea e na qualidade das sementes de feijoeiro. Summa Phytopathologica, v.18, p.178-184, 1992.

PEDERSON, V.D.; FIECHTNER, G. A low-cost, compact data acquisition system for recording visible and infrared reflection from barley crops canopies. In: TENG, P.S, KRUPA, S.V. (Ed.) Assessment of losses which constrain production and crop improvement in agriculture and forestry. St. Paul: University of Minnesota, 1980. p.71-75.

PEDERSON, V.D.; GUDMESTAD, N. Evaluation of foliar diseases of barley with multispectral sensors. In: APS Annual Meeting, University of Minnesota, St. Paul. Proceedings (Abstract). 1977.

PINTER Jr., P.J.; JACKSON, R.D.; EZRA, C.E.; GAUSMAN, H.W. Sun-angle and canopy-architecture effects on the spectral reflectance of six wheat cultivars. International Journal of Remote Sensing, v.6, p.1813-25, Dec. 1985. 
RABBINGE, R.; JORRITSMA, I.T.M.; SCHANS, J. Damage components of powdery mildew in winter wheat. Netherlands Journal of Plant Pathology, v.91, p.235$247,1985$.

ROSSING, W.A.H.; VAN OIJEN, M.; VAN DER WERF, W.; BASTIAANS, L.; RABBINGE, R. Modeling the effects of foliar pests and pathogens on light interception, photosynthesis, growth rate and yield of field crops. In: Ayres, P.G. (Ed.) Pests and pathogens - plant responses to foliar attack. Oxford: Bios Scientific Publishers, 1992. p.161-180.

ROUSE, D.I. Use of crop growth-models to predict the effects of disease. Annual Review of Phytopathology, v.26, p.183-201, 1988.

SARTORATO, A. Resistência vertical e horizontal do feijoeiro comum (Phaseolus vulgaris L.) a Isariopsis griseola Sacc. Piracicaba, 1989. 131p. Tese (Doutorado) Escola Superior de Agricultura "Luiz de Queiroz", Universidade de São Paulo.

SARTORATO, A.; RAVA, C.A. Influência da cultivar e do número de inoculações na severidade da mancha angular (Isariopsis griseola) e nas perdas de produção do feijoeiro comum (Phaseolus vulgaris). Fitopatologia Brasileira, v.17, p.247-251, 1992.

SCHULD, P. Auswirkung des Befalls durch drei Blattpathogenen (Uromyces appendiculatus, Phaeoisariopsis griseola, und Colletotrichum lindemuthianum) auf das Wachstum und den Ertrag von Phaseolus - Bohnen. Hannover, 1996. 215p. Thesis (Ph.D.) - Hannover Universität.

SELLER, P.J. Canopy reflectance, photosynthesis and transpiration. International Journal of Remote Sensing, v.6, p.1335-1372, Aug. 1985.

SHANER, G.; FINNEY, R.E. The effects of nitrogen fertilization on the expression of slow-mildwing in knox wheat. Phytopathology, v.67, p.1051-1055, 1977. 
SILVA, A.F. Da. Dados digitais do satélite spot e de radiometria de campo no estudo da cultura do feijoeiro (Phaseolus vulgaris L.) irrigado. Piracicaba, 1995. 94p. Tese (Doutorado) - Escola Superior de Agricultura "Luiz de Queiroz", Universidade de São Paulo.

SILVA, M.B. Da. Área foliar verde para estimar danos causados por doenças do feijão comum. Viçosa, 1997. 100p. Tese (Doutorado) - Universidade Federal de Viçosa.

STEFFEN, C.A.; LORENZZETTI, J.A.; STECH, J.L.; SOUZA, R.C.M. Sensoriamento remoto: princípios físicos, sensores, produtos e sistema Landsat. São José dos Campos: INPE, 1981.81p.

TANAKA, M.A.; JUNQUEIRA NETO, A. Efeito de fungicidas sobre a intensidade de doenças na parte aérea e a qualidade sanitária da semente de feijão. Fitopatologia Brasileira, v.7, p.381-386, 1982.

TENG, P.S.; JOHNSON, K.B. Analysis of epidemiological components in yield loss assessment. In: KRANZ, J.; ROTEM, J. (Ed.) Experimental Techniques in Plant Disease Epidemiology. Berlin: Springer-Verlag, 1988. p.179-190.

TUCKER, C.L. Red and photographic infrared linear combinations for monitoring vegetations. Remote Sensing of Environment, v.8, p.127-150, May. 1979.

TUCKER, C.L.; GARRATT, M.W. Leaf optical system modeled as stochastic process. Applied Optical, v.16, p.635-642, Mar. 1977.

VAN OIJEN, M. Photosynthesis is not impaired in healthy tissue of blighted potato plants. Netherlands Journal of Plant Pathology, v.96, p.55-63, 1990.

VAN SCHOONHOVEN, A.; PASTOR-CORRALES, M.A. Sistema Estándar para la Evaluación de Germoplasma de Frijol. CIAT (International Center of Tropical Agriculture), Cali, Colombia. 1987. 
VANE, G.; GOETZ, A.F.H. Terrestrial imaging spectrometry. Remote Sensing of Environment, v.24, p.1-29, 1988.

VETTORAZZI, C.A. Sensoriamento remoto orbital. Piracicaba: ESALQ - Departamento de Engenharia Rural, 1992. 134 p. (Didática, 2).

VIEIRA, C. Doenças e pragas do feijoeiro. Viçosa: Imprensa Universitária. UFV, 1983. $231 \mathrm{p}$.

WAGGONER, P.E.; BERGER, R.D. Defoliation, disease, and growth. Phytopathology, v.77, p.393-398, 1987.

WIEGAND, G.L.; RICHARDSON, A.J.; ESCOBAR, D.E. Vegetation indices in crop assessment. Remote Sensing of Environment, v.35, p.105-119, Feb. 1991.

ZADOKS, J.C. On the conceptual basis of crop loss assessment: the threshold theory. Annual Review of Phytopathology, v.23, p.455-73, 1985.

ZADOKS, J.C.; SCHEIN, R.D. Epidemiology and plant disease management. Oxford: Oxford University Press, 1979. 427p.

ZAUMEYER, W.J.; THOMAS, H.R. A monographic study of bean diseases and methods for their control. Washington: U.S.D.A., 1957. p.51-53 (Technical Bulletin 868). 